\title{
Control of selective mRNA translation over the torpor-arousal cycle of thirteen-lined ground squirrels
}

\author{
By \\ Samantha M. Logan \\ BSc. Carleton University, 2015
}

\begin{abstract}
A Thesis Submitted to the Faculty of Graduate Studies and Research in partial fulfillment of the requirements for the degree of

Master of Science
\end{abstract}

\author{
Department of Biology \\ Carleton University \\ Ottawa, Ontario, Canada \\ (C) 2017
}

Samantha M. Logan 
The undersigned hereby recommend to the Faculty of Graduate Studies and Research acceptance of this thesis

\title{
Control of selective mRNA translation over the torpor-arousal cycle of thirteen-lined ground squirrels
}

\author{
submitted by \\ Samantha M. Logan
}

in partial fulfillment of the requirements for the degree of Master of Science

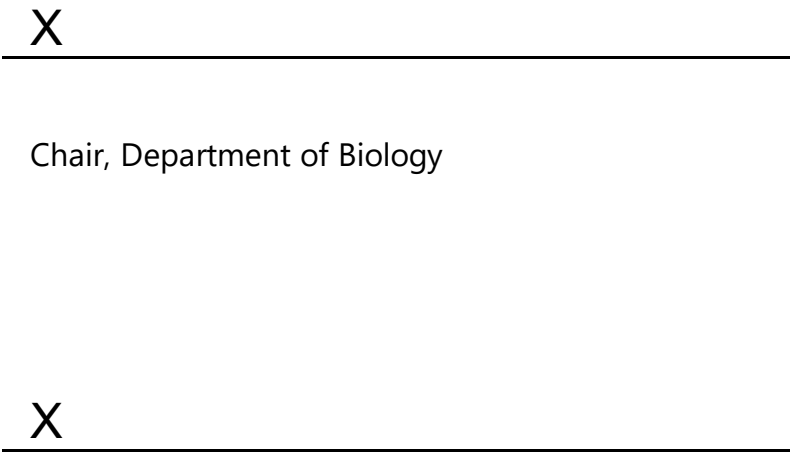

Thesis supervisor

Carleton University 


\begin{abstract}
Mammalian hibernation is an interesting adaptation that allows many capable animals like the thirteen-lined ground squirrel to endure the winter months on a low or absent food supply. Metabolic suppression during hibernation is facilitated by diverse biochemical mechanisms including the global shut-down of energy expensive processes like transcription and translation, the use of post-translational modifications to regulate protein activity, and differential gene/protein expression of essential protein products. Differential protein expression can occur during hibernation, but it remains incompletely understood how transcripts are "chosen" to be translated instead of stored or degraded. This thesis explores two mechanisms that may regulate differential gene and protein expression during hibernation, including RNA-binding protein (RBP) stabilization and transport of transcripts, and translation machinery activation. Notably, RBPs and cap-dependent translation factors were upregulated over the torpor-arousal cycle. These results suggest a possible role for proteins that regulate mRNA stability and enhance translation during metabolic suppression.
\end{abstract}




\section{ACKNOWLEDGEMENTS}

Firstly, I'd like to thank my supervisor, Dr. Ken Storey for allowing me the freedom to investigate the story that is my thesis, having confidence in my ability to take on several side projects and writing tasks on top of my thesis, and for subtly hinting when it was a good time to stop working on arduous projects, but giving me the time to make the decision to quit them on my own. My time in your lab has made me a more confident and deliberate scientist, mentor, and writer, and I am extremely grateful for the opportunities that you have supported me in pursuing.

I'd also like to thank Jan Storey for meticulously editing this thesis as well as the manuscripts that I was able to publish (and not be embarrassed by) over the past 2 years. Although I have learned so much from your comments, I know I have a long way to go until my writing is as precise and flawless as yours. Thank you for being such an excellent mentor and role model for my writing and editing.

Thanks to all Storey lab members for your academic support throughout the years. It has been fun debating everything from biochemistry theory to news stories, and I have learned so much from you all. Special thanks to Bryan Luu for continuing to answer my questions throughout my MSc. The example you have set in terms of your leadership, integrity, and scientific knowledgebase has taught me to push my boundaries in order to put my potential to the test and how to become a better scientist.

Last but not least, I'd like to thank my "common-law husband", Ryan Deslauriers, for listening to me read out my writing for hours-on-end of editing, giving me feedback on my practice presentations before major conferences, and easing my concerns when things were not working out. Thank you for keeping me both sane and humble - I could not have accomplished this without you. 


\section{TABLE OF CONTENTS}

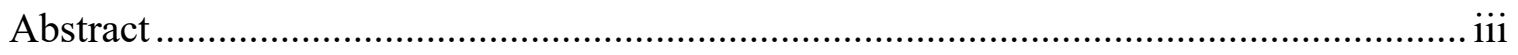

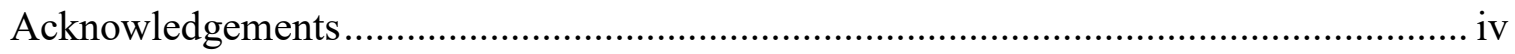

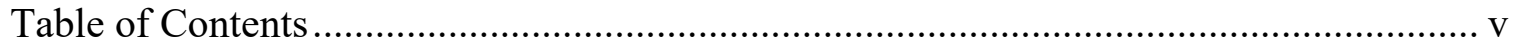

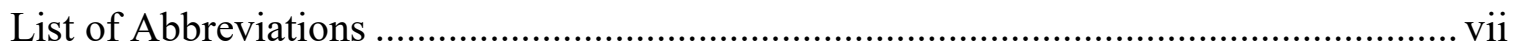

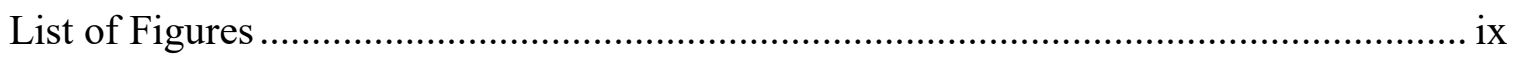

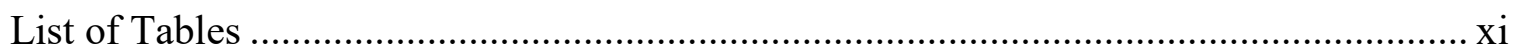

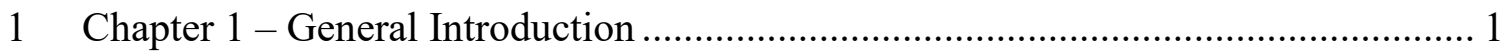

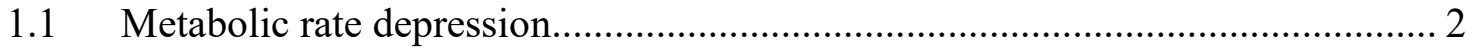

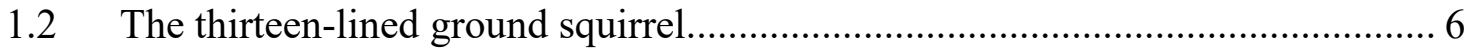

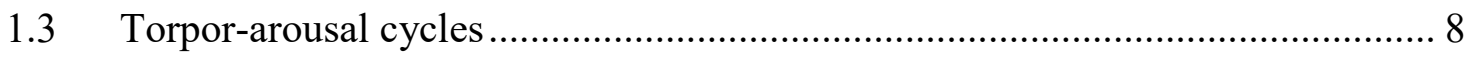

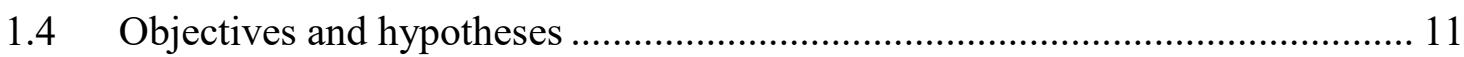

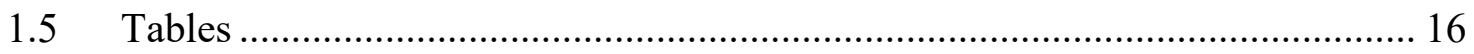

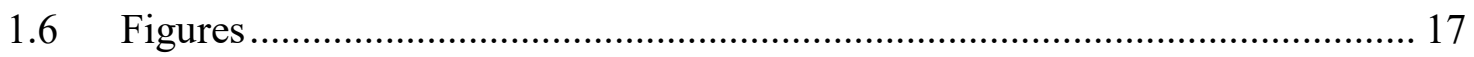

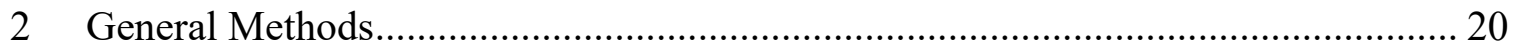

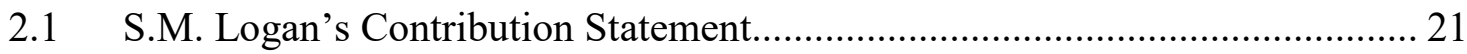

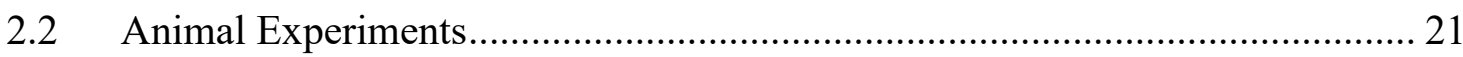

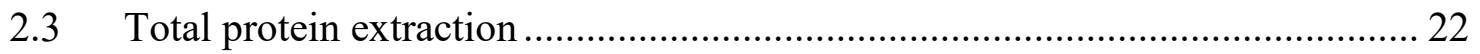

2.4 Cytoplasmic-nuclear protein extraction …………........................................... 23

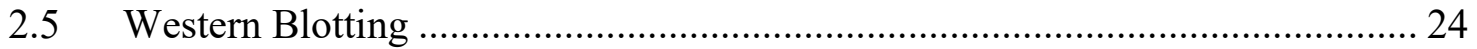

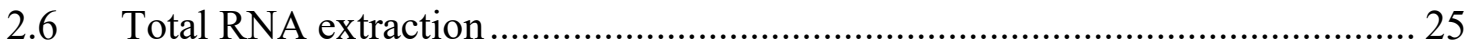

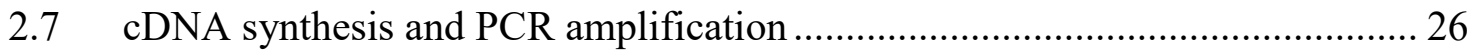

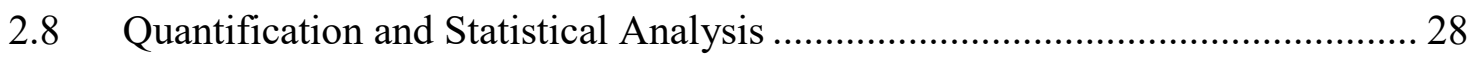

3 Chapter 3 - Cold-inducible protein response to the torpor-arousal cycle in thirteen-

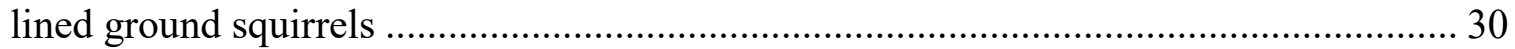

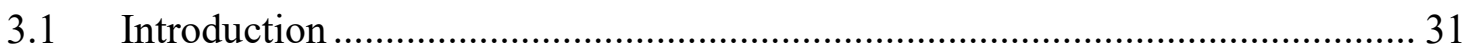

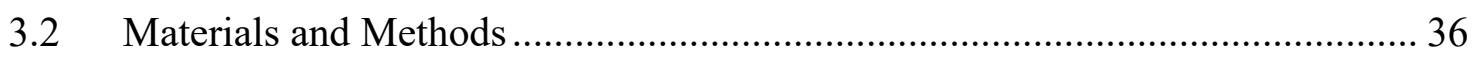

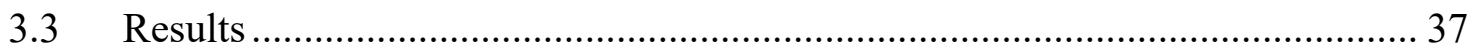

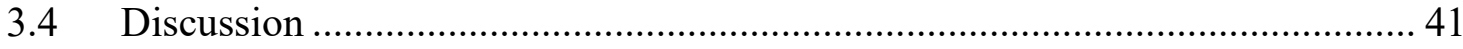

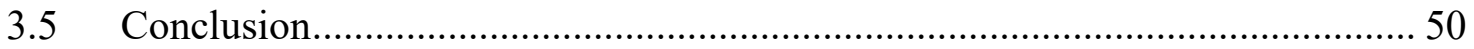

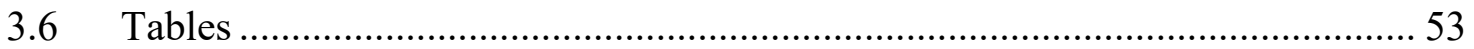

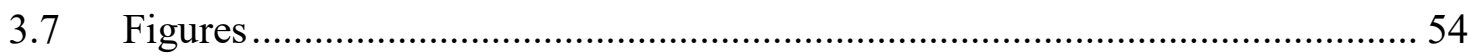


4 Chapter 4 -Tissue-specific regulation of translation in an obligate hibernator, the

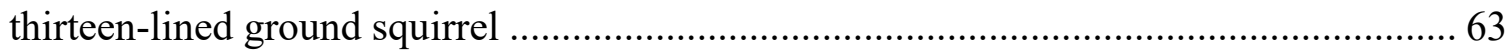

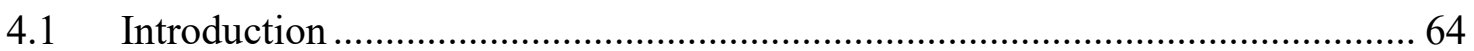

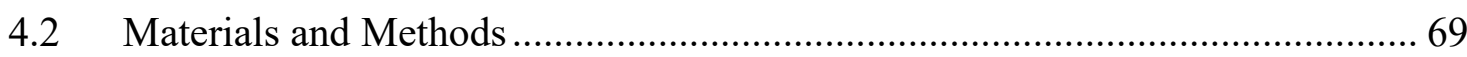

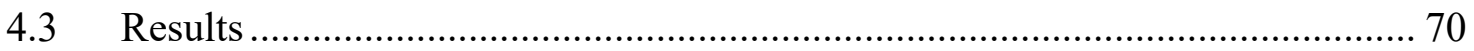

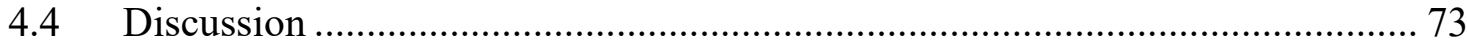

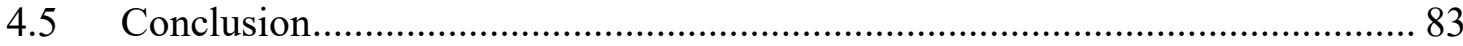

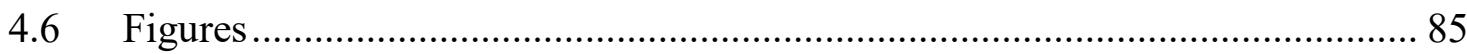

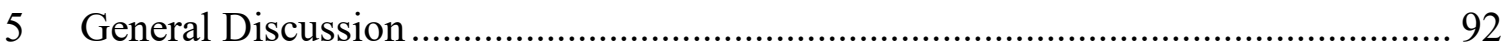

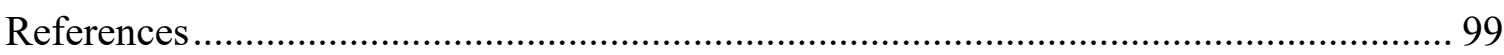

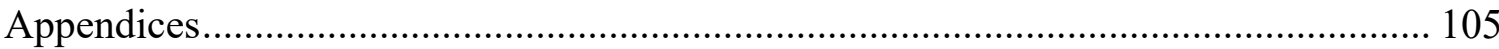

Appendix A: Antibodies Used for Western Blotting ................................................ 105

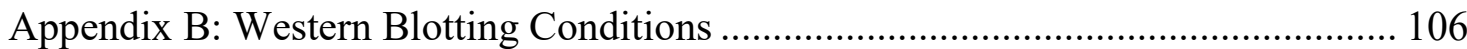

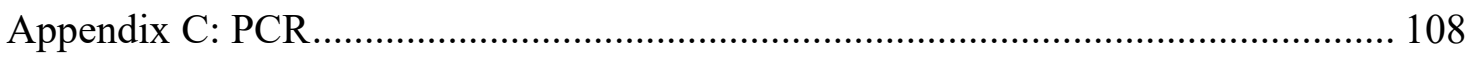




\section{List OF ABbReViations}

4EBP

5'-m7GpppN cap

Actg2

Ago

APS

ATF4

ATP

BAT

Cdk1

Cirp

CREB

DCP

DEPC

DNA

DTT

EA

EC

EDTA

eEF

EEG

eIF

EN

ER

ERK

ET

GDP

GTP

HEPES

HRP

HSP

HuR

IA

IgG

IRES

KID

LIV

LT

microRNA

mRNA
Eukaryotic translation initiation factor $4 \mathrm{E}$ binding protein

5'-7-methylguanosine cap

Gamma actin 2

Argonaute

Ammonium persulfate

Activating transcription factor 4

Adenosine triphosphate

Brown adipose tissue

Cyclin-dependent kinase 1

Cold-inducible RNA-binding protein

CAMP responsive element binding protein 1

Decapping mRNA $1 \mathrm{~A}$

Diethyl pyrocarbonate

Deoxyribonucleic acid

Dithiothreitol

Early arousal

Euthermic in the cold room

Ethylenediaminetetraacetic acid

Eukaryotic translation elongation factor

Electroencephalogram

Eukaryotic translation initiation factor

Entrance into torpor

Endoplasmic reticulum

Extracellular signal-regulated kinase

Early torpor

Guanosine diphosphate

Guanosine triphosphate

4-(2-hydroxyethyl)-1-piperazineethanesulfonic acid

Horseradish peroxidase

Heat shock protein

Human antigen $\mathrm{R}$

Interbout arousal

Immunoglobulin $\mathrm{G}$

Internal ribosome entry site

Kidney

Liver

Late torpor

Micro ribonucleic acid

Messenger ribonucleic acid 


\begin{tabular}{|c|c|}
\hline MUS & Muscle \\
\hline $\mathrm{Na3VO} 4$ & Sodium orthovanadate \\
\hline $\mathrm{NaCl}$ & Sodium chloride \\
\hline $\mathrm{NaF}$ & Sodium fluoride \\
\hline NINDS & National Institute of Neurological Disorders and Stroke \\
\hline $\mathrm{Nr} 1 \mathrm{~d} 2$ & Nuclear receptor subfamily 1 group D member 2 \\
\hline ORF & Open reading frame \\
\hline PABP & Poly $(\mathrm{A})$ binding protein \\
\hline PAGE & Polyacrylamide gel electrophoresis \\
\hline PARP & Poly(ADP-ribose) polymerase 1 \\
\hline PERK & Protein kinase R (PKR)-like endoplasmic reticulum kinase \\
\hline PRMT & Protein arginine N-methyltransferase \\
\hline Ptbp 1 & Polypyrimidine tract binding protein 1 \\
\hline PTM & Post-translational modification \\
\hline PVDF & Polyvinylidene difluoride \\
\hline $\mathrm{Rbm}$ & RNA-binding motif protein \\
\hline RBP & RNA-binding protein \\
\hline RGG & Arginine-glycine rich \\
\hline RPM & Rotations per minute \\
\hline RT-PCR & Real-time PCR \\
\hline SA & Summer active \\
\hline SDS & Sodium dodecyl sulfate \\
\hline SEM & Standard error of the mean \\
\hline $\mathrm{Tb}$ & Body temperature \\
\hline TBST & Tris-buffered saline - tween \\
\hline TEMED & Tetramethylethylenediamine \\
\hline TIA & TIA1 cytotoxic granule associated RNA binding protein \\
\hline tRNA & Transfer RNA \\
\hline Tuba1c & Alpha tubulin $1 \mathrm{c}$ \\
\hline Tubb1 & Beta tubulin 1 \\
\hline UTR & Untranslated region \\
\hline Xrn1 & 5'-3' Exoribonuclease 1 \\
\hline
\end{tabular}




\section{LIST OF FIGURES}

Figure 1.1: Torpor-arousal cycle pattern throughout the length of hibernation

Figure 1.2: RNA-binding protein (Cirp, HuR, Rbm3) general mechanism of action and hypothesis for Chapter 3

Figure 1.3: Interactions between key proteins involved in cap-dependent translation, translation initiation and translation elongation and hypothesis for Chapter 4

Figure 3.1: Relative cold-inducible RNA-binding protein levels in liver of thirteen-lined ground squirrels

Figure 3.2: Relative cold-inducible RNA-binding protein levels in skeletal muscle of thirteen-lined ground squirrels

Figure 3.3: Relative cold-inducible RNA-binding protein levels in kidney of thirteen-lined ground squirrels 56

Figure 3.4: Relative cold-inducible RNA-binding protein levels in brown adipose tissue of thirteen-lined ground squirrels

Figure 3.5: Relative cold-inducible RNA-binding protein levels in cytoplasmic (cyt) and nuclear (nuc) fractions of liver from euthermic in the cold room (EC) and torpid (LT) thirteen-lined ground squirrels

Figure 3.6: Relative cold-inducible RNA-binding protein levels in cytoplasmic and nuclear fractions in skeletal muscle of euthermic (EC) and torpid (LT) thirteen-lined ground squirrel

Figure 3.7: Expression of mRNAs in liver tissue samples was evaluated by RT-PCR for six time points over the torpor-arousal cycle 60

Figure 3.8: Expression of mRNAs in skeletal muscle was evaluated by RT-PCR for time points EC-EA of the torpor-arousal cycle 
Figure 3.9: Expression of $m R N A$ s in kidney samples was evaluated by RT-PCR for time points EC-EA of the torpor-arousal cycle

Figure 4.1: Relative protein and phosphorylation levels of eIF4F complex proteins and inhibitors in ground squirrel liver

Figure 4.2: Relative eIF2 $\alpha$ and eEF2 protein and phosphorylation levels in ground squirrel liver

Figure 4.3: Relative protein and phosphorylation levels of eIF4F complex proteins and inhibitors in ground squirrel muscle

Figure 4.4: Relative eIF2 $\alpha$ and eEF2 protein and phosphorylation levels in ground squirrel muscle

Figure 4.5: Relative protein and phosphorylation levels of eIF4F complex proteins and inhibitors in ground squirrel kidney

Figure 4.6: Relative eIF2 $\alpha$ and eEF2 protein and phosphorylation levels in ground squirrel kidney

Figure 4.7: Summary of relative changes in translation factor protein levels and phosphorylation states throughout the torpor-arousal cycle of thirteen-lined ground squirrels in liver, muscle, and kidney

Figure C.1 Expression of Ptbpl and Nr1d2 in mouse brain, heart, kidney, liver and skeletal muscle of mouse (Mus musculus) 108 


\section{LIST OF TABLES}

Table 1.1: Summary of translational activation/ repression in hibernating ground squirrels described in the literature

Table 3.1: Forward and reverse primer sequences for RNA-binding proteins and target transcripts, purchased from Integrated DNA Technologies (IDT), Inc. used in RT-PCR analysis

Table A.1: Antibody companies and product codes for the antibodies used in the experiments described in this thesis

Table B.1: Western blotting conditions used to quantify the relative levels of proteins in Chapter 3, including Cirp, HuR, and Rbm3 106

Table B.2: Western blotting conditions used to quantify the relative levels of proteins in Chapter 4, including total and phospho-eIF4E, eIF2 $\alpha$, and eEF2, as well as phospho$4 E B P$ S65 


\section{Chapter 1 - General Introduction}




\subsection{METABOLIC RATE DEPRESSION}

Many animals use metabolic rate depression as a survival strategy to deal with harsh environmental conditions and physiological changes that would be too challenging to handle if cellular resources were also used to keep metabolic rate elevated. Decreased food availability and low ambient temperatures are examples of environmental factors that may prompt a capable organism to suppress its metabolic rate and enter a state of torpor. Both are triggering factors in mammalian hibernation in which animals gain large energy savings by transitioning from homeothermy to a heterothermic lifestyle where body temperature $\left(T_{b}\right)$ is allowed to track ambient environmental temperature. During torpor in small mammalian hibernators, $\mathrm{T}_{\mathrm{b}}$ can decrease to as low as $-2.9{ }^{\circ} \mathrm{C}$ depending on the species without affecting organ integrity or function (Ruf and Geiser, 2015). By contrast, a decrease in core $\mathrm{T}_{\mathrm{b}}$ to just $35^{\circ} \mathrm{C}$ would cause humans to increase metabolic rate and risk cardiac injury, while a decrease in core $\mathrm{T}_{\mathrm{b}}$ below $28{ }^{\circ} \mathrm{C}$ is lethal for humans but, incredibly, hibernators drop their $\mathrm{T}_{\mathrm{b}}$ to less than $5^{\circ} \mathrm{C}$ and emerge from torpor unscathed (Storey, 2015; Storey and Storey, 2004). The decline in $\mathrm{T}_{\mathrm{b}}$ is the result of a still undefined master cue that resets the hypothalamic set point to reduce metabolic rate and is essential for these animals to save up to $90 \%$ of the total energy that they would otherwise expend if they were to remain euthermic (meaning of constant $\mathrm{T}_{\mathrm{b}}$ ) for the duration of hibernation (Wang and Lee, 1996). Hibernation can last 7 to 9 months depending on the species and is either one continuous session of torpor as is observed in bears (Fedorov et al., 2009; Rigano et al., 2016) or multiple cycles of prolonged torpor bouts interspersed with periodic arousals back to euthermia before re-entrance into torpor (Grabek et al., 2015a; Storey and Storey, 2000).

Established molecular mechanisms involved in decreasing metabolic rate include a general suppression of ATP-expensive processes like transcription and translation in order 
to match energy demand with a limited fuel supply. Differential expression of selected transcripts (mRNA), proteins, and microRNAs is also used to repress non-essential processes and decrease metabolism and can concurrently be useful in upregulating select processes necessary for survival. Additionally, the use of post-translational modifications of proteins (e.g. phosphorylation, acetylation, methylation, etc.) to control signaling processes, enzyme activity, and DNA availability for transcription is essential for the rapid change between active and metabolically depressed states (Biggar and Storey, 2015; Storey and Storey, 2000). In ground squirrels, research has shown that transcription is inhibited during torpor compared to euthermia based on decreased RNA polymerase II activity, changes in epigenetic regulation (for instance, increases in histone deacetylase activity) to silence gene expression by tightening the association between histones and DNA, and a decrease in the proportion of genes that show upregulated expression during torpor (Biggar and Storey, 2014; Morin and Storey, 2006; Schwartz et al., 2013; Williams et al., 2005). Translation is also greatly reduced during torpor. For example, in the brain of hibernating thirteen-lined ground squirrels $\left(\mathrm{T}_{\mathrm{b}} \sim 5^{\circ} \mathrm{C}\right)$, the rate of translation was only $0.05 \%$ of the euthermic rate and in golden-mantled ground squirrel heart, kidney, and spleen, radiolabeled amino acid incorporation into nascent proteins was decreased to just $0.13-0.5$ \% of euthermic levels (Frerichs et al., 1998; van Breukelen and Martin, 2001). Additionally, several studies comparing euthermic to torpid ground squirrels have shown that translation initiation is inhibited via increased phosphorylation of the eukaryotic initiation factor $2 \alpha(\mathrm{eIF} 2 \alpha)$ or a decrease in polyribosome formation, whereas peptide elongation can be inhibited by increased phosphorylation of the eukaryotic elongation factor 2 (eEF2) (Frerichs et al., 1998; Hittel and Storey, 2002; Knight et al., 2000). 
However, one study showed that the mechanism of inhibiting translation machinery is not always conserved between two hibernator organs (Hittel and Storey, 2002), suggesting that translation is shut-down in a tissue-specific manner. In addition to translation studies being limited in the number of tissues that have been assessed, many of these studies only looked at protein abundance and phosphorylation status of 1-2 translation factors and they used a limited number of sampling points from the torpor-arousal cycle or an improper control group (i.e. summer active) to determine how translation is regulated during torpor. Table 1.1 provides a list of studies that have assessed the biochemistry of translation in torpid ground squirrels. Although inhibition of the translation machinery is an established mechanism of metabolic depression, it is still incompletely understood how each stage of initiation and elongation are controlled at different points of the torpor-arousal cycle in different organs. Thus, Chapter 4 assesses total protein and phosphorylation status of four main translational regulators, the eukaryotic initiation factor $4 \mathrm{E}$ (eIF4E), its inhibitory binding protein (4EBP), eIF $2 \alpha$ and eEF2, at several points of the torpor-arousal cycle and in 3 important hibernator organs. This is essential to fully understand how certain gene products are eventually translated into fully functional proteins, even in the midst of deep torpor.

Despite the global suppression of transcription and translation, hibernators employ a diverse range of molecular mechanisms to ensure the transcription and translation of select genes and gene products, respectively, which have crucial functions in terms of cell protection and survival. For example, the poly(A) tails of transcripts are no shorter during torpor compared to non-hibernating ground squirrels, and there is no difference in mRNA abundance between euthermic and torpid ground squirrels, both suggesting that mRNA 
transcripts are stabilized during torpor (Frerichs et al., 1998; Knight et al., 2000). This is consistent with some studies showing an increase in protein levels of mRNA-sequestering proteins during torpor (Frerichs et al., 1998; Knight et al., 2000; Tessier et al., 2014). For this reason, it is of interest to assess the role of other stress-inducible RNA-binding proteins (RBPs) in the control of mRNA fate during hibernation. The proteins Cirp, HuR and Rbm3 are well-known RBPs that are stress-inducible and have established roles in binding to mRNA in the nucleus and shuttling transcripts to the cytoplasm for enhanced translation (Yaman et al., 2002; Zhu et al., 2016). However, these have never been characterized in the context of hibernation. Chapter 3 of this thesis assesses the role of these RBPs during torpor by analyzing their relative abundance and subcellular distribution, since they are known to in enhance mRNA stability and translation in other models. This chapter will further our understanding of these proteins and determine their relevance in the process of selectively upregulating proteins that are necessary during torpor.

Although research over the past few decades has increased our understanding of controlled gene expression and translation during torpor in a variety of hibernators, it is still not completely understood how certain gene products are selected for translation during periods of hypometabolism. To develop a more complete understanding of the molecular roadblocks put in place during torpor to limit energy expenditure while mediating selective mRNA translation, this thesis aims to characterize two different mechanisms that may regulate the translation of specific gene products. Chapter 3 discusses how RNA-binding proteins are regulated over a torpor bout such that they may mediate RNA stability and translation, and Chapter 4 focuses on translation regulation in several hibernator tissues. Each proposed mechanism is assessed in several organs of the 
thirteen-lined ground squirrel, a model hibernator, at various time points of the torporarousal cycle.

\subsection{THE THIRTEEN-LINED GROUND SQUIRREL}

Thirteen-lined ground squirrels (Ictidomys tridecemlineatus) are native to the prairies

of North America and are excellent model hibernators. They are obligate hibernators, meaning that the squirrels must hibernate on a circannual rhythm regardless of exogenous/environmental cues. Like many other small mammalian hibernators, ground squirrels go through cycles of entering torpor and periodically arousing, where the average torpor bout length is 2 weeks by midwinter (Figure 1.1) (Grabek et al., 2015a; Wang and Lee, 1996). Ground squirrels experience seasonal hibernation between the months of November and April, and the onset of hibernation is likely facilitated by endogenous cues that regulate behaviour and metabolism (Grabek and Martin, 2012; Vaughan et al., 2006). For instance, ground squirrels switch from metabolism based on glucose and other nutrients from their foodstuffs to metabolism based on fatty acid oxidation from stored lipid depots during torpor while enabling reversible insulin resistance (Buck et al., 2002). This stark change in energy metabolism is facilitated by a change in behaviour in the late summer and early fall when animals go through a period of intense eating called hyperphagia, that is likely regulated by changes in hormone levels (Wu et al., 2013) and leads to a rapid weight gain as large reserves of white adipose are laid down. This is just one example of how thirteen-lined ground squirrels are excellent models of metabolic and physiological plasticity. Uncovering the molecular adaptations that these mammals make during hibernation may also be crucial for developing translational therapies for metabolically dysfunctional human patients. For instance, understanding how each organ regulates 
energy expenditure during hypometabolism, and protection against tissue damage whether it be caused by ischemia-reperfusion damage, immobility, respiratory acidosis, frigid core body temperature, nutrient restriction, etc. could be valuable in cryopreservation techniques, transplantation strategies, and treatment of metabolic disorders (diabetes, autoinflammatory disease, cancer, etc.). The studies performed in this thesis have been designed and executed to better understand how thirteen-lined ground squirrels are able to conserve energy in the hypometabolic state while selectively upregulating essential metabolic processes. The studies were undertaken with various organs (skeletal muscle, liver, kidney, and brown adipose) at several sampling points of the torpor-arousal cycle to determine if the proposed molecular adaptations were tissue-specific and at what point of the torpor-arousal cycle each function is activated or repressed.

Skeletal muscle is clearly designed for mobility of animals but also has an essential role in warming the mammalian body via shivering thermogenesis. In hibernating species, the capacity of muscle for shivering thermogenesis is even more important because it is one of two main contributors to the heat production needed to raise hibernator $T_{b}$ from ambient back to euthermic values of about $37^{\circ} \mathrm{C}$. Skeletal muscle from hibernating ground squirrels is also remarkable in that it is resistant to muscle atrophy despite the prolonged immobility of animals during weeks of hibernation; only $\sim 20 \%$ of muscle mass may be lost over the winter months (van Breukelen et al., 2010). Liver is the most studied organ in hibernation research due to its importance in regulating energy metabolism (glycogenolysis, gluconeogenesis, lipogenesis, ketogenesis, etc.) (Fedorov et al., 2009; Rui, 2014) and because it is resistant to ischemia-reperfusion damage from reversible cooling and rewarming as compared to livers of summer active ground squirrels or non- 
hibernators like rats (Hindle et al., 2014). Brown adipose tissue (BAT) is essential for nonshivering thermogenesis during arousal from torpor and also acts to prevent ground squirrel core $\mathrm{T}_{\mathrm{b}}$ from dropping below the thermal "set-point" (the lowest temperature tolerated before energy-utilizing and heat-generating processes are activated to increase $T_{b}$ ) while in torpor when environmental temperatures fall to very low values (Boyer and Barnes, 1999; Drew et al., 2007). Finally, kidney must make unique physiological and metabolic changes since urine production and renal flow are reduced to low levels and periodic rewarming events encourage ischemia-reperfusion damage (Rouble et al., 2013; Storey and Storey, 2013).

\subsection{TORPOR-AROUSAL CYCLES}

During a single hibernation season, ground squirrels can go through 12-20 torporarousal bouts. A torpor bout consists of a descent into torpor (involving a decline in metabolic rate and $\mathrm{T}_{\mathrm{b}}$ ), a period of torpor that can last from hours to weeks, and a period of rewarming where the sympathetic nervous system is activated to increase metabolic rate and $T_{b}$ to pre-hibernation levels. Euthermia is maintained for approximately 24 hours before the next torpor bout is initiated (Wang and Lee, 1996). Rewarming the body during arousal and the short interbout periods of euthermia can consume $60-80 \%$ of the total fuel stores available for energy production for the entire hibernation season, suggesting that arousals must have necessary roles in maintaining/restoring some aspects of tissue metabolism to re-establish homeostasis before the next period of heterothermy (Grabek et al., 2015b; Storey and Storey, 2004). In the studies that make up this thesis, the control group is comprised of ground squirrels that remained euthermic in the cold room $\left(4{ }^{\circ} \mathrm{C}\right)$ and had not entered torpor within 3 days of being subjected to the cold. The torpor-arousal 
stage in which each hibernator was sampled from was carefully determined using body temperatures (measured using a subcutaneous Implantable Programmable Temperature Transponders IPTT-200) and the monitoring of breathing rate. Importantly, disruptions to the animals were kept minimal. The animals were housed in complete darkness and only when required for animal monitoring were they subjected to a brief photographic red safe light (3-5 lux) and minimal noise. Further details are present in Chapter 2: General Methods.

\subsubsection{Entrance into torpor $(\mathrm{EN})$}

Entry into torpor involves a decrease in core body temperature $\left(\mathrm{T}_{\mathrm{b}}\right)$, breathing rate, oxygen consumption, and heart rate, but an increase in vasoconstriction in order to maintain blood pressure (Wang and Lee, 1996). One early study noted that the average cooling rate of the $\mathrm{T}_{\mathrm{b}}$ of Richardson's ground squirrels (Spermophilus richardsonii) during entrance was $0.017{ }^{\circ} \mathrm{C} / \mathrm{min}$ and this cooling phase lasted $24-36$ hours (in this study, entrance was characterized as a cooling phase to a stable $\mathrm{T}_{\mathrm{b}}$ ). Interestingly, this was the case whether these animals were observed in their natural habitat or in a laboratory setting (Wang, 1979). The metabolic cost of entering torpor, measured as the total oxygen consumption (in $\mathrm{O}_{2}$ $\mathrm{cm}^{3}$ ) of all entrance phases in a month averaged across all months where torpor bouts were observed, was estimated to be $13 \%$ of all energy expended during hibernation (Wang, 1979). For the experimental animals used in this thesis, entrance is considered to the phase in which core body temperature is decreasing, and animals were euthanized for tissue sampling when $\mathrm{T}_{\mathrm{b}}$ fell within the $31-18{ }^{\circ} \mathrm{C}$ range (McMullen and Hallenbeck, 2010). 


\subsubsection{Early and late torpor (ET and LT)}

During torpor, heart rate is on average 5-10 beats per minute (a significant decrease from euthermic conditions where heart rate is on average 250 beats per minute) and $\mathrm{T}_{\mathrm{b}}$ is minimal and very close to ambient (Hampton et al., 2010). Breathing rate is low, intermittent and often apneic (breath-hold) (Storey and Storey, 2004). The amount of time spent in deep torpor is the longest during December and January (Wang, 1979). Animals in early torpor (ET) were sampled when a $\mathrm{T}_{\mathrm{b}}$ between $5-8{ }^{\circ} \mathrm{C}$ was stable for at least 24 hours whereas late torpid (LT) animals were hibernating with a $\mathrm{T}_{\mathrm{b}}$ of $5-8{ }^{\circ} \mathrm{C}$ for at least 5 days.

\subsubsection{Early and interbout arousal (EA and IA)}

Early arousal (EA) is characterized by a rapid elevation in $\mathrm{T}_{\mathrm{b}}$, breathing and heart rates and has been observed to last as little as $2-6$ hours (Wang, 1979). $T_{b}$ rises due to brown adipose tissue activation of non-shivering thermogenesis and skeletal muscle shivering thermogenesis (Wang and Lee, 1996). Arousing Richardson's ground squirrels had an average rewarming rate of $0.174{ }^{\circ} \mathrm{C} / \mathrm{min}$ (Wang, 1979). Once hibernators progress through an early season period of shallow torpor-bouts that are short and are accompanied by short arousals, they experience longer interbout arousals (IA) back to euthermia that typically occur about once every 2 weeks in midwinter that last on average 24 hours (Storey, 2010). Periods of arousal are longest during the months of December and January (Wang, 1979). Interbout arousals cost ground squirrels approximately $40-76 \%$ of their total fuel/energy stores, indicating that they must serve an essential role to survival during hibernation (Wang, 1979). Interestingly, electroencephalogram (EEG) data showed that ground squirrel brain waves during arousal periods were similar to slow-wave sleep, 
suggesting that periodic arousals may be important for ground squirrels to get restful sleep, necessary to restore tissue homeostasis (Storey and Storey, 2004).

\subsection{OBJECTIVES AND HYPOTHESES}

\subsubsection{Objective 1: Evaluate the regulation of RNA-binding proteins at 6 well- defined points of the torpor-arousal cycle}

RNA binding proteins (RBPs) have roles in a multitude of well-defined metabolic processes including transcription (e.g. RNA polymerase, Rbm14, PARP), translation (e.g. eIF4E, eIF4B, eEF2), mRNA processing (e.g. TIA-1, DCP1a, Xrn1) and miRNA processing (e.g. Ago, Dicer, Drosha), among others (Anantharaman et al., 2002; Tessier et al., 2014; Yang and Bloch, 2007). Of interest in the field of "molecular adaptations to environmental stress" are stress-inducible RNA-binding proteins, with cold-inducible RNA-binding proteins being particularly relevant in the study of hibernation. This subclass of RBPs includes Cirp (also named A18 HnRNP, or Cirbp) and Rbm3 since they were both originally observed to increase expression in cold-treated cells, but are also activated during the cellular response to low oxygen ( $8 \%$ to $1 \% \mathrm{O}_{2}$ conditions), UV exposure, DNA damage, ER stress, and nutrient or chemical imbalances (De Leeuw et al., 2007). Their binding partner HuR (also named HuA or ELAV1) is a ubiquitously expressed RBP that is also upregulated during cell stress (starvation, UV irradiation, hypoxia, heat shock, etc.). Together, this trio of RBPs have very important roles in regulating translation of select transcripts by binding to, stabilizing, and shuttling certain mRNAs from the nucleus to the cytoplasm for enhanced translation (Pang et al., 2013). However, their roles in mammalian hibernation have yet to be decoded. Previous studies done on hibernators only touch on a 
single aspect of Cirp and Rbm3 regulation - their gene expression (Fedorov et al., 2009; Fedorov et al., 2011; Schwartz et al., 2013; Williams et al., 2005), and often focus on their expression in only a single organ or between a limited number of time points (typically summer active vs. torpid and sometimes interbout arousal). Thus, it is currently unknown how these cold-inducible proteins respond over the course of the full torpor-arousal cycle, in different tissue types, or at the protein level - the protein being the crucial functional molecule. The objective of Chapter 3 is to determine if these proteins may play a role in the cold-shock response in organs of hibernating thirteen-lined ground squirrels. This will be determined by examining their relative abundance at the mRNA and protein levels at several sampling points over the torpor-arousal cycle and in several tissues, as well as their subcellular distribution since they are predominately localized to the nucleus when not actively transporting mRNAs from the nucleus to the cytoplasm (Figure 1.2) (Lleonart, 2010; Yaman et al., 2002).

Finally, transcript abundance is assessed for two RNA targets that Cirp and Rbm3 are both known to bind. A decrease in transcript levels would suggest no Cirp/Rbm3 protection, and an increase or maintenance of transcript levels could suggest that $\mathrm{Cirp} / \mathrm{Rbm} 3$ are binding and protecting these transcripts from decay.

Hypothesis 1: The mRNA and protein levels of Rbm3, Cirp and HuR will increase during entrance into torpor and during torpor in organs of thirteen-lined ground squirrels, with an altered distribution that favours the cytoplasm during torpor. As a result, the relative transcript levels of two of their target mRNAs should remain constant or increase. 


\subsubsection{Objective 2: Determine tissue-specific regulation of translation at various sampling points of the torpor-arousal cycle}

Translation, the energy expensive process of converting messenger RNA (mRNA) into nascent proteins, is generally suppressed during torpor as a means of reducing metabolic rate. Briefly, translation initiation requires the association of the $43 \mathrm{~S}$ complex (containing eIF1, eIF1A, eIF5, and eIF2 coupled to GTP, the initiator methionine tRNA and the $40 \mathrm{~S}$ ribosome) to the 5' end of the mRNA (Gebauer and Hentze, 2004; Sonenberg and Hinnebusch, 2009). The eIF4F complex (consisting of proteins eIF4E, eIF4B, eIF4G, and eIF4A) associates with the 5'-7-methylguanosine (5'-m7GpppN) cap of the mRNA, circularizes the transcript with the help of poly(A)-binding protein (PABP) and forms a bridging complex to the $43 \mathrm{~S}$ complex. The eIF4F complex facilitates $43 \mathrm{~S}$ ribosomal subunit scanning of the mRNA for the start codon AUG. Once GTP is hydrolyzed and eIF2 $\alpha$-GDP is released, the $60 \mathrm{~S}$ ribosomal subunit binds to the first ribosomal subunit to make the $80 \mathrm{~S}$ complex. The next aminoacyl-tRNA is added to the A site and the peptide bond is catalyzed by the $80 \mathrm{~S}$ complex (Sonenberg and Hinnebusch, 2009). The process of translation is explained in Chapter 4 in more detail.

Research has shown a decrease in protein synthesis to $0.05-0.5 \%$ of control levels in brain, heart, kidney, spleen and liver of squirrels hibernating at $\mathrm{T}_{\mathrm{b}}$ of about $5{ }^{\circ} \mathrm{C}$ compared with euthermic controls (Frerichs et al., 1998; van Breukelen and Martin, 2001). Furthermore, there are fewer polysomes during early and late torpor, suggesting that translation is largely inhibited (Knight et al., 2000; van Breukelen and Martin, 2001). These data and the notion that almost $70 \%$ of all winter energy stores are used during interbout arousals could provide evidence for resumption of translation during euthermic interbout 
arousal periods to replenish pools of essential proteins (van Breukelen and Martin, 2001). By contrast, a large number of studies provide evidence for differential transcription and translation during torpor to immediately increase the abundance of important proteins involved in a variety of processes like anti-apoptosis, fatty acid metabolism, molecular transport, but it is still not understood how certain mRNA are chosen to be translated. (Luu et al., 2015; Rouble et al., 2013; Shao et al., 2010; Yan et al., 2006; Yan et al., 2007). Thus, it is essential to understand how translation is regulated during the torpor-arousal cycle to allow for this timely translation of specific mRNAs. To date, there have been studies that assess the abundance and phosphorylation status of translation initiation factors including eukaryotic initiation factor 4E (eIF4E), 4E-binding protein (4EBP), eIF4B, eIF2 $\alpha$ and eIF4GI/II (Epperson et al., 2010; Hittel and Storey, 2002; van Breukelen et al., 2004). One notable study concludes that hibernators may use internal ribosome entry sequences (IRES) to by-pass cap-dependent translation as a mechanism of selective mRNA translation (Pan and van Breukelen, 2011). Of note, these studies are limited in that (1) they compare to a summer active ground squirrel population that is a poor control for studies interested in evaluating changes in hibernator metabolism across the torpor-arousal cycle, (2) they focus on a single tissue, and/or (3) they do not assess translation regulation at multiple time points of the torpor-arousal cycle. The objective of Chapter 4 is to determine how translation initiation and elongation may be regulated in thirteen-lined ground squirrels during torpor to develop a better understanding of the mechanisms put in place to decrease metabolism while also facilitating the timely translation of key gene products (Figure 1.3). Furthermore, it is of great interest to understand these mechanisms at each of the 6 time points of the torpor-arousal cycle and in several hibernator tissues. 
Hypothesis 2: Based on evidence that translation is greatly suppressed during torpor, I propose that all tissues will show inhibition of cap-dependent translation. I propose that eIF4E and p-eIF4E (S209) levels will be lower during ET and LT compared to EC and that p-4EBP (S65) levels will decrease. Levels of eIF2 $\alpha$ and eEF2 will be constant or elevated during torpor and phosphorylation of these proteins will be low since these signals are inhibitory. 


\subsection{TABles}

Table 1.1: Summary of translational activation/ repression in hibernating ground squirrels. Translation machinery and regulators of translation like 4E-binding protein (4EBP), eukaryotic initiation factors (eIF4E, eIF4B, eIF4G, eIF2 $\alpha$ ) and eukaryotic elongation factor 2 (eEF2) are bolded in the first column to clearly identify the targets highlighted in the paper. Phosphorylation events are denoted by " $p$-" preceding the translation factor that is phosphorylated. Increases are denoted by " $\uparrow$ ", decreases are denoted by “ $\downarrow$ ", and no change is denoted by " $\leftrightarrow$ ", where each change is relative to the control (the first time point listed under the heading "time points compared"). Time points include summer active (SA), euthermic in the cold room (EC), entrance $(E N)$, early torpor (ET), late torpor (LT), early arousal (EA), interbout arousal (IA).

\begin{tabular}{|c|c|c|c|c|}
\hline $\begin{array}{c}\text { Translation machinery } \\
\text { targets and major } \\
\text { findings }\end{array}$ & $\begin{array}{l}\text { Hibernator } \\
\text { species }\end{array}$ & Organs & $\begin{array}{c}\text { Time } \\
\text { points } \\
\text { compared }\end{array}$ & Reference \\
\hline $\begin{array}{l}\uparrow \mathbf{p}-4 \mathrm{EBP} \text { and } \mathbf{p - e I F 4 E} \\
\text { during LT and IA. } \\
\leftrightarrow \text { total } 4 \mathrm{EBP}, \text { eIF4B, } \\
\text { eIF4G or p-eIF2 } \alpha(\mathbf{S 5 1 )}\end{array}$ & $\begin{array}{l}\text { Golden- } \\
\text { mantled ground } \\
\text { squirrel }\end{array}$ & Liver & SA, LT, IA & $\begin{array}{l}\text { (van Breukelen } \\
\text { et al., 2004) }\end{array}$ \\
\hline $\begin{array}{l}\text { Active polysomes during } \\
\text { SA, no polysomes activity } \\
\text { during LT and } \\
\text { intermediate phenotype } \\
\text { during ET }\end{array}$ & $\begin{array}{l}\text { Golden- } \\
\text { mantled ground } \\
\text { squirrel }\end{array}$ & Liver & $\begin{array}{l}\text { SA, ET, LT, } \\
\text { EA, IA }\end{array}$ & $\begin{array}{l}\text { (van Breukelen } \\
\text { and Martin, } \\
\text { 2001) }\end{array}$ \\
\hline$\downarrow$ polysomes during LT & $\begin{array}{l}\text { Arctic ground } \\
\text { squirrel }\end{array}$ & Liver & SA, LT, IA & $\begin{array}{l}\text { (Knight et al., } \\
2000 \text { ) }\end{array}$ \\
\hline $\begin{array}{l}\uparrow \text { in } \mathbf{E E F 2} \text {, eIF2 } \alpha \text { protein } \\
\text { levels during EN }\end{array}$ & $\begin{array}{l}\text { Thirteen-lined } \\
\text { ground squirrel }\end{array}$ & Liver & SA, EN & $\begin{array}{l}\text { (Epperson et al., } \\
\text { 2010) }\end{array}$ \\
\hline $\begin{array}{l}\text { Translation of mRNA } \downarrow \text { in } \\
\text { kidney but } \uparrow \text { in BAT. } \\
\text { p-eIF2 } \alpha \uparrow \text { in kidney but } \\
\text { not in BAT }\end{array}$ & $\begin{array}{l}\text { Thirteen-lined } \\
\text { ground squirrel }\end{array}$ & $\begin{array}{l}\text { Brown } \\
\text { adipose } \\
\text { tissue, } \\
\text { kidney }\end{array}$ & EC, LT & $\begin{array}{l}\text { (Hittel and } \\
\text { Storey, 2002) }\end{array}$ \\
\hline $\begin{array}{l}\downarrow \text { polysomes during LT. } \\
\leftrightarrow \text { Total eIF2 } \alpha . \\
\uparrow \text { p-eIF2 } \alpha . \\
\text { No eEF2 ADP } \\
\text { ribosylation in EC or LT. } \\
\leftrightarrow \text { mRNA levels }\end{array}$ & $\begin{array}{l}\text { Thirteen-lined } \\
\text { ground squirrel }\end{array}$ & Brain & EC, LT & $\begin{array}{l}\text { (Frerichs et al., } \\
\text { 1998) }\end{array}$ \\
\hline $\begin{array}{l}\text { No p-eIF2 } \alpha \text { during EN. } \\
\downarrow \text { Total 4EBP. } \\
\uparrow \text { p-4EBP (T37/T46) } \\
\text { during LT }\end{array}$ & $\begin{array}{l}\text { Thirteen-lined } \\
\text { ground squirrel }\end{array}$ & Brain & $\begin{array}{l}\text { EC, EN, ET, } \\
\text { LT, EA, IA }\end{array}$ & $\begin{array}{l}\text { (Miyake et al., } \\
\text { 2015) }\end{array}$ \\
\hline $\begin{array}{l}\downarrow \text { p-4EBP1 (T37/46) } \\
\text { during LT }\end{array}$ & $\begin{array}{l}\text { Thirteen-lined } \\
\text { ground squirrel }\end{array}$ & Liver & EC, LT & $\begin{array}{l}\text { (McMullen and } \\
\text { Hallenbeck, } \\
\text { 2010) }\end{array}$ \\
\hline $\begin{array}{l}\text { Skeletal muscle p-4EBP } \\
\text { (T37) } \downarrow \text { during ET and LT } \\
\text { Heart p-4EBP (T37) } \uparrow \\
\text { during EA }\end{array}$ & $\begin{array}{l}\text { Thirteen-lined } \\
\text { ground squirrel }\end{array}$ & $\begin{array}{l}\text { Skeletal } \\
\text { muscle, } \\
\text { heart }\end{array}$ & $\begin{array}{l}\text { EC, EN, ET, } \\
\text { LT, EA, IA }\end{array}$ & $\begin{array}{l}\text { (Wu and Storey, } \\
\text { 2012) }\end{array}$ \\
\hline $\begin{array}{l}\uparrow \mathbf{p}-4 \text { EBP1 (S65) during } \\
\mathrm{LT}\end{array}$ & $\begin{array}{l}\text { Thirteen-lined } \\
\text { ground squirrel }\end{array}$ & $\begin{array}{l}\text { Skeletal } \\
\text { muscle }\end{array}$ & SA, LT & $\begin{array}{l}\text { (Andres-Mateos } \\
\text { et al., 2013) }\end{array}$ \\
\hline
\end{tabular}




\subsection{FigureS}
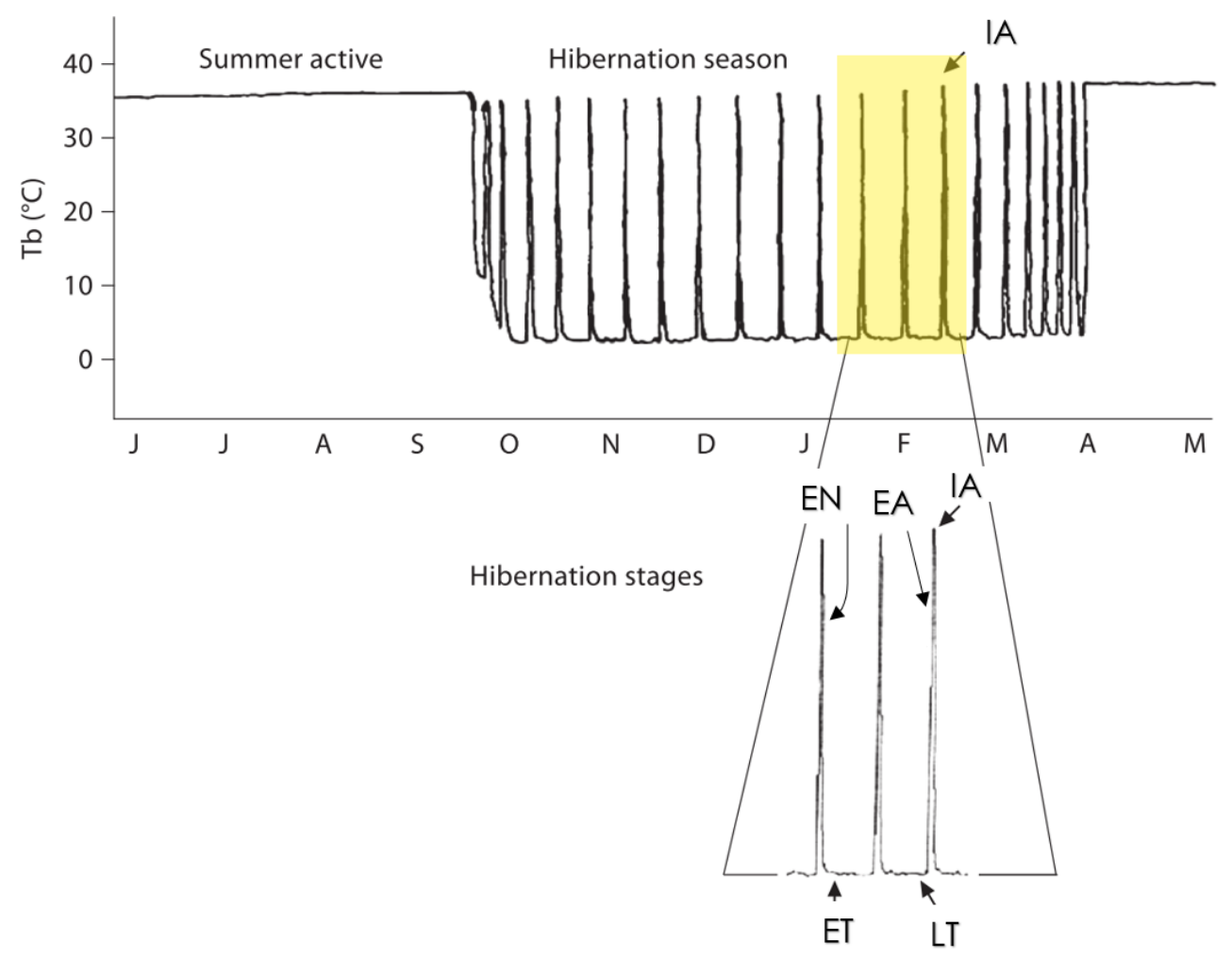

Figure 1.1: Torpor-arousal cycle pattern throughout the length of hibernation (September to April) where body temperature (Tb) of a ground squirrel is plotted as a function of time. The highlighted region shows two complete torpor-arousal cycles that are defined by the points entry into torpor (EN), early torpor (ET), late torpor (LT), early arousal (EA) and interbout arousal (IA). Figure adapted from (Storey, 2010). 


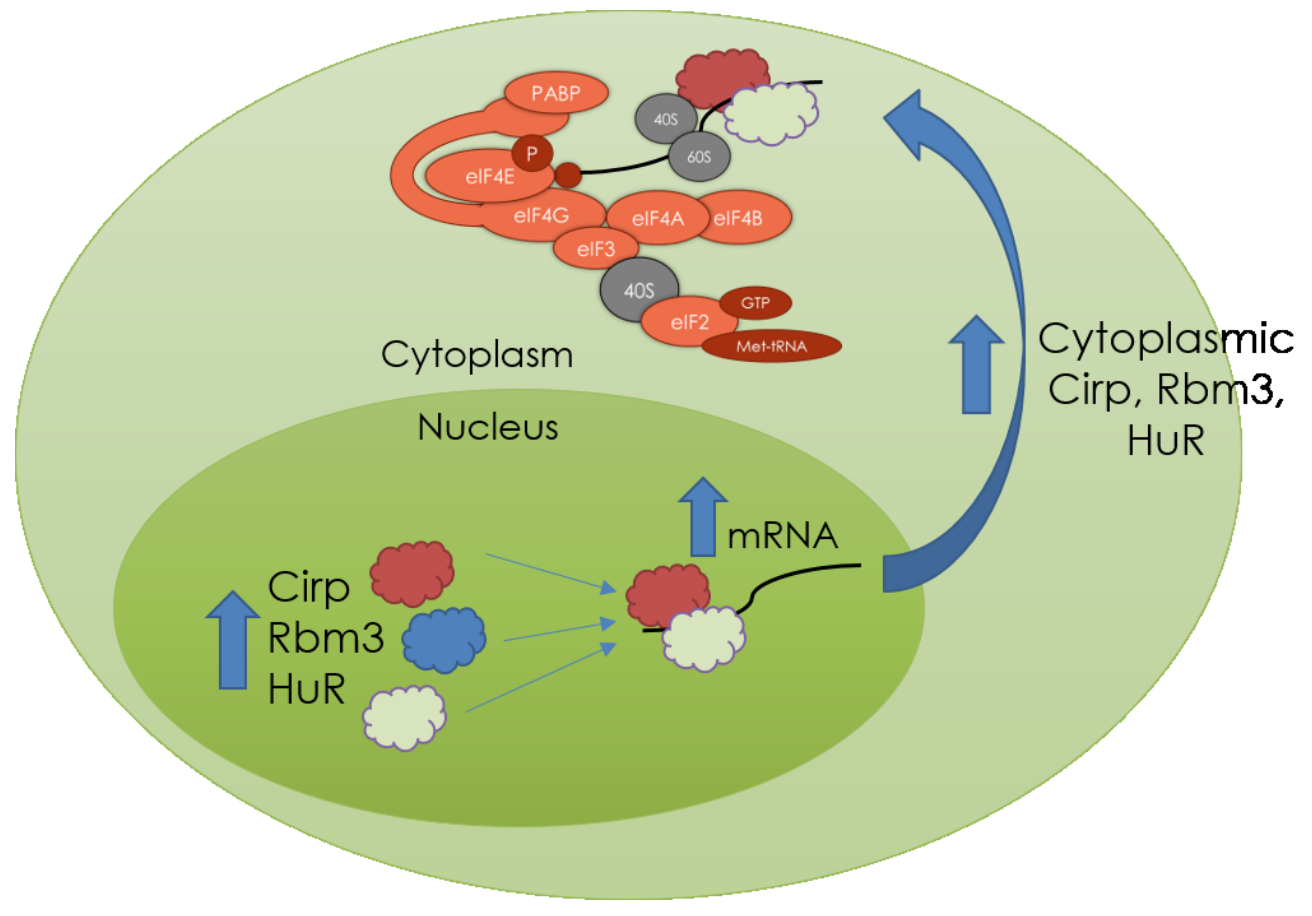

Figure 1.2: Cirp, Rbm3 and HuR are hypothesized to increase in protein expression and translocate from the nucleus to the cytoplasm during torpor. They are also hypothesized to stabilize target transcripts (Ptbpl and Nr1d2) so it is hypothesized that the mRNA levels of these target transcripts will either stay constant or increase during torpor. The RNA-binding proteins are shown to be bound to the $m R N A$ to illustrate their roles in $m R N A$ stability and increasing the translation of specific transcripts. 


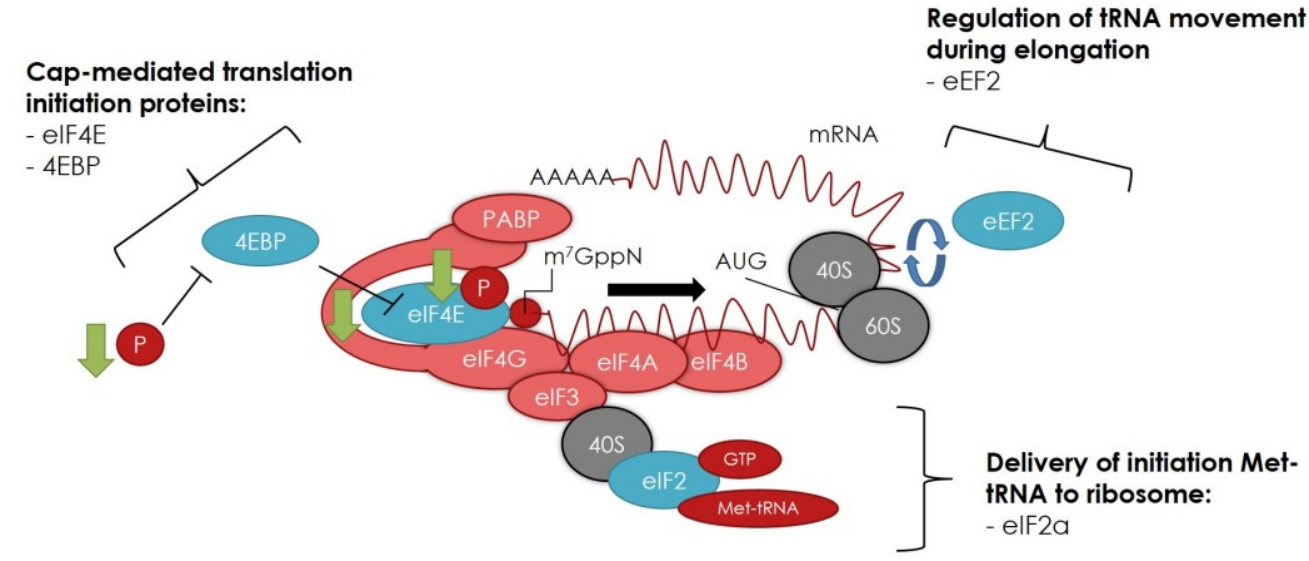

Figure 1.3: Key proteins involved in cap-dependent translation. Relative eukaryotic translation initiation factor $4 E$ (eIF4E, p-eIF4E S209) protein and phosphorylation levels, as well as phosphorylated 4E-binding protein (p-4EBP S65) levels were hypothesized to decrease as a mechanism of inhibiting global protein translation. Eukaryotic translation initiation and elongation factors (eIF2 $\alpha$ and eEF2) and their inhibitory phosphorylation events ( $p$-eIF2a S5I and p-eEF2 T56) were also measured since their abundance during directly affects translation initiation and elongation. 


\section{Chapter 2 - General Methods}




\subsection{S.M. LOGAN's CONTRIBUTION STATEMENT}

The procedures presented under the heading of "Animal Experiments" below were performed by researchers other than S.M. Logan. All remaining techniques, data collection, and data analysis outlined under all other headings within this chapter were performed solely by S.M. Logan.

\subsection{ANIMAL EXPERIMENTS}

Thirteen-lined ground squirrels (Ictidomys tridecemlineatus) weighing approximately 150-300 g, were wild-captured by a United States Department of Agriculture-licensed trapper (TLS Research, Bloomingdale, IL) and transported to Dr. J.M. Hallenback's laboratory at the Animal Hibernation Facility, National Institute of Neurological Disorders and Stroke (NIH, Bethesda, MD), where the hibernation experiments were performed. NINDS animal care and use committee (ACUC) animal housing and experimental procedures were followed. Each thirteen-lined ground squirrel was anesthetized with $5 \%$ isofluorane and fitted with a sensor chip (IPTT-300; Bio Medic Data Systems) injected under the skin. Each squirrel was housed individually in a shoebox cage at $21^{\circ} \mathrm{C}$. Animals were fed a standard rodent diet and water ad libitum until they gained sufficient lipid stores to enter hibernation. To enable a natural transition into torpor, all animals were transferred to an environmental chamber at $\sim 5{ }^{\circ} \mathrm{C}$ in constant darkness. Sampling points throughout the torpor-arousal cycle were chosen based on body temperature $\left(T_{b}\right)$ measured with the subcutaneous sensor chip, time, and respiration rates. The characteristics of the chosen sampling points are defined below: 
EC designates euthermic, cold room; these euthermic animals had a stable $\mathrm{T}_{\mathrm{b}}\left(\sim 37^{\circ} \mathrm{C}\right)$ in the $5{ }^{\circ} \mathrm{C}$ cold room and could enter torpor but had not done so for at least three days.

EN designates entrance; animals were in the entrance phase of the hibernation bout $\left(\mathrm{T}_{\mathrm{b}}=\right.$ $18-31^{\circ} \mathrm{C}$ ) characterized by decreasing $\mathrm{T}_{\mathrm{b}}$.

ET designates early torpor; animals had a stable $\mathrm{T}_{\mathrm{b}}$ of $5-8{ }^{\circ} \mathrm{C}$ for one day.

LT designates late torpor; animals have $\mathrm{T}_{\mathrm{b}}$ values of $5-8^{\circ} \mathrm{C}$ and were continuously in deep torpor for at least 5 days.

EA designates early arousal; animals are characterized by an increased respiratory rate of more than 60 breaths $/ \mathrm{min}$ and a rising $\mathrm{T}_{\mathrm{b}}$ of $9-12^{\circ} \mathrm{C}$.

IA designates interbout arousal; after a multi-day torpor with core body temperature returned to $\sim 37^{\circ} \mathrm{C}$ for approximately 18 hours.

All thirteen-lined ground squirrels had been through a series of torpor-arousal bouts prior to sampling. The animals were exposed to minimal noise and a red safe light (3-5 lux) during brief animal monitoring periods. Animals were sampled as in McMullen \& Hallenbeck (2010) (McMullen and Hallenbeck, 2010). Tissue samples were shipped to Carleton University on dry ice. The tissues were stored at $-80^{\circ} \mathrm{C}$ until use.

\subsection{TOTAL PROTEIN EXTRACTION}

Frozen tissue samples ( $\mathrm{n}=4$ independent biological replicates) of liver, skeletal muscle, kidney, and brown adipose were prepared for 6 time points (EC, EN, ET, LT, EA, and IA). Frozen samples were quickly weighed and crushed into small pieces under liquid nitrogen. A Polytron P10 homogenizer was used to homogenize tissue 1:2 w:v with ice- 
cold homogenizing buffer adjusted to $\mathrm{pH} 7.5$, containing $20 \mathrm{mM}$ HEPES, $200 \mathrm{mM} \mathrm{NaCl}$, $0.1 \mathrm{mM}$ EDTA, $10 \mathrm{mM} \mathrm{NaF}, 1 \mathrm{mM} \mathrm{Na} 3 \mathrm{VO}_{4}, 10 \mathrm{mM} \beta$-glycerophosphate, a few crystals of phenylmethylsulfonyl fluoride (BioShop), and $1 \mathrm{uL}$ of Sigma protease inhibitor (BioShop). Following centrifugation of each sample at $10,000 \mathrm{rpm}$ for $10 \mathrm{~min}$ at $4{ }^{\circ} \mathrm{C}$, the supernatant containing soluble proteins was collected for each sample. Total protein concentration was determined using the Bio-Rad reagent (Bio-Rad; Cat\#500-0005, Hercules, CA) with absorbance read at $595 \mathrm{~nm}$ on a MR500 microplate reader. The concentration of the samples was adjusted to $10 \mu \mathrm{g} / \mu \mathrm{L}$ (or $5 \mu \mathrm{g} / \mu \mathrm{L}$ in the case of kidney) by adding appropriate amounts of homogenizing buffer and then $2 \mathrm{X}$ sodium dodecyl sulfate (SDS) loading buffer (100 mM Tris-base adjusted to $\mathrm{pH}$ 6.8, 4 \% w:v SDS, $20 \%$ v:v glycerol, $0.2 \% \mathrm{w}: \mathrm{v}$ bromophenol blue, $10 \% \mathrm{v}$ :v 2-mercaptoethanol) was added to each sample in a 1:1 v:v ratio before samples were mixed and boiled. The final $5 \mu \mathrm{g} / \mu \mathrm{L}$ protein (or $2.5 \mu \mathrm{g} / \mu \mathrm{L}$ kidney) samples were stored at $-40{ }^{\circ} \mathrm{C}$ until use.

\subsection{CYTOPLASMIC-NUCLEAR PROTEIN EXTRACTION}

Cytoplasmic and nuclear protein fractions were prepared using liver and muscle tissue of euthermic and hibernating thirteen-lined ground squirrel $(n=4-5$ from different individuals from each of these time points). Tissue samples weighing between $0.275 \mathrm{~g}$ and $0.410 \mathrm{~g}$ were homogenized using 5-10 piston strokes of the Dounce homogenizer following the addition of $1 \mathrm{~mL}$ of homogenization buffer (100 mM HEPES pH 7.9, $100 \mathrm{mM} \mathrm{KCl}$; $100 \mathrm{mM}$ EDTA; $20 \mathrm{mM} \beta$-glycerophosphate), and $10 \mu \mathrm{L}$ of both $100 \mathrm{mM}$ DTT and protease inhibitor cocktail (Bioshop). Samples were centrifuged at $4{ }^{\circ} \mathrm{C}$ for $10 \mathrm{~min}$ at $10,000 \mathrm{rpm}$. The supernatant containing the cytoplasmic fraction was separated from the pellet, which was re-suspended in $125 \mu \mathrm{L}$ of extraction buffer (20mM HEPES pH 7.9, 400 
$\mathrm{mM} \mathrm{NaCl}, 1 \mathrm{mM}$ EDTA, $10 \% \mathrm{v} / \mathrm{v}$ glycerol, $20 \mathrm{mM} \beta$-glycerophosphate) with $1.5 \mu \mathrm{L}$ of $100 \mathrm{mM}$ DTT and $1.5 \mu \mathrm{L}$ of protease inhibitor cocktail (Bioshop). The samples in extraction buffer were placed on their sides in a box of ice and were rocked for an hour and every 10 min the samples were tapped on the benchtop to loosen the pellet. Then, the samples were centrifuged for $10 \mathrm{~min}$ at $10,000 \mathrm{rpm}$ in a fridge chilled to $4{ }^{\circ} \mathrm{C}$. The supernatant containing the nuclear fractions were removed and protein concentration was determined for both the cytoplasmic and nuclear fractions using the Bio-Rad reagent (BioRad; Cat\#500-0005, Hercules, CA) with absorbance read at $595 \mathrm{~nm}$ on a MR500 microplate reader. The BioRad assay (previously described) was used to determine the concentration of each of the cytoplasmic and nuclear fractions. SDS-PAGE followed by immunoblotting with a histone H3 antibody (diluted 1:1000 in TBST (20 mM Tris base, pH 7.6, $140 \mathrm{mM} \mathrm{NaCl}, 0.05 \%$ v:v Tween-20); Cell Signaling) was used to test nuclear extraction purity. Extracts were stored at $-80{ }^{\circ} \mathrm{C}$ until use or further processing with SDS loading buffer for Western Blotting (as per the method described under Total Protein Extraction, above).

\subsection{WESTERN BLOTTING}

Equal amounts of prepared protein homogenate and 4-5uL of PiNK Plus pre-stained protein ladder (10.5-175 kDa, FroggaBio) were loaded onto 10-15 \% SDS-PAGE gels, electrophoresed for 70-100 min at $180 \mathrm{~V}$ using the BioRad Mini Protean III system in Trisglycine running buffer ( $0.25 \mathrm{M}$ Tris-base, $2.45 \mathrm{M}$ glycine, $0.035 \mathrm{M}$ SDS). The SDS-PAGE resolving gels used were $10-15 \%$ acrylamide depending on the protein target (see Appendix B), and used a Tris-glycine buffer with a $\mathrm{pH}$ of 8.8 . The $5 \%$ stacking gels were composed of $170 \mu \mathrm{L} 30 \%$ acrylamide, $130 \mu \mathrm{L} 1 \mathrm{M}$ Tris (pH 6.8), $10 \mu \mathrm{L} \mathrm{10 \%} \mathrm{SDS,} 10 \mu \mathrm{L}$ 
$10 \%$ ammonium persulfate (APS) and $1 \mu \mathrm{L}$ tetramethylethylenediamine (TEMED) in 680 $\mu \mathrm{L} \mathrm{ddH}_{2} \mathrm{O}$. Depending on the protein target's molecular weight, proteins were transferred onto 0.45 micron polyvinylidene difluoride (PVDF) paper, either at $160 \mathrm{~mA}$ for 70-90 min or at 30-50 V for 45-60 min in Tris-glycine transfer buffer $(25 \mathrm{mM}$ Tris $\mathrm{pH} 8.5,192 \mathrm{mM}$ glycine and $10 \%$ v:v methanol). Blots were blocked with $2.0 \%-5.0 \%$ w:v milk made up in TBST for 20-30 min, to prevent unspecific binding of antibodies. The membranes were incubated at $4{ }^{\circ} \mathrm{C}$, overnight, on a rocker with specific primary antibodies (diluted 1:1000 or 1:2000 v:v with TBST). Rabbit polyclonal primary antibodies used for every target except for HuR which was the only rabbit monoclonal antibody and HMGB1 which was the only mouse monoclonal antibody. After the removal of primary antibody, the membranes were exposed to an HRP-linked anti-rabbit IgG secondary antibody (diluted with TBST to 1:8000-1:4000 v:v) for 30 min. An HRP-linked anti-mouse IgG secondary antibody (diluted 1:8000 v:v with TBST) was used for HMGB1 experiments. The membranes were washed for 15-30 minutes in TBST before visualizing with enhanced chemiluminescence (ECL) reagents. The amount of protein in each lane was reassessed using Coomassie Blue staining ( $0.25 \% \mathrm{w}: \mathrm{v}$ Coomassie brilliant blue, $7.5 \% \mathrm{v}: \mathrm{v}$ acetic acid, $50 \%$ methanol) of the PVDF membranes.

\subsection{TOTAL RNA EXTRACTION}

Briefly, approximately $50 \mathrm{mg}$ of frozen skeletal muscle, liver, and kidney tissue was weighed and homogenized in $1 \mathrm{~mL}$ of Trizol (Invitrogen) using a Polytron PT1200 homogenizer. Four to five biological replicates were made for each tissue from independent animals, for each of the 5-6 experimental time points. Time points used for all tissues included EC, EN, ET, LT, and EA, while IA was also used for liver. Each sample was 
vortexed briefly following the addition of $200 \mu \mathrm{L}$ of chloroform, before being centrifuged for 10 minutes at $10,000 \mathrm{rpm}$ and $4{ }^{\circ} \mathrm{C}$. The supernatant containing the RNA was separated from the pellet and $750 \mu \mathrm{L}$ of isopropanol was added to the supernatant to precipitate the RNA. Each sample was centrifuged for 15 minutes at $12,000 \mathrm{rpm}$ at $4{ }^{\circ} \mathrm{C}$, washed with 1 $\mathrm{mL}$ of $70 \%$ ethanol, and then centrifuged again for $12,000 \mathrm{rpm}$ for $5 \mathrm{~min}$. The supernatant was removed and the pellets air dried for 10-15 minutes. RNA purity was assessed for each biological replicate for all three tissues by measuring the absorbance at 260 and $280 \mathrm{~nm}$. RNA integrity was assessed by visualizing $18 \mathrm{~S}$ and $26 \mathrm{~S}$ ribosomal bands on a $1 \%$ agarose gel with SybrGreen staining. In the case of the liver RNA extractions, there appeared to be some DNA contamination (based on a $260 \mathrm{~nm} / 280 \mathrm{~nm}$ ratio of 2.2 and high molecular weight bands on the agarose gel). To remove the contaminating DNA, the extracted RNA was treated with a DNase I, RNase-free, HC (50 U/ $\mu \mathrm{L}$; Thermo Scientific, \#EN0523). The resulting RNA samples were visualized on a $1 \%$ agarose gel with SybrGreen staining to confirm the DNA contamination was eliminated before proceeding with cDNA synthesis.

\subsection{CDNA SYNTHESIS AND PCR AMPLIFICATION}

To begin, RNA samples were normalized in a total volume of $10 \mu \mathrm{L}$ DEPCautoclaved $\mathrm{ddH}_{2} \mathrm{O}$ such that each biological replicate contained $2.5 \mu \mathrm{g}$ RNA (muscle), 1.65 $\mu \mathrm{g}$ RNA (liver), and $1.25 \mu \mathrm{g}$ (kidney). The normalized RNA samples were incubated with $1 \mu \mathrm{L}$ of Oligo-dT (200 ng/ $\mu \mathrm{L}$ 5'-TTTTTTTTTTTTTTTTTTTTTTV-3'; where V=A, G, or C; Sigma Genosys) and placed in a thermocycler at $65^{\circ} \mathrm{C}$ for $5 \mathrm{~min}$ before being chilled on ice for $5 \mathrm{~min}$ to allow the Oligo-dT adapter to bind to the poly(A) tails of transcripts. Reverse transcription was performed with the following reagents: $4 \mu \mathrm{L}$ of $5 \mathrm{X}$ first-strand buffer (Invitrogen), $2 \mu \mathrm{L}$ of $0.1 \mathrm{M}$ DTT (Invitrogen), $1 \mu \mathrm{L}$ of $10 \mathrm{mM}$ dNTPs (BioShop), 
and $1 \mu \mathrm{L}$ of MMLV Reverse transcriptase (Invitrogen). Each sample was spun down before incubating at $42{ }^{\circ} \mathrm{C}$ for $45 \mathrm{~min}$ in the thermocycler. Serial dilutions $\left(10^{-1}, 10^{-2}\right.$, and $\left.10^{-3}\right)$ of the cDNA samples were prepared for relative quantification of select mRNAs and reference genes. PCR reagents were prepared and using a BioRad MyIQ2 Detection System (BioRad, Hercules, CA, USA).

The thirteen-lined ground squirrel (Ictidomys tridecemlineatus) genome from the NCBI webpage (http:/www.ncbi.nlm.nih.gov/genome/?term=ictidomys), along with Primer BLAST (http://www.ncbi.nlm.nih.gov/tools/primer-blast/) was used to create the PCR primers. The primers were synthesized by Integrated DNA Technologies (Coralville, Iowa, USA). The primer sequences for each gene are listed in Chapter 3. All PCR runs underwent melt-curve analysis and dilution curve testing to identify which primer set amplified more than one PCR product or amplified non-mRNA products, as indicated by more than one melt curve or by no change in $C_{t}$ values between serial dilutions, respectively. Additionally, each single product from each working primer set was sent for sequencing (BioBasic, Markham, ON) to confirm that the correct message was amplified.

The PCR protocol began with 3 min of secondary structure denaturing at $94{ }^{\circ} \mathrm{C}$, followed by 49 cycles of $94{ }^{\circ} \mathrm{C}$ for 10 seconds, $60{ }^{\circ} \mathrm{C}$ annealing temperature for 20 seconds, and elongation at $75{ }^{\circ} \mathrm{C}$ for 20 seconds. The protocol was concluded with one final step of $55^{\circ} \mathrm{C}$ for 10 seconds and $75^{\circ} \mathrm{C}$ for 20 seconds. The optimal cDNA dilution $\left(10^{-1}\right.$ or $\left.10^{-2}\right)$ and annealing temperature was determined for each gene apart of the study. Further details are included in appropriate data chapters of this thesis.

To isolate cleaned PCR product for sequencing analysis (BioBasic, Markham, ON), a freeze-squeeze approach was taken. Gel containing the PCR product was excised from 
the larger gel, frozen in liquid nitrogen for at least $5 \mathrm{~min}$, then placed in $0.6 \mathrm{~mL}$ Eppendorf tubes with punctured bottoms and glass wool filters. The tubes containing gel and PCR product were placed in $1.5 \mathrm{~mL}$ Eppendorf tubes and spun at 12,000 RPM for $5 \mathrm{~min}$. To the supernatant, 0.1 volume of $3 \mathrm{M}$ sodium acetate and 1 volume of isopropanol were added before centrifuging again at 12,000 RPM for $15 \mathrm{~min}$. The pellet was washed with $0.5 \mathrm{~mL}$ of $70 \%$ ethanol and allowed to air dry for 10-15 min before resuspending in $30 \mu \mathrm{L}$ water.

\subsection{Quantification and Statistical Analysis}

Western blot bands were imaged using the Chemi-Genius Bioimaging system (Syngene, Frederick, MD) following Western blotting were quantified using GeneTools software. Background was taken into account. For time-course Western blot quantification, not all protein homogenates could be run on the same gel so one set of samples (e.g. all biological replicates for EN) was run on each gel and the band densities of the other samples were standardized to the same sample (e.g. EN1 on all three gels). Then, the average band density for each time point was normalized against the average EC band density, such that the relative band density of EC would be 1 for graphing purposes. For protein subcellular distribution analysis, a similar method was applied where the same control cytoplasmic samples were run on both gels such that protein levels would be relative to these samples. Each PVDF membrane was stained using Coomassie Blue staining ( $0.25 \%$ w:v Coomassie brilliant blue, $7.5 \%$ v:v acetic acid, $50 \%$ methanol) to visualize the total amount of protein in each lane. Immunoblot band density in each lane was standardized against the summed intensity of a group of Coomassie stained protein bands in the same lane as previously described (Eaton et al., 2013). Data are expressed as means \pm SEM, $n=4$ independent samples from different animals for Western blot analysis. 
Differences between control and the other torpor-arousal time points were analyzed using SigmaPlot software and considered statistically significant when the one-way ANOVA with the Tukey post-hoc test yielded a result of $p<0.05$. For subcellular distribution analysis, a Student's t-test was used to compare relative cytoplasmic protein levels in EC and LT, and separately, the relative nuclear protein levels during LT relative to EC. Differences between control and hibernation conditions were considered statistically significant when the Student's t-test yielded a result of $p<0.05$.

Raw $C_{t}$ values obtained from each PCR run were converted to a linear form using $2^{-\mathrm{Ct}}$ calculations and were normalized against the reference gene. The chosen reference gene was considered acceptable by determining that its expression did not change between control and other points of the torpor-arousal cycle. If a one-way ANOVA with a Tukey post-hoc test showed no change throughout the torpor-arousal cycle, the gene was considered a candidate reference gene. For this experiment, gamma actin (ACTG2) was used as the reference gene in skeletal muscle, alpha tubulin 1c (TUBA1C) was used in liver, and beta tubulin (TUBB1) in kidney. Standardized values for each experimental condition were expressed as mean \pm SEM, where $n=3-5$ biological replicates. Differences between control and the other torpor-arousal time points were analyzed using SigmaPlot software and considered statistically significant when the one-way ANOVA with the Tukey post-hoc test yielded a result of $p<0.05$. 


\section{Chapter 3 - Cold-inducible protein response to the torpor-arousal cycle in thirteen-lined ground squirrels}




\subsection{INTRODUCTION}

\subsubsection{RNA-binding proteins}

RNA-binding proteins (RBPs) are important in countless, well-defined metabolic pathways within our cells including transcription, pre-mRNA processing/transport, mRNA degradation, translation, and non-coding RNA processing and activity (Anantharaman et al., 2002). Current data predicts that $6-8 \%$ of all known proteins classify as RBPs (Gerstberger et al., 2014; Si et al., 2015). This underlines the importance of identifying RBPs and characterizing their interactions with RNAs in biological processes. Although many RBPs and their binding partners have been identified, and the RBPs that play major roles in the processes listed above are well characterized, the roles of many RBPs in gene regulation and cell viability remain incompletely understood. Cold-inducible binding protein (Cirp, also named A18 Hnrnp and Cirbp), RNA binding motif protein 3 (Rbm3), and Hu-antigen R (HuR, also named HuA and Elav1) are of interest because they are a few of the best characterized, most highly conserved eukaryotic RNA-binding proteins that are stress responsive, have known roles in regulating the translation of specific transcripts, and most importantly, their role during torpor has not been fully elucidated.

Cirp and Rbm3 are classified as cold-shock proteins since they were both originally observed to increase expression in cold-treated cells from non-hibernating species. The RBM3 gene was haphazardly identified in the search for genes involved in X-linked disorders, on a 350 kilobase segment of the pi 1.2 region of the human $\mathrm{X}$ chromosome (specifically Xp11.23) following cDNA sequencing and bioinformatic analysis. It was called "RNA binding motif protein" due to its similarity in motifs with other RNA-binding proteins (Derry et al., 1995). The CIRP gene was first identified via a PCR-based cloning 
method with the aim of identifying genes induced upon cold shock $\left(37^{\circ} \mathrm{C}\right.$ to $\left.32{ }^{\circ} \mathrm{C}\right)$ in mouse testis (Nishiyama et al., 1997a). CIRP is mapped to the 19p13.3 locus which is a region of the genome that, when mutated, has been implicated in various cancers and neurological disorders (Nishiyama et al., 1997b). Cirp and Rbm3 proteins have high sequence similarity (64\% similarity in humans), including a highly similar RNA recognition motif $(\mathrm{RRM})$ at the $\mathrm{N}$-terminal end that is essential for binding target transcripts, and a less similar glycine-rich domain at their C-terminus which has been proposed as being important for both Cirp and Rbm3 in binding to both RNA and DNA because it likely serves as a nuclear localization signal (Lleonart, 2010; Nishiyama et al., 1997b; Zhu et al., 2016). They have many of the same RNA targets because they both bind to the same RNA binding motif upon cellular stress, which is called RADAKA and codes for 5'-GAUACGA-3' (Liu et al., 2013). Furthermore, apart from cold exposure, both Cirp and $\mathrm{Rbm} 3$ are stimulated by various other stressors, including hypoxic conditions ( $8 \%-1$ $\% \mathrm{O}_{2}$ conditions) through a HIF1-independent mechanism, UV irradiation, osmotic stress, ER stress, DNA damage, chemical imbalances, and starvation, making Cirp and Rbm3 a highly interesting set of proteins to study in animals that use hypometabolism to adapt to extreme environments (De Leeuw et al., 2007). Cirp and Rbm3 are similar in sequence, binding specificity, and role but they are distinct proteins with specialized regulatory mechanisms and may have divergent roles during cold stress.

ELAVL1 is the gene that codes for HuR, an RNA-binding protein of the embryonic lethal, abnormal vision, drosophila-Like (ELAV) family, and is mapped to the 19p13.2 locus. HuR is not classified as a cold-shock protein but instead was first identified as being the only ubiquitously expressed ELAV family member with similar binding specificity to 
mRNA as its brain-restricted ELAV family members (HuD, HuE, and He1N1) (Ma et al., 1996). Similar to Rbm3 and Cirp, HuR expression is induced in response to various cellular stressors including hypoxia, heat shock, and UV irradiation. HuR binds AU-rich regions of RNA to protect and transport mRNA to the cytoplasm and can associate with both Rbm3 and Cirp proteins during times of cell stress, making it a relevant target to study in hibernators like the ground squirrel that are capable of lowering core body temperature to less than $5{ }^{\circ} \mathrm{C}$ (Atasoy et al., 1998; Pang et al., 2013). It may have a role inhibiting the degradation of the poly(A) tail by impeding access to exonucleases and complimentary microRNAs (Atasoy et al., 1998; Guo et al., 2010; Li et al., 2002; Yaman et al., 2002). Indeed, studies on hibernating Arctic ground squirrels showed that the poly(A) tails of select mRNAs are no shorter at any time point of the torpor-arousal cycle compared to control squirrels, suggesting that the poly(A) tails of transcripts are protected by RBP binding (Knight et al., 2000). However, current research attributes transcript protection to RBPs like poly(A)-binding protein (PABP) (Knight et al., 2000), but this might just be because PABP regulation during hibernation is much better characterized compared to stress-inducible RBPs like Cirp, Rbm3, or HuR.

Cirp and Rbm3 are predominantly present in the nucleus because they contain a $\mathrm{C}$ terminal arginine-glycine rich (RGG) domain that serves as a nuclear localization signal. Methylation of the Cirp RGG domain by protein arginine N-methyltransferase 1 (PRMT1) is important in its movement from the nucleus to the cytoplasm (Lleonart, 2010; Zhu et al., 2016). The glycine-rich domain of Rbm3 does not contain any arginine residues so it likely possesses a unique nuclear shuttling mechanism (Zhu et al., 2016). For instance, alternative splicing may be its primary mechanism of cytoplasmic translocation such that during cold- 
stress, it is transcribed with a different coding sequence that contains residues can be posttranslationally modified to regulate subcellular distribution (Zhu et al., 2016). The translocation from the nucleus to the cytoplasm is essential for their role in controlling the storage and translation of specific transcripts during different developmental stages or times of stress. Once in the cytoplasm, Cirp often associates with stress granules while $\mathrm{Rbm} 3$ travels to the endoplasmic reticulum to regulate membrane-associated protein kinase R (PKR)-like endoplasmic reticulum kinase (PERK). Cyclin-dependent kinase 1 (CDK1) phosphorylates HuR in its hinge region at serine 202 to promote nuclear association whereas phosphorylation at serine 221 by protein kinase $\mathrm{C}$ alpha and sigma is associated with mRNA binding and nuclear export. Furthermore, HuR can be methylated by protein arginine $\mathrm{N}$-methyltransferase 4 (PRMT4 also known as CARM1) but how this methylation event regulates its export is still poorly understood (Pang et al., 2013). HuR is also predominantly nuclear and translocates to the cytoplasm. Studies show that HuR coimmunoprecipitates with Cirp, and Cirp overexpression increases HuR in stress granules while decreased Cirp expression lowers HuR in stress granules (Guo et al., 2010; Lleonart, 2010).

\subsubsection{Cold stress}

Thirteen-lined ground squirrels hibernate during the winter months to conserve energy when food is scarce and ambient temperatures fall well below $0{ }^{\circ} \mathrm{C}$. Even in their underground dens, which approach the temperature of the frozen ground, these hibernators are subjected to cold-stress from the environment and from reducing their core body temperature. During each torpor-arousal cycle, the $T_{b}$ of thirteen-lined ground squirrels drops from $37^{\circ} \mathrm{C}$ to $0-5^{\circ} \mathrm{C}$, causing their blood to become cold, viscous, and more difficult 
to pump (Storey and Storey, 2004). Colder core body temperature itself can alter many molecular processes, from enzyme kinetics to protein-protein interactions (Storey and Storey, 2004), making the response to cold-stress an interesting and important one to study.

Usually, experiments pertaining to the mammalian cold-shock response involve decreasing the core body temperature $\left(\mathrm{T}_{\mathrm{b}}\right)$ of animals (mice or rats) or cell culture temperature from $37{ }^{\circ} \mathrm{C}$ down to $31-33{ }^{\circ} \mathrm{C}$. This is considered a "moderate" cold shock, characterized by a temperature change that stresses cells but they are still able to grow, as opposed to severe cold stress $\left(0-10^{\circ} \mathrm{C}\right)$ which completely arrests cell growth in mammalian systems (Al-Fageeh and Smales, 2006). Maximum cirp expression occurs after $12 \mathrm{~h}$ of moderate cold shock whereas $\mathrm{rbm} 3$ is maximally expressed after $6-12 \mathrm{~h}$, indicating differences in the kinetics of their activation (Danno et al., 1997; Zhu et al., 2016). Both CIRP and RBM3 genes are more highly expressed in internal organs upon cold-shock, not just in peripheral organs like skin and testes, and each has a unique tissue distribution (e.g. $r b m 3$ is not present in human heart or thyroid cells) indicating that these proteins may have distinct, tissue-specific roles in the mammalian cold-shock response (Danno et al., 1997). Interestingly, the response of these stress-inducible RBPs in mammals has hardly been studied with respect to cold stress lower than $32{ }^{\circ} \mathrm{C}$. It is rare that organs (other than skin or testes) from non-hibernating organisms (where most mammalian studies have been done on whole rats and mice or individual human organs) are able to sustain core temperatures lower than this for extended periods of time since the proliferation of cells in culture is often stopped below $32{ }^{\circ} \mathrm{C}$ (Lleonart, 2010). This chapter characterizes RBP regulation at low $\mathrm{T}_{\mathrm{b}}$ throughout the torpor-arousal cycle of hibernating ground squirrels, to determine if cold-shock proteins have a role in protecting various hibernator organs from cell stress. 
Western blotting was used to characterize relative total protein expression across the torpor-arousal cycle and cytoplasmic-nuclear distribution between control and torpor, whereas RT-PCR was used to determine the relative gene expression of the RBPs of interest and mRNA ( $p t b p 1$ and nrld2) that are known targets of Cirp and Rbm3 (based on an immunoprecipitation experiment done on cold-shock mice) (Liu et al., 2013).

\subsection{Materials AND MethodS}

\subsubsection{Animal Experiments, Total Protein Extraction and Cytoplasmic-Nuclear Protein Extraction}

These methods were conducted as described in Chapter 2.

\subsubsection{Western Blotting}

Western blotting was performed as described in Chapter 2. Total protein levels of the cold-shock RNA-binding proteins (Cirp and Rbm3) were measured in total protein extracts of liver, muscle, and brown adipose tissue, whereas RNA-binding protein HuR was measured in these tissues plus kidney. For cytoplasmic-nuclear distribution analysis, total protein levels of Cirp, HuR and Rbm3 were detected using cytoplasmic and nuclear fractions isolated from liver and muscle. Antibodies against Cirp, Rbm3 and HuR were used (please refer to Appendix A: Antibodies Used for Western Blotting for full details for each antibody). For a detailed list of the experimental conditions used for each protein target in each studied tissue, please refer to Appendix B: Western Blotting Conditions.

\subsubsection{Quantification of relative transcript levels}

Relative mRNA levels were determined using RNA extraction and PCR as described in Chapter 2. Primers used for cirp, hur, rbm3, $n r 1 d 2$ and $p t b p 1$ are as follows 
in Table 3.1. The reference gene used for muscle was gamma actin, liver was alpha tubulin, and kidney was beta tubulin.

\subsubsection{Quantification and Statistics}

Quantification and statistics were carried out as described in Chapter 2.

\subsection{RESULTS}

\subsubsection{Analysis of RNA-binding protein levels over the course of the torpor-arousal cycle}

Relative total protein levels of Cirp, HuR, and Rbm3 were analyzed in liver, muscle, kidney, and brown adipose tissue of the thirteen-lined ground squirrel, comparing EC with EN, ET, LT, EA and IA time points of the torpor-arousal cycle. Strong bands of Cirp protein were found at $28 \mathrm{kDa}$ in all four tissues as specified by the company that supplied the antibody (Santa Cruz Biotechnology, Inc.). However, liver also showed a second, less pronounced, band at $18 \mathrm{kDa}$ that cross-reacted with the antibody. Both bands were quantified for liver to better estimate the relative abundance of Cirp over the torporarousal cycle.

In liver, Cirp (18 kDa) protein levels were constant across torpor-arousal with respect to the euthermic in the cold room (EC) condition but a significant decrease (over $50 \%$ ) was seen in a comparison of the entrance phase (EN) with early arousal (EA) (Figure 3.1). However, compared to the EC value, Cirp ( $28 \mathrm{kDa})$ levels increased nearly 4-fold during EN and remained high during early torpor (ET) at 3.2-fold greater than the EC value. Subsequently, levels declined in late torpor (LT) and decreased strongly to just $40 \%$ of EC value during EA before returning to euthermic levels during interbout arousal (IA). Two 
protein bands that were very close in molecular weight cross-reacted with the primary antibody targeting $\mathrm{HuR}$ and were quantified together to estimate relative HuR levels over the torpor-arousal cycle. HuR total protein levels increased significantly during EN and ET to 2.2 and 1.9-fold higher than the EC value, respectively, before returning to EC levels during the subsequent phases (LT, EA and IA). Relative Rbm3 levels were constant over most phases of the torpor-arousal cycle but decreased significantly during LT to just $31 \%$ of the EC value.

Total protein levels of Cirp (28 kDa) and Rbm3 were quantified in skeletal muscle from thirteen-lined ground squirrel over the torpor-arousal cycle (Figure 3.2). Compared to EC, muscle Cirp (28 kDa) protein levels increased 1.5-fold during EN, before increasing again during ET and LT to values that were 2.0- and 2.4-fold higher than EC. Subsequently, Cirp $(28 \mathrm{kDa})$ levels decreased significantly to just $20 \%$ of the EC level during EA but rose during IA to about $60 \%$ of the EC level. Rbm3 levels remained relatively constant throughout the torpor-arousal cycle except for a significant decrease during EN to less than $40 \%$ of the EC level.

Total HuR levels in kidney peaked during ET when they reached 3-fold higher than the EC level before returning to EC levels from LT through IA sampling points (Figure 3.3).

Similar trends were seen for brown adipose tissue, where Cirp (28 kDa) total protein levels increased significantly during LT and EA to 2 -fold and 1.5-fold higher than the EC level, respectively, before dropping to $23 \%$ of the EC value in IA (Figure 3.4). HuR protein levels were generally constant across the sampling points except for a 
significant difference between EN and EA (where HuR levels increased 1.4-fold between these time points). Similar to liver and skeletal muscle, brown adipose Rbm3 protein levels decreased during ET and LT to $58 \%$ and $44 \%$ of EC, respectively. Rbm3 protein levels recovered during the arousal period to control levels, as in liver and muscle.

\subsubsection{Cyto-nuclear distribution of RNA-binding proteins over the torpor-arousal cycle}

To get a better understanding of how Cirp, Rbm3, and HuR are regulated during hibernation of thirteen-lined ground squirrels, changes in the cytoplasmic and nuclear distribution of these RNA-binding proteins were determined using Western blotting, comparing the EC and LT sampling points. In liver, relative Cirp (18 kDa) protein levels did not change between the cytoplasm and the nucleus comparing EC with LT (Figure 3.5). In contrast, cytoplasmic Cirp ( $28 \mathrm{kDa}$ ) levels increased during LT by 5.9 -fold. Nuclear Cirp levels also increased during LT (by 2.6-fold) compared to euthermic nuclear Cirp levels. Two bands representing HuR were quantified and the results showed an increase in cytoplasmic HuR during LT compared to cytoplasmic euthermic levels, but nuclear HuR levels were unchanged by torpor. Finally, cytoplasmic Rbm3 levels did not change but nuclear Rbm3 levels decreased during LT with respect to EC nuclear Rbm3 levels by over $45 \%$.

Cytoplasmic-nuclear distribution was also assessed for Cirp (28 kDa), HuR and Rbm3 using skeletal muscle from thirteen-lined ground squirrels (Figure 3.6). Two bands near the expected molecular weights of Cirp $(28 \mathrm{kDa})$ and $\mathrm{HuR}$ were quantified together There were no quantifiable differences in cytoplasmic or nuclear HuR or Rbm3 levels, comparing EC and LT. However, cytoplasmic Cirp (28 kDa) protein levels significantly 
increased by 1.24-fold during LT, relative to cytoplasmic EC levels $(p<0.05)$. Furthermore, nuclear Cirp (28 kDa) levels increased by 1.5 -fold of EC during LT.

\subsubsection{Gene expression of RNA-binding proteins and select targeted genes over the torpor-arousal cycle}

PCR was used to assess how cirp, rbm3, and hur gene expression was regulated over the torpor-arousal cycle as well as how these proteins might influence the levels of mRNAs that they are known to bind to (i.e. transcript levels of $p t b p 1$ and $n r 1 d 2$ ). The relative expression of the gene transcripts of these three proteins were compared for EC, EN, ET, LT, EA and IA time points of the torpor-arousal cycle. In liver, relative transcript levels of cirp and hur remained constant throughout the torpor-arousal cycle but Rbm3 mRNA levels increased by nearly 12 -fold during EA compared to EC (Figure 3.7). The ptbpl gene encodes another RNA-binding protein, whose mRNA transcripts can be bound at the 3'-UTR and stabilized or processed by both Cirp and Rbm3 (confirmed experimentally in mice) (Liu et al., 2013). Due to the low abundance of $p t b p 1$ transcripts in skeletal muscle according to the Human Protein Atlas database (see Appendix C: Figure 1 for more information), they were only measured in liver. Relative $p t b p l$ transcript levels did not change throughout the torpor-arousal cycle in liver.

All time points except IA were analyzed in muscle and kidney from thirteen-lined ground squirrels. There were no changes in the relative transcript levels of cirp, hur or rbm3 across the torpor-arousal cycle in either tissue (Figure 3.8, Figure 3.9). The transcript $n r l d 2$ corresponds to a circadian clock gene that has been validated as an mRNA target of both Rbm3 and Cirp, is highly abundant in muscle and kidney, but not in liver, and therefore its transcript levels were only assessed in muscle and kidney (according to Human 
Protein Atlas database information summarized in Appendix C: Figure C.1). PCR analysis showed no change in the relative transcript levels of $n r 1 d 2$ over the torpor-arousal cycle in thirteen-lined ground squirrel muscle. There were also no changes in cirp, rbm3, or $p t b p 1$ transcript levels in kidney from thirteen-lined ground squirrels but $n r l d 2$ gene expression increased compared to the control during EA (to just 13-fold higher than the EC level, $p<$ $0.05)$.

\subsection{Discussion}

Hibernation is characterized by decreased in metabolic rate and core body temperature. This is partly accomplished by suppressing energy expensive processes like transcription and translation, while upregulating select processes necessary to maintain tissue homeostasis and whole-organism survival. Thus, any increases in transcript or protein abundance shed light on processes necessary for hibernator survival. RNA-binding proteins (RBPs) are important in countless, well-defined metabolic pathways within our cells. RBPs regulate our most important cellular pathways, including transcription, premRNA processing/transport, mRNA degradation, translation, and non-coding RNA processing and activity (Anantharaman et al., 2002). RNA-binding proteins, and particularly those that are expressed upon cold stress like Cirp and Rbm3, are essential to study in hibernators that need extensive control over transcription and translation such that only the most important messenger RNAs are translated.

To date, cold-shock proteins have only been researched in hibernators in terms of their transcript levels, which provides a very narrow view of their role during torpor. Studies on facultative hibernators (whose hibernation can be induced at any time of the year) are the 
most complete, demonstrating that hamster heart has 3 CIRP mRNA isoforms. Compared to euthermic hamsters housed at $22^{\circ} \mathrm{C}$, naturally hibernating and artificially-induced hibernating hamsters both expressed CIRP but the ratio of short to long isoforms of cirp changed from 1:1 to 2:1, when hamsters were forced into hypothermic states and prevented from adapting to the change in environment (Sano et al., 2015). One study of black bears (Ursus americanus), an obligate hibernator that maintains its body temperature above $30^{\circ} \mathrm{C}$, showed that $\mathrm{rbm} 3$ transcript levels increased during torpor in muscle and liver, whereas another demonstrated that $r b m 3$ and 20-30 other protein biosynthesis-related genes were highly expressed in both heart and liver (Fedorov et al., 2009; Fedorov et al., 2011). The only studies of ground squirrels found that rbm3 transcript levels were increased in I. tridecemlineatus hypothalamus and cerebral cortex under three states (preparation for hibernation, torpor, and arousal from torpor) compared to spring active controls, and that Spermophilis lateralis (golden-mantled ground squirrel) rbm3 transcript levels increased in brain, heart and liver when comparing late torpid and interbout aroused squirrels to summer active ground squirrels (Schwartz et al., 2013; Williams et al., 2005). The work in this chapter more fully explored the role of three RBPs (Rbm3, Cirp, HuR) during hibernation by characterizing protein and transcript abundance in muscle, liver, kidney and brown adipose tissue of I. tridecemlineatus, collected over 6 time points of the torpor-arousal cycle. Furthermore, protein cytoplasmic-nuclear distribution was analyzed, comparing EC and LT in liver and muscle, to more fully understand how these coldinducible RBPs are regulated during hibernation. A major difference between studies previously done on hibernators and this one included the use of a euthermic control (squirrels capable of hibernating but that had maintained a body temperature of $37^{\circ} \mathrm{C}$ in 
the cold room for several days) as opposed to either summer active or spring active controls used in other studies. Using a spring or summer active animal as a control does not take into consideration possible confounding factors such as major differences in ambient temperature experience, metabolic fuel stores, or life stage between the "control" and experimental animals. For example, spring/summer active animals are euthermic, actively eating and are ready to breed or have reproduced and are lactating whereas hibernating animals are in a heterothermic life stage, an inactive reproductive state, and derive metabolic fuel solely from stored reserves laid down in their bodies during a hyperphagia phase (the time of intense eating) in the previous autumn. Using euthermic controls in the same cold room as the hibernating animals is essential for understanding the responses of proteins as animals enter into or arouse from the hypothermic hypometabolic state of torpor. This is particularly true of cold-shock proteins since ambient temperature is a crucial environmental cue that is known to influence their gene and protein expression.

\subsubsection{CIRP}

Firstly, relative protein levels of each RNA-binding protein were assessed in muscle, liver, kidney and BAT. Western blotting identified two isoforms of Cirp in liver but only the higher molecular weight isoform was detected in muscle and BAT. The Cirp band observed at $18 \mathrm{kDa}$ in liver was not differentially expressed over the torpor-arousal cycle (Figure 3.1). Interestingly, several studies cite the occurrence of 3 different cirp transcripts that are expressed at different temperatures. The long transcript has an additional open reading frame $(\mathrm{ORF})$ that contains a premature stop codon, so the resulting protein is $\mathrm{C}$ terminally truncated and non-functional (Sano et al., 2015). The short mRNA isoform of cirp is translated into the full-length, fully functional protein, and is the only one expressed 
during hibernation in hamster hearts, suggesting that alternative splicing may be an important mechanism of regulating CIRP expression and activity during stress (Zhu et al., 2016). If the $18 \mathrm{kDa}$ Cirp isoform is the C-terminally truncated isoform of Cirp, then it would make sense that it is not upregulated at any point of the torpor-arousal cycle: the Cterminally truncated isoform cannot be phosphorylated or methylated, resulting in a protein unable to transport transcripts from the nucleus to the cytoplasm. By contrast, the $28 \mathrm{kDa}$ isoform of Cirp was more abundant during EN and ET in muscle and liver compared to EC, and Cirp protein expression remained elevated during LT in muscle (Figure 3.1, Figure 3.2). This suggests that cold-shock or other stressors associated with the onset of torpor (as body temperature decreases from $37{ }^{\circ} \mathrm{C}$ to $\sim 5^{\circ} \mathrm{C}$ over $2-5$ days) promoted cirp translation in these tissues. Similarly, Cirp protein levels in BAT were elevated during LT compared to EC, when body temperature is at its minimum for extended periods of time, suggesting Cirp may be important to control translation during cold-stress (Figure 3.4). Interestingly, a trend is observed where BAT, muscle, and liver Cirp levels decrease to EC levels or less during EA and IA when ground squirrel $\mathrm{T}_{\mathrm{b}}$ is increasing towards or stable at $37^{\circ} \mathrm{C}$. Thus, hibernators may use a common response across various tissues where Cirp is not involved in translation regulation during euthermic conditions. The response of Cirp (28 $\mathrm{kDa}$ ) to torpor in this study is consistent with what is observed in non-hibernators attempting to adapt to cold stress. Rats exposed to $4^{\circ} \mathrm{C}$ for 2 weeks have increased Cirp protein and transcript levels in brain and brown adipose tissues. Rat liver and muscle only show increased Cirp protein levels but transcript levels remain unchanged (Wang et al., 2015). 
The cytoplasmic versus nuclear distribution of Cirp in muscle and liver was also compared for the EC and LT sampling points. Cirp (18 kDa) levels did not increase in the cytoplasm during torpor, providing additional evidence that the $18 \mathrm{kDa}$ isoform of Cirp is not functional during torpor. However, Cirp $(28 \mathrm{kDa})$ protein levels increased in both the cytoplasm and the nucleus of liver and skeletal muscle during torpor, which suggests that Cirp is involved in binding to transcripts in the nucleus and shuttling them to the cytoplasm for controlled translation (Figure 3.5, Figure 3.6). A similar experiment using immunofluorescence showed more Cirp in rat heart, muscle, liver and BAT cytoplasm following cold stress, further reinforcing the theory that Cirp facilitates cold adaptation by translocating to the cytoplasm (Wang et al., 2015). These results are consistent with unchanging total liver Cirp (18 kDa) protein levels and increased liver and muscle Cirp (28 $\mathrm{kDa})$ protein levels. Together, these results suggest that Cirp ( $28 \mathrm{kDa})$ could be involved in an essential molecular mechanism of avoiding liver damage and muscle atrophy in hibernators and non-hibernators alike.

PCR was used to help elucidate how the RBP response to cell stress is regulated throughout the torpor-arousal cycle in thirteen-lined ground squirrel liver, muscle and kidney (Figure 3.7, Figure 3.8, Figure 3.9). Despite changes in Cirp protein levels, cirp transcript levels did not increase in any tissue relative to the euthermic control, suggesting that hibernators do not induce CIRP gene expression during torpor, but perhaps actively translate store cirp mRNA in order to elevate protein levels and control cytoplasmicnuclear distribution via post-translational modification upon cold stress, although the latter notion would have to be confirmed when a phospho-Cirp or methyl-Cirp antibody becomes available. This theory is consistent with the observed increase in Cirp (28 kDa) protein 
levels in liver, muscle and BAT, as well as the change in liver and skeletal muscle Cirp cytoplasmic and nuclear distributions. Furthermore, studies using murine hippocampal cells have shown that cirp transcript abundance increases in response to "moderate hypothermia" (a decrease in $\mathrm{T}_{\mathrm{b}}$ from $\sim 37^{\circ} \mathrm{C}$ to $\sim 32{ }^{\circ} \mathrm{C}$ ) but not during deep hypothermia $\left(\sim 17^{\circ} \mathrm{C}\right)$ (Tong et al., 2013). It is possible that even hibernating species do not elevate CIRP gene expression at $\mathrm{T}_{\mathrm{b}}$ less than $32{ }^{\circ} \mathrm{C}$ (which corresponds to time points EN, ET, $\mathrm{LT}$, and EA), despite CIRP being an important cold-shock gene. Of note, thirteen-lined ground squirrels have two isoforms of cirp mRNA, just like hamsters. In this experiment, PCR primers were designed to amplify Cirp isoform 1, which corresponds to the longer transcript and the truncated protein. Primers were not designed for the short isoform, since both isoforms would have amplified due to identical sequence other than the region of isoform 1 that contains the additional ORF. Thus, based on studies done in hamster where

only the short isoform corresponding to the fully functional protein was expressed during hibernation, it was expected that there would be no change in the expression of the long cirp isoform in hibernating thirteen-lined ground squirrel (Sano et al., 2015).

\subsubsection{Rbm3}

$\mathrm{Rbm} 3$ protein levels were, in general, unchanging throughout the torpor-arousal cycle in liver, muscle, and BAT. Significant decreases during LT in liver (Figure 3.1), EN in muscle (Figure 3.2), and ET and LT in BAT (Figure 3.4) suggest that Rbm3 may not involved in metabolic adaptation to heterothermia in these tissues from thirteen-lined ground squirrels. Furthermore, there was a decrease in nuclear Rbm3 levels during LT in liver but no corresponding increase in cytoplasmic Rbm3 during this time, which could be explained by Rbm3 being less abundant (i.e. not translated) during cold stress in this animal 
(Figure 3.5). No changes in muscle Rbm3 subcellular distribution suggest that Rbm3 may not be overly important in common metabolic adaptation to cold stress in multiple tissues (Figure 3.6). Cirp and Rbm3 are highly homologous and have many of the same target genes, so it is possible that in order to conserve fuel, the hibernator cell strategically upregulates the activity of only one of these cold-inducible proteins (Liu et al., 2013).

There were virtually no changes in $r b m 3$ transcript levels in liver (Figure 3.7), muscle (Figure 3.8) or kidney (Figure 3.9) over the torpor-arousal cycle except for an increase in liver $r b m 3$ transcript levels during EA compared to EC, EN, ET and LT. This does not align with total protein data that showed $\mathrm{Rbm} 3$ protein levels to be unchanged during the arousal phase in liver. It is possible that both protein and transcript levels are elevated before torpor (i.e. elevated in the autumn months or under EC conditions) to prepare for heterothermy and metabolic suppression during the winter months, and that $\mathrm{Rbm} 3$ protein levels are maintained at this level for the entire winter season. This theory is consistent with a study on brain of thirteen-lined ground squirrels which showed elevated rbm3 transcript levels during October, in torpor, and during interbout arousal as compared to April levels in active ground squirrels (Schwartz et al., 2013). Thus, EC levels of rbm3 gene expression across the torpor-arousal cycle could represent consistent rbm3 gene expression, whereas the dip in Rbm3 protein levels during LT in liver, EN in muscle and $\mathrm{ET} / \mathrm{LT}$ in BAT could be indicative of globally suppressed translation during torpor, which is believed to be a requirement of metabolic suppression in many species (Boyer and Barnes, 1999; van Breukelen and Martin, 2001). However, being that Rbm3 total protein levels and cytoplasmic-nuclear distribution did not change relative to EC, it is unlikely that 
Rbm3 plays an enhanced torpor-specific role in preventing cell damage from cold-stress in liver, muscle, kidney or BAT. Again, future studies will be needed to confirm this.

\subsubsection{HuR}

HuR protein levels increased during EN and ET in liver (Figure 3.1) and increased during ET in kidney (Figure 3.3) but did not change in BAT (Figure 3.4), indicating that this protein is regulated in a tissue-specific manner during hibernation. In this study, liver HuR levels were observed to increase in the cytoplasm during LT, like Cirp (28 kDa) (Figure 3.5). HuR, like Cirp and Rbm3, is known to move to the cytoplasm upon cellular stress (heat shock, starvation, UV irradiation, etc.) and can function as a shuttling protein for transcripts by binding to the AU-rich elements of the mRNA 3'-UTR (Yaman et al., 2002). Additionally, HuR is an important RNA-binding protein that serves as a binding partner for both Rbm3 and Cirp (Guo et al., 2010). Thus, the upregulation of liver total HuR and Cirp protein levels during EN and ET as well as the increase in cytoplasmic HuR and Cirp during torpor suggests that HuR and Cirp are both activated upon cold stress during hibernation may form a complex to stabilize mRNA and promote the translation of specific messages. Interestingly, kidney total HuR protein levels increased during ET compared to EC, similar to liver, whereas the only significant difference seen in BAT total HuR protein levels was a slight increase during EA compared to EN. These data further emphasize the tissue-specific role of RBPs in response to torpor in thirteen-lined ground squirrels, with an emphasis on a possible role for HuR in the liver and kidney stress response, especially when ground squirrel $\mathrm{T}_{\mathrm{b}}$ decreases during EN and ET. 


\subsubsection{Target transcripts}

Polypyrimidine tract binding protein 1 (Ptbp1) and nuclear receptor subfamily 1 , group $\mathrm{D}$, member $2(\mathrm{Nr} 1 \mathrm{~d} 2)$ are experimentally determined targets of Rbm3 and Cirp in cold-exposed mice (Liu et al., 2013). The relative mRNA levels of $p t b p 1$ and $n r l d 2$ were assessed in liver, muscle, and kidney to provide an indication of the stability of possible Cirp/Rbm3-bound transcripts over the course of the torpor-arousal cycle. As previously mentioned, $p t b p l$ was not detected in muscle and $n r l d 2$ was not detected in liver since they have low expression in these tissues. This was confirmed using the EMBL-EBI's Expression Atlas (see Appendix $\boldsymbol{C}$ for the visual representation of Ptbp1 and Nr1d2 gene expression in mouse). Apart from an increase in kidney $n r l d 2$ transcript levels during EA relative to EC, there were no changes in transcript levels in liver, muscle or kidney. Although there is evidence that transcripts are continuously degrading throughout torpor, they do so at a rate much slower than the rate of degradation during EC, and although there are also simultaneous increases in gene transcription, the majority of transcripts are being stabilized by various molecular mechanisms, such as by increasing polyadenylation, preventing terminal degradation, storage away from RNases in stress granules, etc. (Grabek et al., 2015a). In general, the stable expression of $p t b p 1$ and $n r l d 2$ transcripts in liver, muscle, and kidney suggests that these Cirp, Rbm3 and HuR target transcripts are relatively stable throughout torpor and are not being degraded at a rate that surpasses their generation in the hypometabolic state. This is consistent with other studies that show that poly(A) tail length indicating mRNA stability is not significantly shorter during any one time point of the torpor-arousal cycle in Arctic ground squirrels (Knight et al., 2000), and that in some cases mRNA poly(A) tails can even increase in length during a torpor-bout in order to 
prevent degradation or facilitate translation (Grabek et al., 2015a). Perhaps, CIRP and HuR (but not Rbm3) are involved in the stabilization of these transcripts since at least one of these proteins is more highly expressed in liver, muscle, and kidney, and in select tissues, there was also subcellular localization data to support this. Although this study presents significant data suggesting a role for Cirp and HuR in the cold-shock response in thirteenlined ground squirrels, further work will need to be done to confirm the role of Cirp and HuR in RNA stabilization in each of these tissues.

\subsection{CONCLUSION}

Contrary to what was expected, it was demonstrated in this chapter that certain RBPs (Cirp and HuR) but not all (i.e. Rbm3) are more abundant and localize to the cytosol during torpor. Torpor in the thirteen-lined ground squirrel is a naturally-induced state of controlled but severe hypothermia, which provided an interesting context to study the response of cold-shock RNA-binding proteins Cirp and Rbm, as well as their stress-inducible binding partner, HuR. It was hypothesized that the protein expression of all three RBPs would increase during torpor, partly because transcriptomics studies done previously on hibernators suggested important roles for Rbm3 and Cirp in transcript stability and translation during torpor, and because HuR performs the same role as Cirp/Rbm3 but binds a different RNA consensus sequence and thus a different set of transcripts. Rbm3 levels decreased during entrance into torpor (EN), early torpor (ET) or late torpor (LT) in liver, skeletal muscle, and brown adipose tissue. By contrast, Cirp (28 kDa) levels increased during EN, ET, or LT in liver, skeletal muscle, and brown adipose tissue, while the shorter (and likely non-functional) isoform of Cirp (18 kDa) did not change protein expression in liver. HuR protein levels also increased during EN and ET in liver, and during ET kidney. 
The increase in Cirp and HuR protein levels, and the decrease in Rbm3 relative to the euthermic in the cold room (EC) control during EN, ET, and LT in multiple organs suggests that thirteen-lined ground squirrels use a conserved response to cold shock involving Cirp and HuR in all organs, although the protein levels of these three should be assessed in several other hibernator organs to verify this. The increase in Cirp and HuR but not Rbm3 could be a mechanism to reduce metabolic redundancy since both Cirp and Rbm3 bind to the same RNA consensus sequence and have many of the same target transcripts (Liu et al., 2013). Thus, it would be more energy efficient to increase the activity of only CIRP and HuR since they bind different mRNAs. The importance of Cirp and HuR was substantiated by cytoplasmic-nuclear distribution analysis in liver where Cirp and HuR were shown to increase abundance in the cytoplasm during torpor, signifying that they may both play roles in delivering mRNA to translation machinery in this organ. The same trend that was seen for liver Cirp was observed for muscle Cirp, suggesting the increase in cytoplasmic and nuclear Cirp levels during torpor may be part of a key molecular mechanism for ensuring cellular homeostasis during this time. Finally, transcript levels were assessed to determine if the gene expression of these RBPs is consistent with RBP protein levels. In general, transcript levels were held constant suggesting that CIRP and HUR are constitutively expressed like CIRP is in many cell lines (Nishiyama et al., 1997b) and is differentially translated upon severe cold-shock in hibernating thirteen-lined ground squirrel organs. Furthermore, the two downstream transcripts assessed ( $p t b p 1$ and $n r 1 d 2$ ) were either constantly expressed or upregulated over the torpor bout, suggesting a role for Cirp and HuR in $p t b p l$ and $n r l d 2$ transcript stability. This will need to be confirmed using immunoprecipitation techniques to determine if Cirp and HuR indeed bind these messages. 
Overall, these results provide a novel perspective on the role of cold-inducible RNAbinding proteins in four thirteen-lined ground squirrel organs, where Cirp and HuR but not Rbm3 are potentially important in the cold-shock response. 


\subsection{TABLES}

Table 3.1: Forward and reverse primer sequences for RNA-binding proteins and target transcripts, purchased from Integrated DNA Technologies (IDT), Inc. used in RT-PCR analysis, where alpha tubulin, gamma actin and beta tubulin are reference genes for the tissues mentioned in brackets

\begin{tabular}{l|l|l} 
Gene & Forward Primer (5'-3') & Reverse Primer (5'-3') \\
\hline CIRP & TGCAGTCCAGTCCAGCATAG & CATCCACTCCCATCCAGACC \\
\hline RBM3 & GGCAGCCTCCCTATTCTTCC & CCACGAACAGCTTCCCTTCT \\
\hline HUR & AGAACAAAAACGTGGCGCTC & GGGAGAACCTGAACCTCTGC \\
\hline PTBP1 & $\begin{array}{l}\text { GCTGAAGTGACCTTAACAGAC } \\
\text { CA }\end{array}$ & GCCCGAGCCGTCAGTC \\
\hline $\begin{array}{l}\text { Alpha Tubulin } \\
\text { (TUBA1C) } \\
\text { (liver) }\end{array}$ & GAGTTTTCTGAGGCCCGTGA & $\begin{array}{l}\text { AGCAGCAAGGTCAATACTCTTC } \\
\text { A }\end{array}$ \\
\hline $\begin{array}{l}\text { Gamma Actin } \\
\text { (ACTG2) } \\
\text { (muscle) }\end{array}$ & CTGTCTTCCCCTCCATCGTG & CCTCATCCCCAACGTAGCTG \\
\hline $\begin{array}{l}\text { Beta Tubulin } \\
\text { (TUBB1) } \\
\text { (kidney) }\end{array}$ & GGTGAACAGTGGGTCTCCTG & CCGCATCCTTGCTTTGAACC \\
\hline
\end{tabular}




\subsection{FigureS}

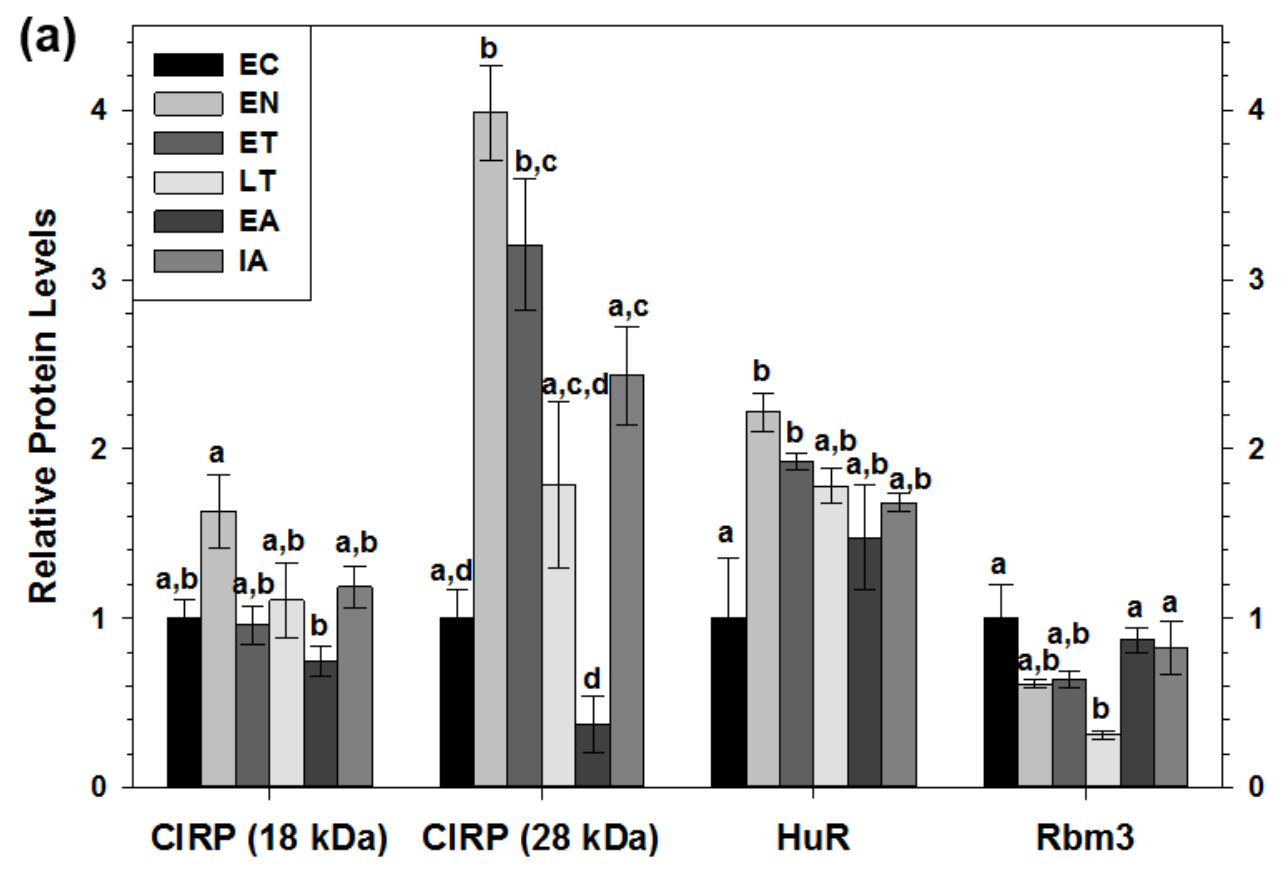

(b)

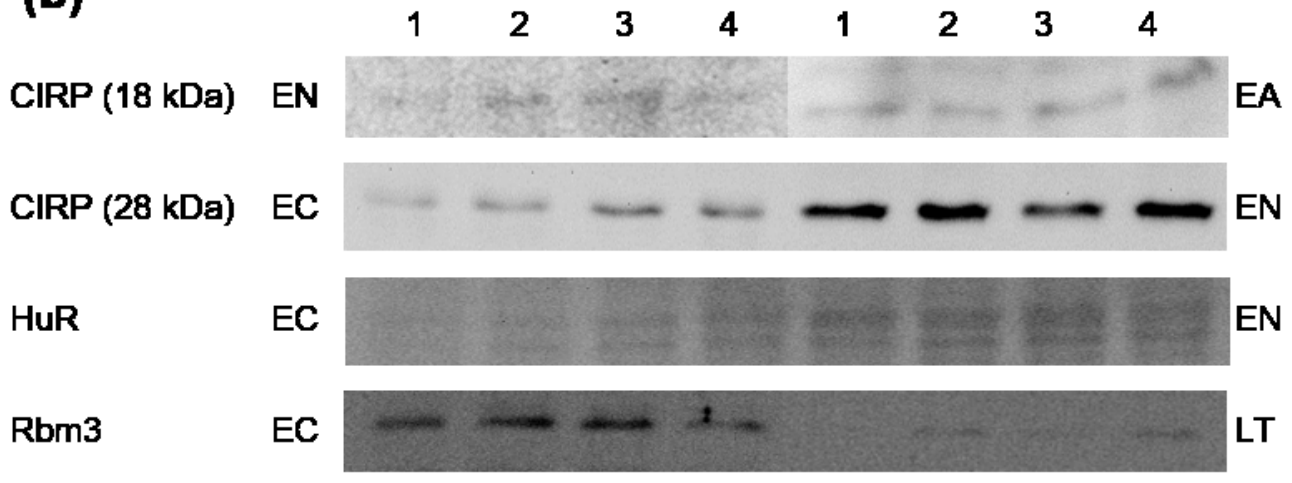

Figure 3.1: Relative cold-inducible RNA-binding protein levels in liver of thirteen-lined ground squirrels. (a) Histogram showing mean standardized expression levels of Cirp (18 kDa and 28 $k D a), H u R$, and Rbm3 ( \pm S.E.M., $n=3-4$ independent protein isolations from different animals). (b) Representative western blots for certain torpor-arousal time points, generally showing euthermic in the cold room (EC) control bands and bands of the sampling point that showed the largest change relative to EC. Sampling points in addition to EC include entry into torpor (EN), early torpor (ET), late torpor (LT), early arousal (EA), and interbout arousal (IA). Data were analyzed using ANOVA with a Tukey post-hoc test. Shared letters indicate data that are not significantly different from each other and different letters indicate statistical significant differences between sample points $(p<0.05)$ 
(a)

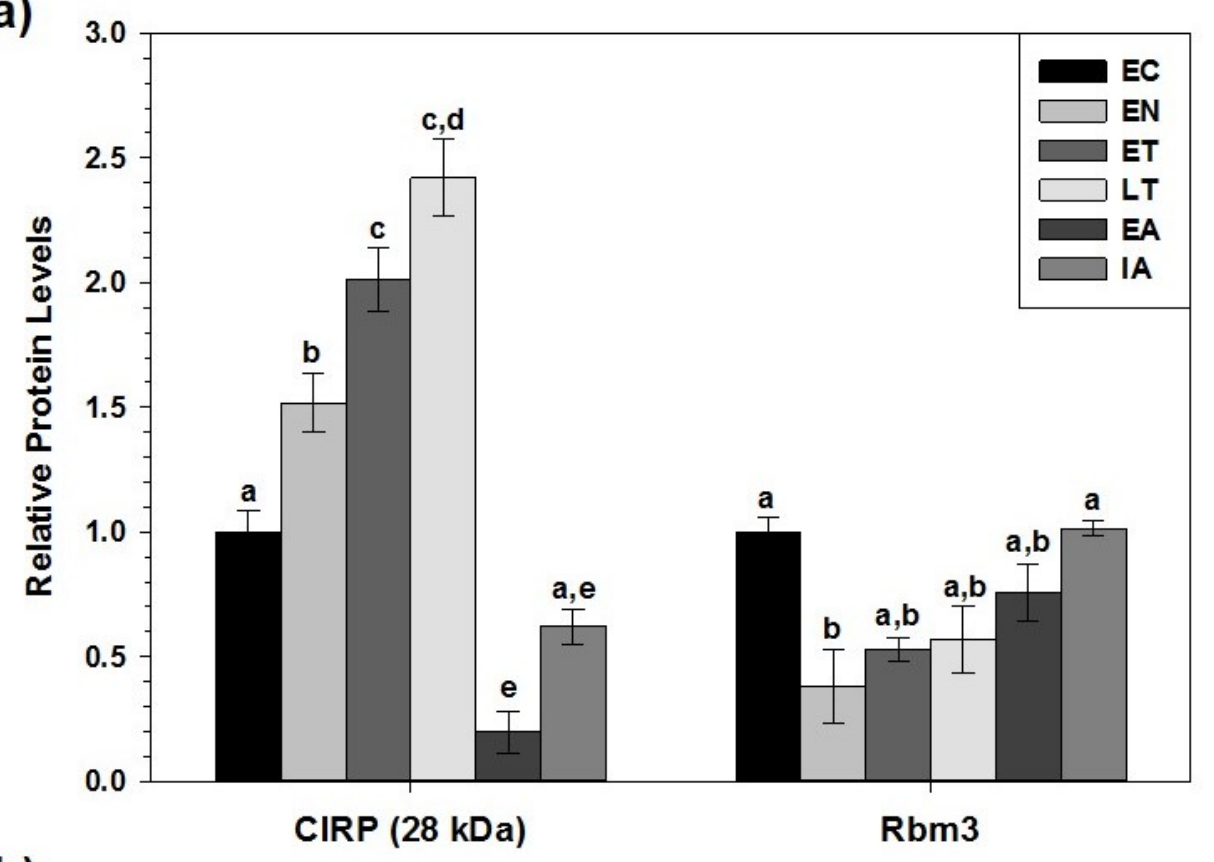

(b)

$\begin{array}{llllllll}1 & 2 & 3 & 4 & 1 & 2 & 3 & 4\end{array}$

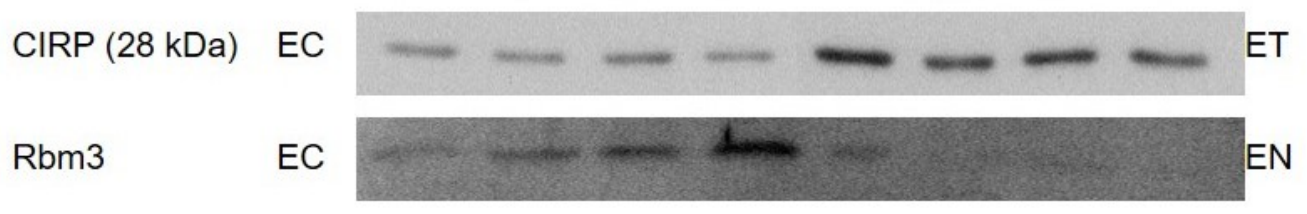

Figure 3.2: Relative cold-inducible RNA-binding protein levels in skeletal muscle of thirteenlined ground squirrels. (a) Histogram showing mean standardized expression levels of Cirp (28 $\mathrm{kDa}$ ) and Rbm3 ( \pm S.E.M., $n=4$ independent protein isolations from different animals. (b) Representative western blots. Other information as in Figure 3.1. 
(a)

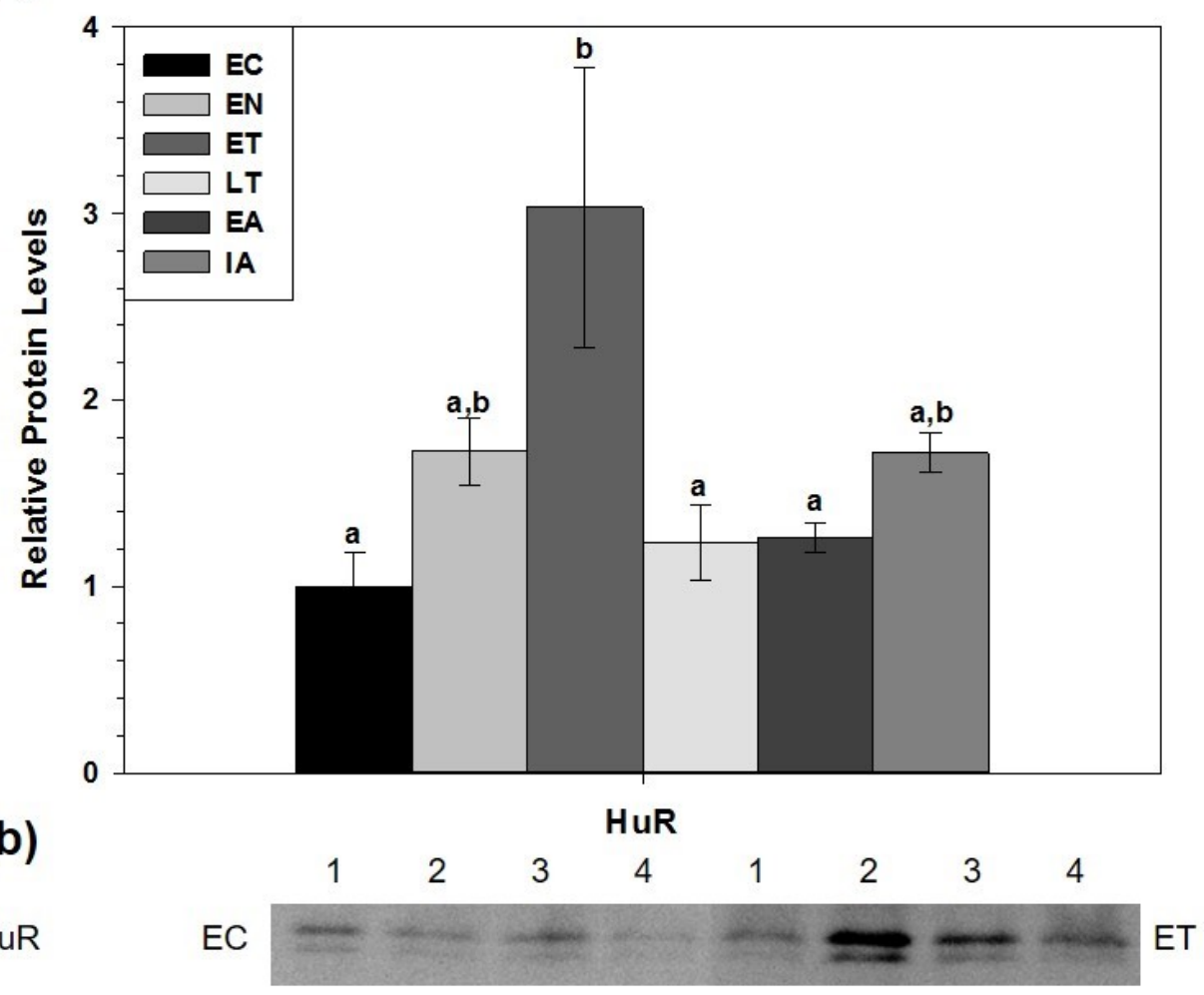

Figure 3.3: Relative cold-inducible RNA-binding protein levels in kidney of thirteen-lined ground squirrels. (a) Histogram showing mean standardized expression levels of HuR ( \pm S.E.M., $n=4$ independent protein isolations from different animals. (b) Representative western blots. Other information as in Figure 3.1. 
(a)

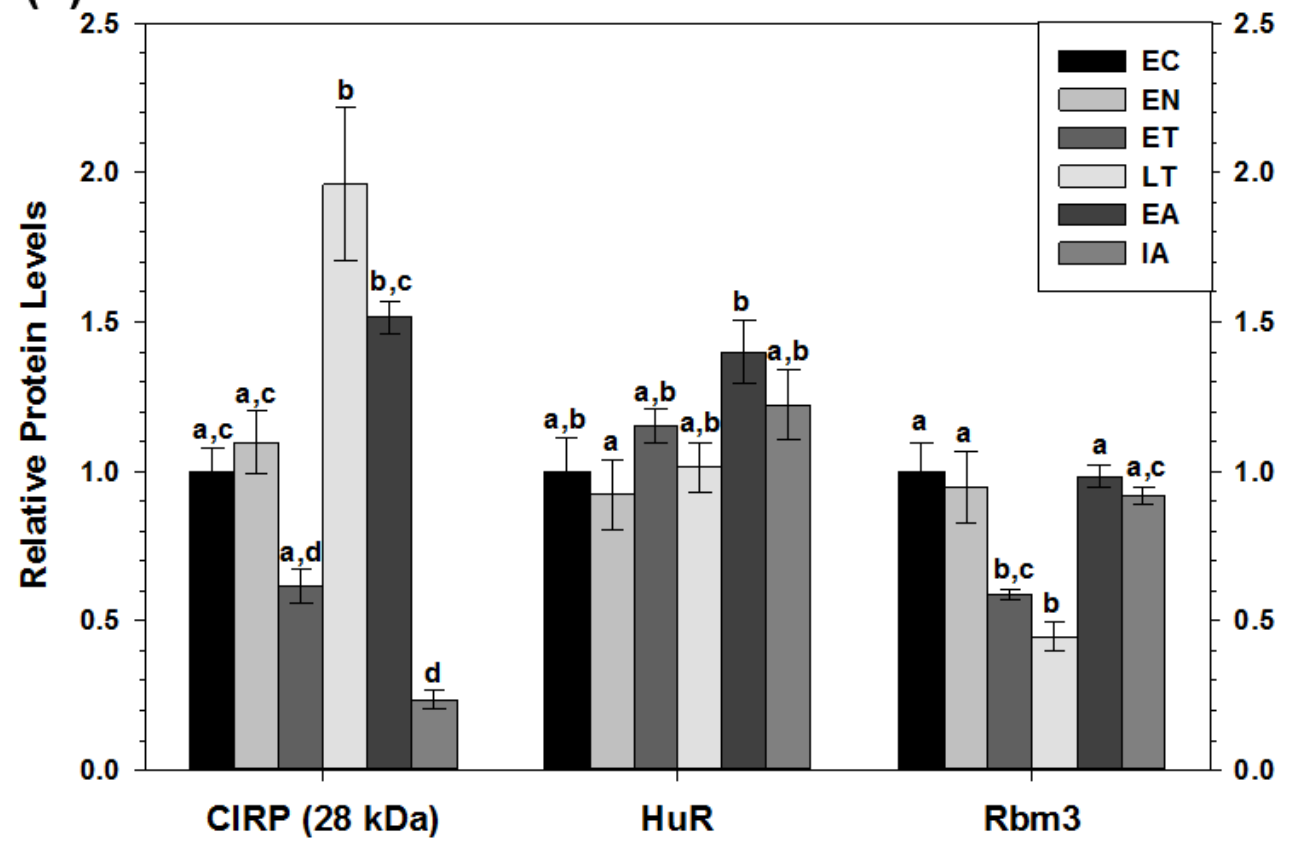

(b)

CIRP

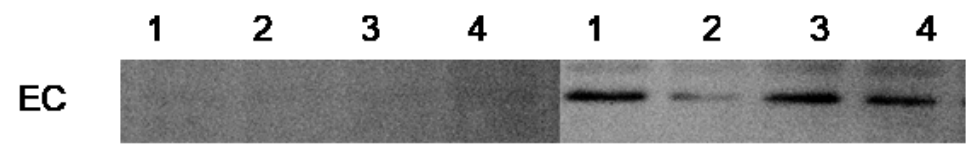

LT

HuR

EC

EN

Rbm3

EC

LT

Figure 3.4: Relative cold-inducible RNA-binding protein levels in brown adipose tissue of thirteen-lined ground squirrels. (a) Histogram showing mean standardized expression levels of Cirp (28 kDa), HuR, and Rbm3 ( \pm S.E.M., $n=4$ independent protein isolations from different animals. (b) Representative western blots. Other information as in Figure 3.1. 
(a)

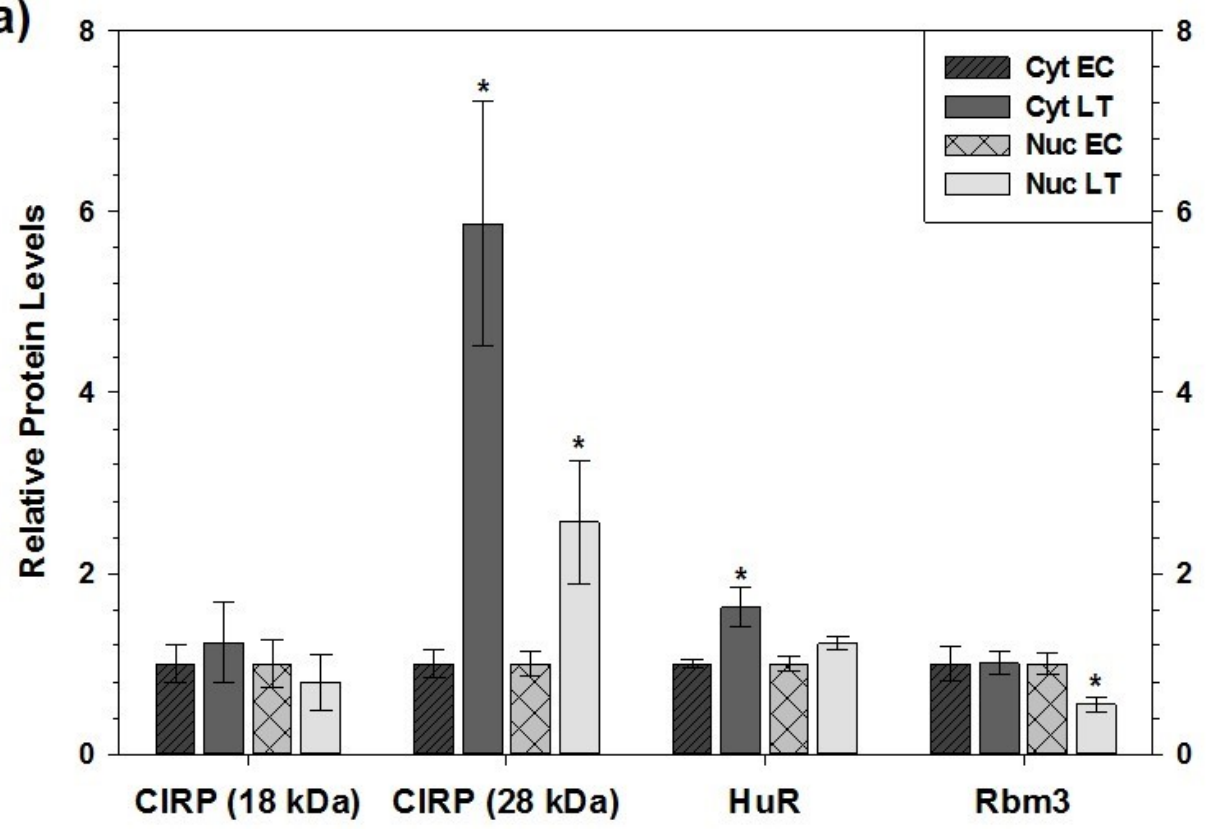

(b) Cyt-EC Cyt-LT Nuc-EC Nuc-LT

$\operatorname{CIRP}(18 \mathrm{kDa})$

CIRP (28 kDa)

HuR

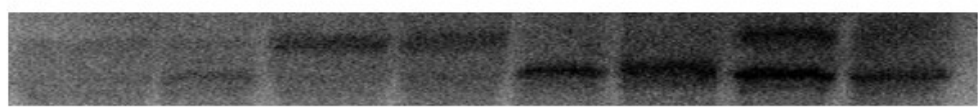

$\mathrm{Rbm} 3$

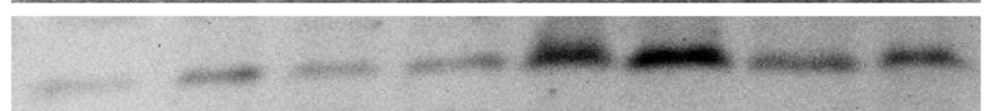

Figure 3.5: Relative cold-inducible RNA-binding protein levels in cytoplasmic (cyt) and nuclear (nuc) fractions of liver from euthermic in the cold room (EC) and torpid (LT) thirteen-lined ground squirrels. (a) Histogram shows mean standardized expression levels of Cirp (18 kDa and $28 \mathrm{kDa}$ ), HuR, and Rbm3 ( \pm S.E.M., $n=4$ independent protein isolations from different animals. (b) Representative western blots show two different samples $(n=2)$ of the total $n=4$ for each subcellular fraction and time point. Two bands representing HuR were quantified together as "total HuR" since the higher band likely represents a post-translational modification of HuR. Data were analyzed using a Student's t-test. An asterisk above the LT time point indicates a significant difference from the EC value for the same subcellular compartment $(p<0.05)$. 


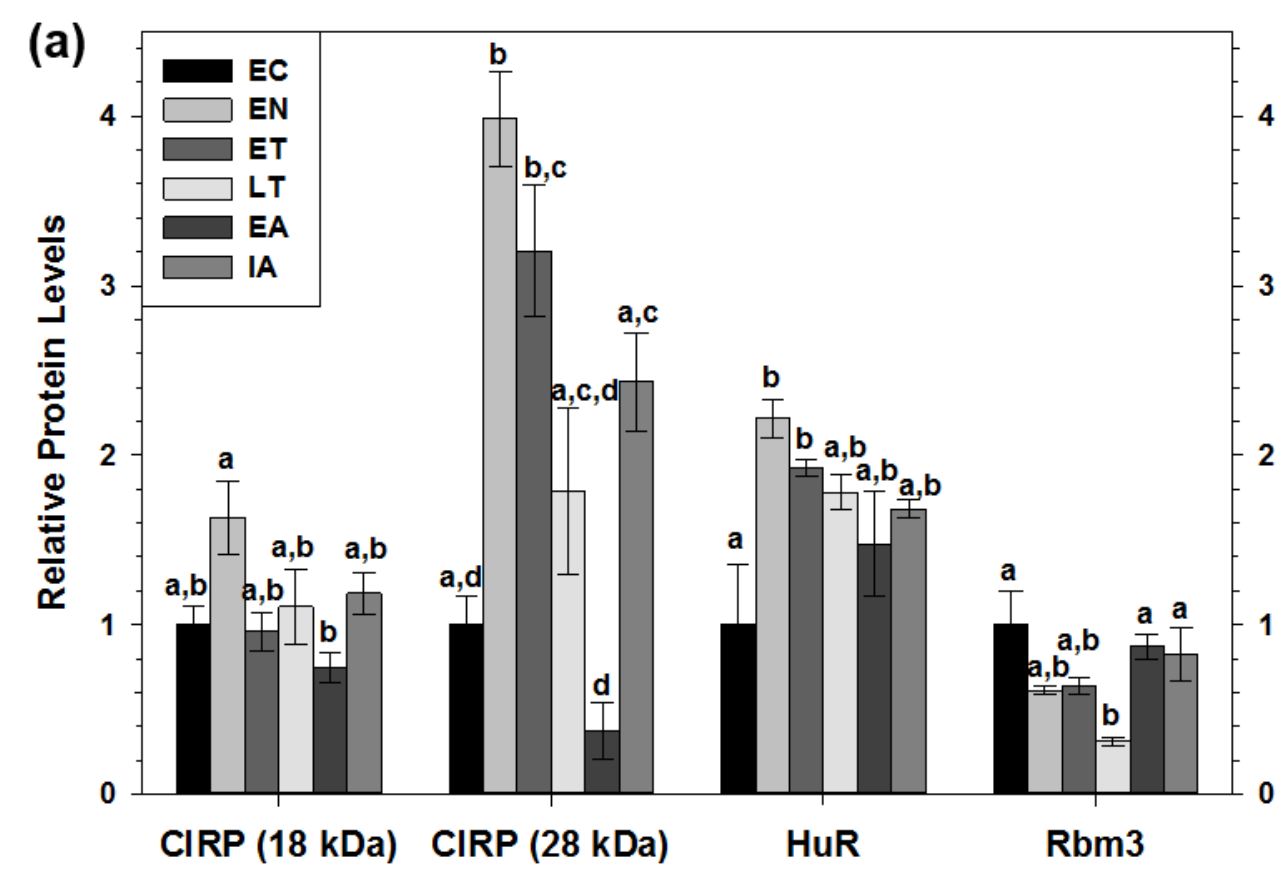

(b)

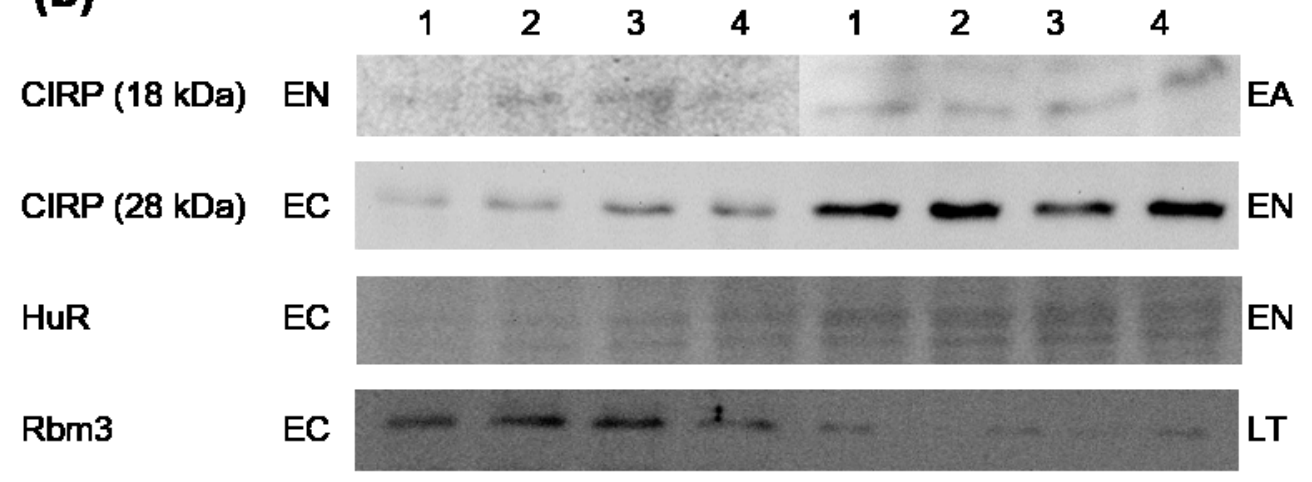

Figure 3.6: Relative cold-inducible RNA-binding protein levels in cytoplasmic and nuclear fractions in skeletal muscle of euthermic (EC) and torpid (LT) thirteen-lined ground squirrel. (a) Histogram showing mean standardized expression levels of Cirp (28 kDa), HuR, and Rbm3 ( \pm S.E.M., $n=4-5$ independent protein isolations from different animals). (b) Representative western blots show two different samples $(n=2)$ of the total $n=4-5$ for each subcellular fraction and time point. Other information as in Figure 3.5. 


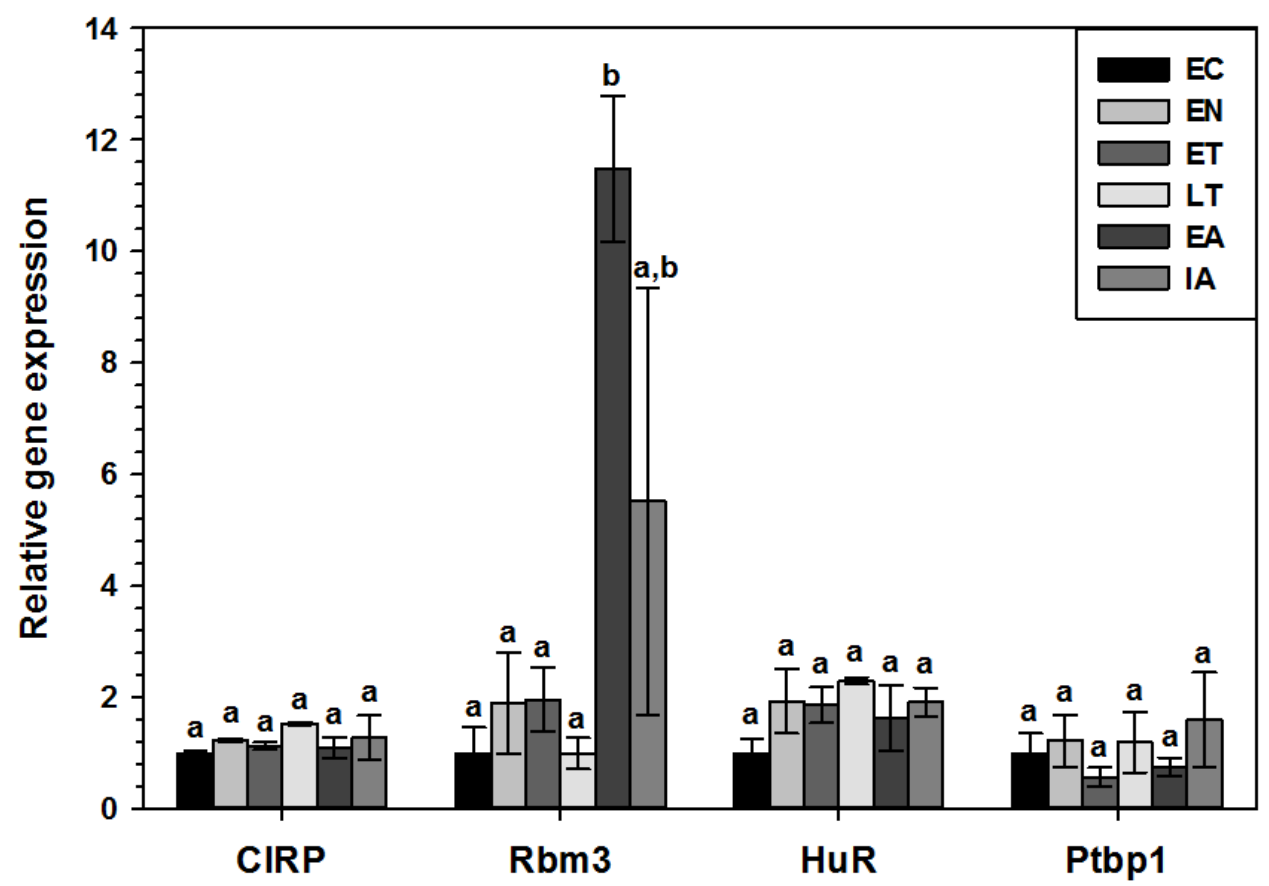

Figure 3.7: Expression of mRNAs in liver tissue samples was evaluated by RT-PCR for six time points over the torpor-arousal cycle. Relative expression of the indicated mRNAs was standardized to the expression of tubulin alpha $1 \mathrm{c} \mathrm{mRNA}$ amplified from the same sample.

Relative mRNA expression levels were then expressed relative to that of the EC value, which was set as 1.0. Data are mean $\pm S E M(n=3-4$ independent trials from different animals). Data were analyzed using ANOVA with a Tukey post-hoc test. Shared letters indicate data that are not significantly different from each other and different letters indicate statistical significant differences between sample points $(p<0.05)$. No letters above time points indicate that there were no significant differences between any two points of the time course ( $p>0.05)$. 


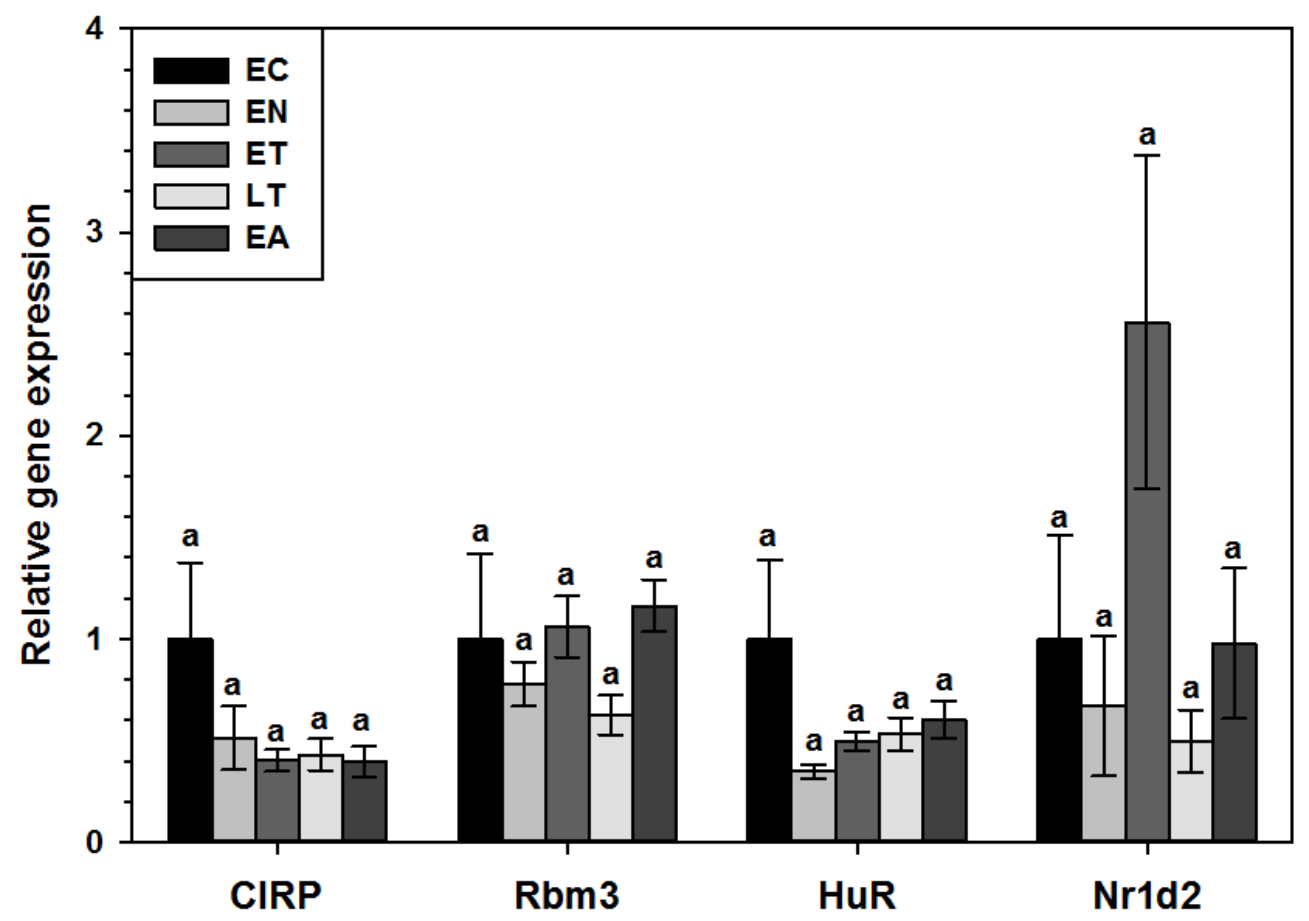

Figure 3.8: Expression of mRNAs in skeletal muscle was evaluated by RT-PCR for time points EC-EA of the torpor-arousal cycle. Relative expression of mRNAs was standardized to the expression of actin gamma $m R N A$ from the same sample. Data were then expressed relative to values for EC which were set to 1.0. Data are mean $\pm S E M(n=3-4$ independent trials from different animals). Data were analyzed using ANOVA with a Tukey post-hoc test. No significant differences between time points were found for any of the transcripts. 


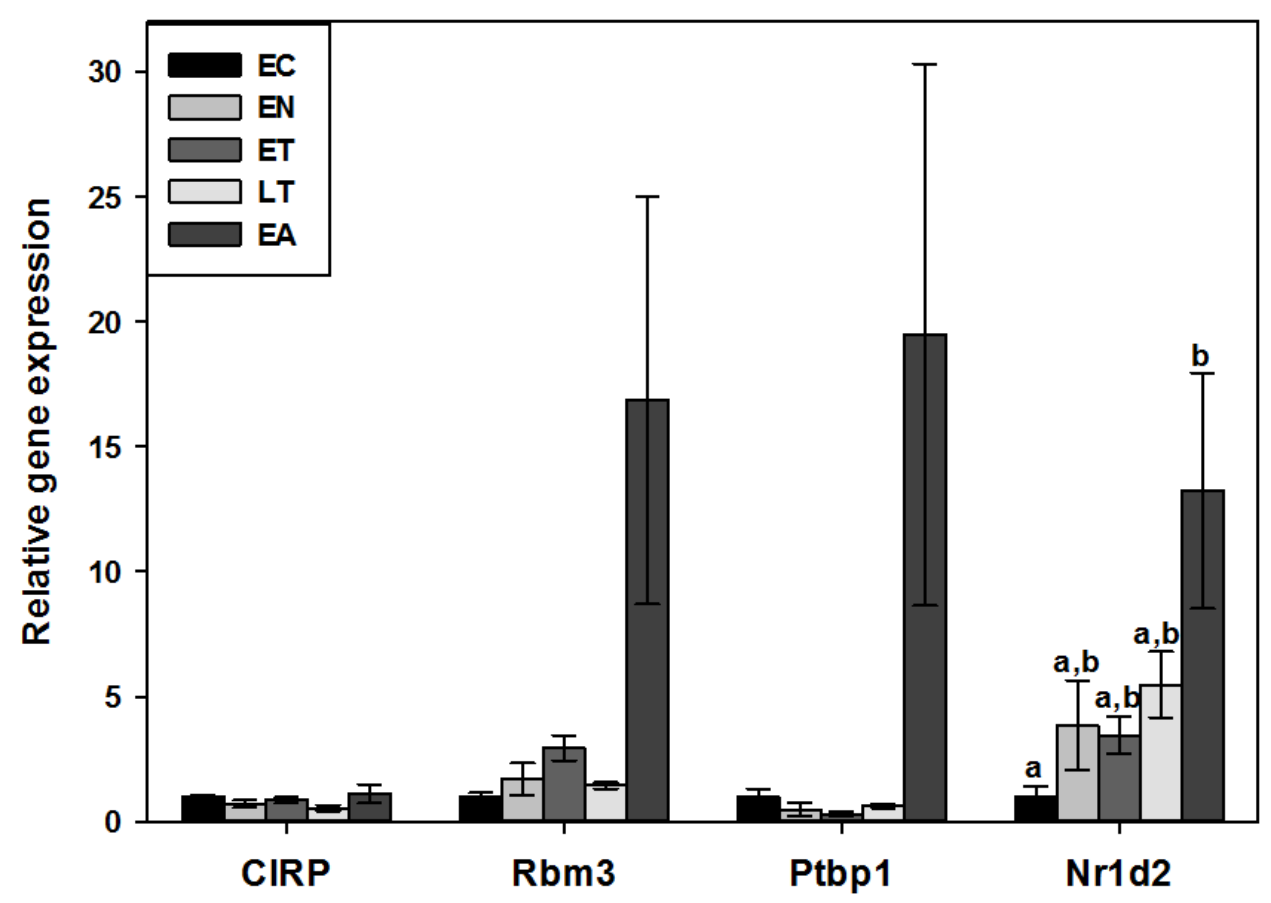

Figure 3.9: Expression of mRNAs in kidney samples was evaluated by RT-PCR for time points $E C$-EA of the torpor-arousal cycle. Relative expression of indicated mRNAs was standardized to the expression of alpha tubulin $m R N A$ from the same sample. Data were then expressed relative to values for EC which were set to 1.0. Data are mean $\pm S E M(n=3-4$ independent trials from different animals). Data were analyzed using ANOVA with a Tukey post-hoc test. Shared letters indicate data that are not significantly different from each other and different letters indicate statistical significant differences between sample points $(p<0.05)$. No letters above time points indicate that there were no significant differences between any two points of the time course $(p>0.05)$. 


\section{Chapter 4 - Tissue-specific regulation of translation in an obligate hibernator, the thirteen- lined ground squirrel}




\subsection{INTRODUCTION}

Winter is accompanied by intense environmental stresses, including frigid temperatures and lack of food, which can prompt certain capable animals to hibernate to survive. Mammals such as ground squirrels, bears, and bats, use hibernation to conserve energy by depressing their metabolic rate and, as a result, greatly reduce their body temperature until the spring when environmental conditions are again favourable for active life. When hibernating, their heart beat reduces to 5-10 beats/minute from 200-300 beats/minute, their body temperature decreases to $0-5^{\circ} \mathrm{C}$, and their breathing rate drops to just $2.5 \%$ of the normal rate. By this mechanism, ground squirrels can save almost $90 \%$ of the energy that they would need otherwise to maintain their body temperature at $37{ }^{\circ} \mathrm{C}$ over the winter. Hibernating thirteen-lined ground squirrels are great model organisms for examining the molecular responses that cells need to make in order to survive starvation, hypoxia, muscle atrophy, and ischemia-reperfusion injury.

Many animals that use hypometabolic states to survive unfavourable environmental conditions must strongly suppress protein synthesis and other energy-expensive processes to conserve cellular ATP (Larade and Storey, 2007; Morin and Storey, 2006; Ramnanan et al., 2009; Seibel et al., 2014; Zhang et al., 2015). Translation, which requires 4 ATP molecules per peptide bond formed, is reduced to near-zero levels in hibernating ground squirrels compared to basal protein synthesis rates in euthermic animals (Ramnanan et al., 2009; van Breukelen and Martin, 2001). For example, protein synthesis in thirteen-lined ground squirrel brain decreased during hibernation to just $0.04 \%$ of the value in active squirrels (Frerichs et al., 1998). Studies on ground squirrels have also shown increases in reversible phosphorylation of proteins that mediate translation initiation and elongation, as 
well as increased ribosome dissociation from mRNA (Frerichs et al., 1998; Hittel and Storey, 2002). Although suppression of protein synthesis has been observed in several tissue types of multiple hibernating organisms, most of these studies have been confounded by the use of a seasonal control (summer animals) and usually focus on a single tissue per study so it is harder to conclude if the same mechanisms to suppress translation are used in every tissue. In the studies described in this chapter, the responses of the translation machinery are assessed at multiple points of the torpor-arousal cycle using euthermic animals acclimated in a cold room as the control (EC) and comparing multiple tissue types (liver, muscle and kidney). The importance of using EC as a control as opposed to a summer active (SA) "control” animal is huge. Among other things, SA animals are living at very different ambient and body temperatures, are in a very different life/reproductive stage, are actively eating and have not gone through the hyperphagia phase to build up body fat. Thus, using an autumn/winter euthermic control held at $5^{\circ} \mathrm{C}$ that is fully capable of hibernating, as opposed to a summer control, strengthens our ability to identify and focus on those the molecular adaptations that occur specifically to enable metabolic rate depression when animals enter a torpor bout, instead of confounding studies with differences in the physiology and circannual rhythms in gene expression inherent in a comparison of summer active animals with winter hibernating ones.

Suppression of protein synthesis is essential for hibernating animals to conserve energy but complete inhibition of translation could potentially kill an organism within a few hours (Frerichs et al., 1998). Two theories that could explain how hibernating animals can survive despite very low rates of protein synthesis during torpor are as follows: (a) transcripts and protein products that are lost or damaged during cell stress while in torpor 
are regenerated during interbout arousals (IA), or (b) select gene products continue to be synthesized during torpor to ensure every organ has the required proteins to maintain organ viability (Hittel and Storey, 2002). There is evidence for both theories. For example, a study done on hibernating arctic ground squirrels (Spermophilus parryii) found a disaggregation of polysomes during early and late torpor but a re-aggregation of polysomes during the arousal phase, similar to the polysome profile of SA ground squirrels (Knight et al., 2000). This suggests that hibernating ground squirrels may increase protein synthesis during arousal periods, potentially to restore the levels of proteins essential to hibernator survival. However, multiple studies have also shown that hibernating animals differentially express selected proteins during torpor bouts (Luu et al., 2015; Rouble et al., 2013; Shao et al., 2010; Yan et al., 2006; Yan et al., 2007).

Regulation of mRNA translation depends on several factors including mRNA sequence (upstream open reading frames, the presence of an internal ribosome-entry site [IRES], etc.), and structure (presence of a 5'-7-methylguanosine cap or 3' poly(A) tail, hairpins, pseudoknots, etc.), as well as mRNA subcellular localization and translation machinery activation (Gebauer and Hentze, 2004). Before translation can begin, mRNAs must be shuttled to the cytoplasm from the nucleus or out of stress granules that contain repressed mRNAs (Sonenberg and Hinnebusch, 2009; Tessier et al., 2014). The 40S ribosome is recruited the 5' end of the mRNA with the help of eukaryotic initiation factors eIF1, eIF1A, eIF5, and eIF2 coupled to GTP and the initiator methionine tRNA (MettRNA) (Gebauer and Hentze, 2004; Sonenberg and Hinnebusch, 2009). This complex is termed the $43 \mathrm{~S}$ complex. The eIF4F complex is comprised of proteins eIF4E, eIF4B, eIF4G, and eIF4A. The roles of these proteins are as follows: eIF4E associates with the 5'- 
7-methylguanosine ( $\left.5^{\prime}-\mathrm{m}^{7} \mathrm{GpppN}\right)$ cap of the mRNA, eIF4A has DEAD-box RNA helicase activity that is enhanced by eIF4B binding, and eIF4G serves as a scaffold protein that maintains interactions between eIF proteins. By interacting with poly(A) binding protein (PABP), eIF4G also circularizes the mRNA to be translated, which is thought to bring the 3' regulatory domains into close proximity to translation initiation proteins at the 5 ' end and/or allow for the re-initiation of translation following translation termination (Gebauer and Hentze, 2004; Sonenberg and Hinnebusch, 2009). The eIF4F complex associates with the 5' end of the mRNA in cap-dependent initiation and forms a bridging complex with the 43S complex (Gebauer and Hentze, 2004). Under cell stress or starvation conditions, translation initiation can be greatly reduced by limiting the expression of the eIF proteins and changing their phosphorylation states (Sonenberg and Hinnebusch, 2009). Additionally, protein synthesis can be inhibited by microRNAs or RNA-binding proteins that recognize and bind specific RNA sequences in the 3' end of mRNAs to recruit eIF inhibitors (Sonenberg and Hinnebusch, 2009). As an aside, IRES-mediated translation does not depend on the binding of the eIF4F complex but rather on the RNA secondary structures that guide the ribosomal complexes to internal 5'-UTR regions near or at the initiation start site (Gebauer and Hentze, 2004). This type of translation is used by viral mRNAs when the host cell is compromised and eIF translation factors are inhibited (Sonenberg and Hinnebusch, 2009) and also for the translation of various stress responsive proteins - those that provide cytoprotective actions when cells are highly stressed and normal metabolism is disrupted (Chan et al., 2013; Spriggs et al., 2010).

Binding of the $43 \mathrm{~S}$ complex to the initiation codon creates a stable structure called the $48 \mathrm{~S}$ complex. Hydrolysis of GTP associated with eIF2 is necessary for the $60 \mathrm{~S}$ 
ribosomal subunit to complete the initiation complex (Gebauer and Hentze, 2004). Global protein synthesis is largely regulated by the phosphorylation of eIF $2 \alpha$ and $4 \mathrm{EBP} 1$. Phosphorylation of eIF2 $\alpha$ at Ser51 sequesters eIF2 $\alpha$ and eIF2B which inhibits eIF2 $\alpha$ from participating in the GTP-exchange reaction. This results in a diminished supply of MettRNA for translation initiation (Gebauer and Hentze, 2004; Hittel and Storey, 2002).

Another crucial factor that regulates translation efficiency is the reversible phosphorylation of eIF4E at serine 209 that increases eIF4E binding affinity to the 5'$\mathrm{m}^{7} \mathrm{GpppN}$ cap of the mRNA, thereby increasing cap-dependent translation (Flynn and Proud, 1995). Hypophosphorylated 4EBP competes with eIF4A for eIF4E bind sites, preventing eIF4E from interacting with the 5' cap. However, phosphorylation of 4EBP incapacitates this binding ability, thereby allowing and translation to go forward (Proud et al., 2001; van Breukelen et al., 2004). Importantly, research has shown that threonine 37 and threonine 46 of 4EBP must be phosphorylated as a priming event before threonine 70 and then serine 65 can be phosphorylated (Gingras et al., 2001). Thus, p-4EBP (S65) was chosen as a target of interest to get a better understanding of what is actually occurring in the cells of hibernators.

Finally, eukaryotic elongation factor 2 (eEF2) is important to promote the GTPdependent translocation of the protein chain from the A-site to the P-site of the ribosome and this key step of translation is inhibited by phosphorylation of eEF2 at threonine 56 (Proud et al., 2001).

In the current study, the relative total protein levels of eIF4E, eIF2 $\alpha$, eEF2 as well as the relative changes in phosphorylation of eIF4E, eIF2 $\alpha$, eEF2 and 4EBP were assessed 
at the 6 time points of the torpor-arousal cycle (EC, EN, ET, LT, EA, and IA) in liver, muscle and kidney of thirteen-lined ground squirrels. Based on previous findings in hibernating mammals, it was proposed that translation would be largely inhibited during torpor, and this would be evident by lower protein levels of these translation factors compared to EC. In addition, it was postulated that there would be altered phosphorylation states of translation factors during hibernation consistent with inhibition of translation: i.e. increased eIF2 $\alpha$ (S51) and eEF2 (T56) phosphorylation levels and reduced eIF4E (S209) and 4EBP (S65) phosphorylation. This study provides evidence for hibernating ground squirrels using tissue-specific mechanisms of controlling protein synthesis. However, common trends between tissues included the inhibition of 4EBP via phosphorylation, increased eIF4E total protein levels and/or phosphorylation status, and increased p-eIF2 $\alpha$ phosphorylation in all tissues.

\subsection{Materials AND Methods}

\subsubsection{Animal Experiments and Total Protein Extraction}

These methods were conducted as described in Chapter 2.

\subsubsection{Western Blotting}

Western blotting was performed as described in Chapter 2. Total protein levels of the translation factors (eIF4E, eIF2 $\alpha$, eEF2) and their respective phosphorylated counterparts (p-eIF4E Ser209, p-eIF2 $\alpha$ Ser51, p-eEF2 Thr56 and p-4EBP S65) were measured in total protein extracts of liver, muscle, and kidney. Antibodies against eIF4E, eIF2 $\alpha$, eEF2, peIF4E Ser209, p-eIF2 $\alpha$ Ser51, p-eEF2 Thr56 and p-4EBP S65 were used (please refer to Appendix A: Antibodies Used for Western Blotting for full details for each antibody). For 
a detailed list of the experimental conditions used for each protein target in each studied tissue, please refer to Appendix B: Western Blotting Conditions.

\subsubsection{Quantification and Statistics}

Quantification and statistics were carried out as described in Chapter 2.

\subsection{Results}

\subsubsection{Analysis of translation factor levels over the course of the torpor-arousal cycle in liver}

Immunoblotting was used to determine the relative protein and/or phosphorylation levels of eIF2 $\alpha$, eIF4E, 4EBP1, and eEF2 in liver, comparing euthermic thirteen-lined ground squirrels in the cold room (EC) with five other time points in the torpor-arousal cycle including EN, ET, LT, EA, and IA. Compared to EC levels, eIF4E protein levels remained relatively constant, except for a small decrease during interbout arousal (IA) to just under $70 \%$ of the EC value (Figure 4.1). Phosphorylation levels of eIF4E (S209) increased 4.1-fold and 3.7-fold compared to EC during entry into torpor (EN) and early arousal (EA), respectively, before further increasing during IA to nearly 6.8 -fold the euthermic level. Relative phosphorylation levels of p-4EBP1 (S65) gradually increased over the torpor-arousal cycle (trend only), until EA levels were significantly increased compared to EC (by approximately 2.2-fold). Phosphorylation levels of 4EBP1 (S65) increased even more during IA with significant increases over levels in EC, EN, and early torpor (ET) values (e.g. 2.7-fold higher than the EC level).

Analysis of eIF2 $\alpha$ in liver by immunoblotting showed 2.9-fold and 3.3-fold increases in protein levels over EC during ET and late torpor (LT), respectively (Figure 
4.2). Subsequently, eIF2 $\alpha$ decreased back to euthermic levels during IA. Phospho-eIF2 $\alpha$ (S51) levels also increased during LT as compared to EC (by just over 3-fold) before decreasing again to EC levels during EA and IA.

Similarly, eEF2 protein levels in liver increased during EN, ET and LT compared to EC (by 2.7, 4.5 and 3.4-fold, respectively) and remained elevated during EA ( 2.8-fold over the EC value). The increase in eEF2 during ET was also significant with respect to EN. Total eEF2 protein levels decreased 4.5-fold with respect to EA during IA, returning to euthermic levels. Phosphorylated eEF2 (T56) levels were reduced during EN and remained consistently low throughout EN-IA at levels that were $16-26 \%$ of the EC value.

\subsubsection{Analysis of translation factor levels over the course of the torpor-arousal cycle in muscle}

Western blotting was used to determine the relative protein and/or phosphorylation levels of eIF4E, 4EBP1, eIF2 $\alpha$ and eEF2 in skeletal muscle of ground squirrels over the torpor-arousal cycle. As compared with EC controls, relative eIF4E protein levels showed an upward trend during EN, rose significantly during ET (4.7-fold over EC), and then peaked during LT at 9.4-fold higher than the EC value (Figure 4.3). EIF4E total protein levels decreased relative to LT levels during EA (to 3.3-fold the EC level). Subsequently, eIF4E levels increased again during IA as compared to EC, EN and EA (e.g. 7.0-fold higher than EC). In contrast, phospho-eIF4E (S209) levels remained low throughout the torporarousal cycle except during IA when it increased to nearly twice the EC value. Three phospho-4EBP (S65) bands including two dark and one faint band appeared between the 14 and $22 \mathrm{kDa}$ protein markers and these were grouped for quantification. Phosphorylated 4EBP1 (S65) levels were generally low across the torpor-arousal cycle except for peaks 
during LT and IA where levels rose by 2.2-fold and 2.5-fold as compared to EC, respectively.

Total eIF $2 \alpha$ protein levels followed a similar pattern to eIF4E protein across the torpor-arousal cycle, where levels rose modestly (but not significantly) during EN to 1.6fold the EC value, and then significantly increased during ET and LT by 2-fold and 2.8fold the EC value, respectively (Figure 4.4). Subsequently, relative eIF2 $\alpha$ protein levels decreased to $60 \%$ of EC during EA, which was significant with respect to EN-LT, and subsequently to just $5 \%$ of during IA, compared with the EC value. Relative p-eIF2 $\alpha$ (S51) phosphorylation levels also increased during EN and LT to 1.8-fold and 2.2-fold the EC value, respectively. Subsequently, phosphorylation levels were significantly reduced during EA and fell even farther during IA to values that were just $60 \%$ of the EC level.

Finally, relative levels of total eEF2 and its phospho-form (threonine 56) were measured in muscle over the torpor-arousal cycle. Total eEF2 levels remained constant except for a 1.7-fold increase during IA as compared to EC. Similarly, phospho-eEF2 (T56) levels did not change except during LT where values increased over 4-fold, compared with EC.

\subsubsection{Analysis of translation factor levels over the course of the torpor-arousal cycle in kidney}

As with liver and muscle, immunoblotting was used to determine the relative levels of select translation factors in kidney over the torpor-arousal cycle. Although phosphoeIF4E (S209) levels did not change, eIF4E levels increased during EN and LT relative to the control (by 2.1-fold and 1.9-fold the EC level, respectively) and remained at a 
heightened level (but not significantly different from EC) level through the arousal period (Figure 4.5). Phosphorylated 4EBP1 (S65) levels increased only during ET to 1.6-fold over the EC value and this change was also significant with respect to EN.

Protein levels of eIF2 $\alpha$ in kidney did not change much relative to EC except for a decrease during IA to $40 \%$ of EC (Figure 4.6). The decrease during IA was significant compared to all time points except for EN. Phosphorylation of eIF2 $\alpha$ at serine 51 increased during ET, LT, and EA to levels that were 4.6-, 3.6-, and 3.1-fold over EC, respectively. These increases in p-eIF2 $\alpha$ (S51) were also significant with respect to EN. Subsequently, p-eIF2 $\alpha$ levels decreased during IA to an intermediate level that was $<50 \%$ of the LT value yet still 2-fold higher than EC.

Protein levels of eEF2 did not change significantly over the torpor-arousal cycle in kidney, but phosphorylated eEF2 (T56) levels did, peaking during ET and remaining high during LT (at 3.5-fold and 2.5-fold over EC, respectively). Phospho-eEF2 levels decreased again during EA (compared to ET) but were significantly higher than EC during IA (by 2.3-fold).

\subsection{Discussion}

Hibernators survive the extreme environmental conditions that they are faced with (no nutrient intake for at least 6 months, steep decline of ambient temperature, heavy snowfall, etc.) by entering torpor. As a result of their own rapid transition into and out of hypometabolism, cells are faced with threats such as ischemia-reperfusion injury, hypoxia, rapid changes in temperature, etc., and adaptations must be made at the molecular level if the hibernator is to survive. Protein composition largely determines the structure and 
function of cells. If protein synthesis were to be completely blocked like it is following exposure to the diphtheria toxin, the affected organism would die. Therefore, homeostasis must be maintained by ensuring that important proteins are available to protect the cell against DNA damage, apoptosis, and cellular starvation, among other stresses, while allowing some other processes (such as growth) to be largely suspended over the winter months. Two theories have emerged to attempt to explain the mechanism of translational suppression and re-activation that hibernators use to ensure cellular homeostasis throughout hibernation. The first suggests that genes are differentially expressed as they are needed, including during hibernation, to supply cells with the necessary protein products and the second theory suggests that interbout arousals are essential periods of euthermia used to replenish proteins that have been damaged or lost in cells during torpor (Frerichs et al., 1998; Hittel and Storey, 2002). The relative changes in total protein and relative phosphorylation of proteins of the translational machinery (eIF4E, eIF2 $\alpha$, and eEF2) that were analyzed in thirteen-lined ground squirrel liver, muscle, and kidney are diagramed in Figure 4.7. This was done to better understand how translation machinery is regulated to inhibit or facilitate translation over the torpor-arousal cycle, with the goal of gaining insight into when translation may be important to ensure survival, and to determine if this regulation of protein synthesis is conserved between tissues of the same animal.

\subsubsection{Changes in total protein and phosphorylation status of translation factors in liver of the thirteen-lined ground squirrel over the torpor-arousal cycle}

Liver eIF4E levels remained constant throughout the torpor-arousal cycle, indicating that hibernator livers do not regulate eIF4E protein levels during torpor (ET, LT), possibly because de novo synthesis of proteins is very energetically expensive or more 
likely because there are other effective mechanisms for regulating eIF4E activity. Instead, liver eIF4E appears to be dynamically regulated by changes in phosphorylation state as evidenced by the strong 4-7-fold increases in p-eIF4E (S209) content during EN, EA and IA that suggest a role of post-translational modifications (PTMs) in regulating eIF4E activity. This is intuitive because PTMs require much less cellular energy (ATP) to implement than manufacturing proteins de novo. It is well understood that phosphorylation at S209 of eIF4E increases eIF4E binding ability such that it binds 3-4 times more strongly to the $5^{\prime}-\mathrm{m}^{7} \mathrm{GpppN}$ cap (Joshi et al., 1995). Therefore, these results suggest that thirteenlined ground squirrel liver may use both periods of entry into torpor and arousals to increase translation, which may be important to upregulate novel proteins or replenish the levels of key damaged proteins. Similar results were seen in a comparison of torpid (LT) and interbout aroused (IA) golden-mantled ground squirrels where total eIF4E levels did not change relative to a summer active (SA) control but p-eIF4E (S209) levels rose during LT and IA compared to SA (van Breukelen et al., 2004). In the present study, the relative phosphorylation level of p-4EBP1 (S65) was also assessed in liver over the torpor bout. Hypophosphorylated 4EBP1 inhibits eIF4E association with eIF4G, and this interaction is inhibited when 4EBP1 is hyperphosphorylated. Phosphorylation of 4EBP at serine 65, the last site of four on 4EBP1 to be phosphorylated in a sequence of phosphorylation events that includes T37, T46, and T70, was assessed since hyperphosphorylation is necessary for 4EBP1 inactivation (Gingras et al., 2001). The levels of p-4EBP1 (S65) increased during EA and IA in liver, which suggests that there are fewer 4EBP1-eIF4E interactions during the arousal period. This result is consistent with an increase in p-eIF4E (S209) during EA and IA, which provides further evidence for increased eIF4E activity and an increase in 
cap-dependent translation during the arousal phase. To address my hypothesis that capdependent translation will be inhibited during early and late torpor, unchanging eIF4E, peIF4E (S209) and p-4EBP (S65) levels during this time (compared to EC) do not show an activation of cap-dependent translation during this time. Further studies will need to be done to confirm if cap-dependent translation is indeed inhibited during ET and LT in liver.

The cap-dependent translation machinery may be more active during arousal in liver compared to during torpor, but the translation factors that regulate cap-dependent translation are not the only translation factors that control protein synthesis. The relative total protein levels of eIF2 $\alpha$ increased during ET and LT before they decreased to EC levels during EA and IA. EIF2 $\alpha$ is important because it brings the methionine-tRNA to the translation start site in the ribosome, which is essential for translation initiation and subsequent elongation steps. An increase in eIF2 $\alpha$ levels would suggest an increase in translation initiation during torpor, possibly to replenish important degraded protein products or to increase the relative levels of proteins that are involved in maintaining tissue homeostasis (e.g. DNA damage and repair pathways, anti-apoptosis pathways, etc.). However, liver p-eIF2 $\alpha$ (S51) phosphorylation levels also increased during LT, to 3.1-fold higher than the EC value. Phosphorylation of eIF2 $\alpha$ at serine 51 sequesters eIF2 $\alpha$-GDP away from the translation machinery where it associates with the recycling protein eIF2B and is unable to switch GTP in for GDP; hence, this results in a diminished supply of MettRNA for translation initiation (Frerichs et al., 1998; Gebauer and Hentze, 2004; Sonenberg and Hinnebusch, 2009). Generally, increased p-eIF2 $\alpha$ (S51) levels suggest a global downregulation of protein synthesis, but interestingly, some studies show evidence of increased translation of certain mRNAs following the installment of this post-translational 
modification (PTM) to eIF2 $\alpha$. For example, translation of activating transcription factor 4 (ATF4, an inhibitor of the transcription factor CREB) increased in mouse brain following eIF2 $\alpha$ phosphorylation at S51, leading to increased brain plasticity and memory (Sonenberg and Hinnebusch, 2009). Additionally, increased translation of yeast GCN4 (a transcription factor responsible for amino acid biosynthesis genes) mRNA was observed following eIF $2 \alpha$ S51 phosphorylation (Gebauer and Hentze, 2004). The mechanism at play here could be a decreased incidence of scanning ribosomes recognizing a second upstream open reading frame (uORFs) in transcript sequences that have multiple overlapping uORFs (e.g. ATF4 and GCN4 mRNA), because there is a lower abundance of active translation complex proteins during times of cell stress. Thus, the correct, fully functional protein in this scenario is more likely to be translated during times of stress rather than incorrect translation products (Chan et al., 2013; Spriggs et al., 2010). It is possible that this phenomenon occurs in response to hibernation as well. EIF2 $\alpha$ may be more abundant for immediate translation of select transcripts where kinases regulate quick on/off mechanisms for translation complexes so that stress-responsive transcripts are translated during this time. It is possible that the dephosphorylation of eIF2 $\alpha$ is not detected because only few translation initiation complexes are activated during times of metabolic suppression so that overall, the majority of translation complexes are phosphorylated (inhibited). Increased peIF2 $\alpha$ (S51) could be a mechanism of inhibiting global protein synthesis to save cellular energy during torpor, but it is still possible that despite the increase in S51 phosphorylation, hibernating ground squirrel liver cells may use alternate mechanisms to translate select mRNAs, either via the de-phosphorylation of a small proportion of eIF $2 \alpha$ or circumventing this initiation step altogether. This will need to be assessed in future experiments. 
Finally, relative eEF2 levels were assessed in liver of ground squirrels at each time point of the torpor-arousal cycle. Relative eEF2 protein levels increased and remained elevated during EN through to EA but decreased during IA to euthermic levels, implicating eEF2 as a possible regulator of protein synthesis during torpor. EEF2 is responsible for ribosome translocation along the mRNA being translated, moving the nascent protein from the A-site to the P-site of the ribosome with each successful addition of an amino acid. Thus, translation elongation appeared to be upregulated during the hibernator's descent into torpor, during torpor, and during EA. Phosphorylation of eEF2 at T56 inhibits eEF2 activity and was shown to decrease during EN and remained significantly low compared to EC throughout the rest of the torpor bout, suggesting that elongation was not inhibited by phosphorylation during torpor. Not only is this consistent with total eEF2 protein levels, this is also consistent with elevated p-eIF4E (S209) and eIF2 $\alpha$ levels during the EN to EA time points of the torpor-arousal cycle. Together these results suggest that protein synthesis is not inhibited by cap-mediated translation machinery or at the elongation step in liver of ground squirrels in a hypometabolic state. By contrast, elevated p-eIF4E (S209) and elevated p-4EBP (S65) levels during IA suggest these post-translational modifications are paramount to regulating any protein synthesis that occurs during interbout arousals. These results help support the notion that certain genes are differentially expressed during torpor and that hibernators do not solely rely on protein synthesis during interbout arousals to replenish protein products. 


\subsubsection{Changes in total protein and phosphorylation status of translation factors in muscle of the thirteen-lined ground squirrel over the torpor-arousal cycle}

Similarly, relative total protein and phosphorylation levels of eIF4E, 4EBP1, eIF2 $\alpha$, and eEF2 were evaluated in muscle of thirteen-lined ground squirrels to assess changes in tissue-specific protein synthesis throughout the torpor-arousal cycle. Firstly, immunoblotting showed that relative eIF4E levels increased significantly during ET, LT and IA to 4.7-fold, 9.5-fold, and 7.1-fold higher than the EC value, respectively. Increased eIF4E protein levels could indicate more cap-dependent translation initiation in muscle during both torpor and arousal stages. Elevated cap-dependent translation initiation could be useful during ET and LT when metabolism is repressed since muscle cells may require the transcription and translation of certain protein products to contend with low cellular ATP, oxygen, and nutrient levels, as well as stress due to very low body temperatures. Evidence of the need for increased protein synthesis in muscle during ET or LT includes the upregulation of serum- and glucocorticoid-regulated kinase 1 (SGK1) in thirteen-lined ground squirrel muscle during torpor, which like Akt, functions in the disinhibition of eIF4E for protein synthesis to help prevent disuse-induced muscle atrophy (Ivakine and Cohn, 2014). In contrast to liver p-eIF4E (S209) levels, muscle p-eIF4E (S209) levels remained constant throughout the torpor-arousal cycle until IA, when phosphorylation levels increased to nearly 2-fold of the EC levels. Increased eIF4E total protein levels and increased p-eIF4E (S209) (thus, tighter binding of eIF4E to the 5'-m7GpppN cap) could be required during IA when more protein synthesis is required to replenish lost or damaged protein products, or when specific protein products are used to combat cellular damage caused by ROS. Furthermore, p-eIF4E (S209) levels may remain constant in muscle before 
the arousal phase because total eIF4E protein levels increased during ET, LT and IA, which would already provide and abundance of $5^{\prime}-\mathrm{m}^{7} \mathrm{GpppN}$ cap-binding proteins for translation complex formation. Phosphorylated 4EBP1 (S65) levels spiked during both LT and IA, which is consistent with high eIF4E total protein levels during these time points, and could indicate that translation is not inhibited by cap-dependent translation machinery proteins during torpor and arousal periods. Although the precise mechanisms of promoting capdependent translation are different (more total protein vs. more phosphorylated protein), eIF4E remains relatively active in both liver and muscle and may be primarily regulated by 4EBP1 phosphorylation over the torpor-arousal cycle. Again, the hypothesis that capdependent translation will be inactivated during torpor is not supported by the Western blot data, since eIF4E and p-4EBP (S65) levels remain elevated during torpor in thirteen-lined ground squirrel skeletal muscle.

Similar to the liver data for eIF $2 \alpha$ levels, total muscle eIF $2 \alpha$ protein levels increased during ET and LT (to 2.0-fold and 2.8-fold over EC values, respectively), before they decreased during EA to euthermic levels and then decreased during IA to $5 \%$ of the EC value. Hence, elevated eIF2 $\alpha$ total protein levels during ET and LT may indicate increased translation initiation during torpor, possibly to increase differential expression of proteins essential in maintaining cellular homeostasis during torpor, as suggested for liver of hibernating squirrels. However, relative to EC, p-eIF2 $\alpha$ (S51) levels increased during EN and LT. Just like in liver, this increase in eIF2 $\alpha$ could inhibit global protein synthesis processes during this time to conserve cellular energy. However, it is important to consider that total eIF $2 \alpha$ levels also increased during these times, so the ratio of phosphorylated to total eIF $2 \alpha$ levels may not be overly different from the control. Total eIF $2 \alpha$ levels may 
have increased to regulate translation complex availability during torpor, but these complexes may not be active except during small windows of time or in a smaller proportion within the cell. Future experiments with shorter time periods between the chosen sampling points may help indicate when p-eIF2 $\alpha$ (S51) is dephosphorylated for select transcript translation. Very low total eIF2 $\alpha$ protein levels during IA suggests that ground squirrel muscle may simply initiate translation of essential proteins as needed throughout torpor instead of replenishing all lost or degraded protein products during the arousal period to maintain homeostasis.

In contrast, eEF2 levels remained relatively constant throughout torpor, but increased during IA compared to EN, ET and EA. This could provide some evidence for the theory that IA is used to replenish protein products during arousal. In line with this argument, phosphorylated p-eEF2 (T56) levels increased by over 4.0-fold during LT, compared with EC, further providing evidence for the arrest of protein synthesis during torpor in hibernating thirteen-lined ground squirrel muscle.

In summary, the results suggest that translation is generally suppressed in skeletal muscle during torpor, where the mechanism may involve increased p-eIF2 $\alpha$ (S51) and peEF2 (T56) levels. Increases in total eIF4E, eIF2 $\alpha$, and eEF2 protein levels as well as p4EBP (S65) during torpor could suggest that despite global translation inhibition, there are more translation factors available for the formation of initiation and elongation complexes during LT. Specifically, cap-dependent translation appears to be active during both LT and IA, suggesting that in skeletal muscle, translation of only the transcripts with IRES elements is not the overarching mechanism hibernators use to discern which gene products are translated. Although total eIF2 $\alpha$ levels were low during the arousal period, muscle may 
use interbout arousals as a time for protein synthesis as indicated by elevated p-eIF4E (S209) during EA and IA, significantly higher p-4EBP1 (S65) during IA, and increased eEF2 total protein levels.

\subsubsection{Changes in total protein and phosphorylation status of translation factors in kidney of the thirteen-lined ground squirrel over the torpor-arousal cycle} Although there were no changes in p-eIF4E (S209) levels, p-4EBP1 (S65) levels increased during ET in kidney suggesting disinhibited cap-dependent translation at this time. Total eIF4E protein levels increased during EN, LT and IA but this was not consistent with the pattern for p-4EBP1 (S65) levels (Figure 4.5). This might be explained by there being different translational regulation at different time points of the torpor-arousal cycle. For instance, the translation of most stress-responsive proteins involved in the protection of kidney tissue may be amplified by there being more eIF4E during EN, when body temperature declines from $37^{\circ} \mathrm{C}$ to $31-18^{\circ} \mathrm{C}$. Levels of phosphorylated 4EBP1 may increase during ET to enhance the translation of gene products needed to withstand days in deep torpor. During LT and IA, high eIF4E abundance may be important to rapidly translate any mRNA essential for survival but p4EBP levels remain low to minimize energy use. Despite relatively unchanging p-eIF4E (S209) and p-4EBP1 (S65) levels, there seems to be more eIF4E available for capdependent translation during entrance, torpor and arousal, suggesting that again, capdependent translation is not inhibited, and the translation of mRNAs harboring IRES elements may not be the primary mechanism hibernators use to upregulate select mRNAs during torpor, as one previous study may suggest (Pan and van Breukelen, 2011). 
On top of largely unchanging 4EBP1 phosphorylation levels, kidney appears to have inhibited translation initiation as evidenced by decreased total eIF $2 \alpha$ levels during arousal (EA and IA), along with drastically elevated p-eIF2 $\alpha$ (S51) levels during ET, LT, and EA. This is also consistent with unchanging eEF2 levels as well as increased p-eEF2 (T56) levels during ET and LT, suggesting that translation is generally suppressed over the entire torpor-arousal cycle in kidney. Similar studies have reported an inhibition of translation in kidney from hibernating golden-mantled ground squirrel, where the incorporation of radio-labeled amino acids into proteins was less than $1 \%$ of euthermic levels (van Breukelen and Martin, 2001) and another study that showed p-eIF2 $\alpha$ (S51) levels were increased during LT of thirteen-lined ground squirrels (Hittel and Storey, 2002). This is consistent with kidney function being strongly suppressed over the torporarousal cycle since urination must be prevented until arousal to preserve ions and water stores (Jani et al., 2013).

\subsection{Conclusion}

This results from this study suggest that thirteen-lined ground squirrels use tissuespecific mechanisms to suppress or upregulate translation initiation/elongation machinery in a timely manner over the torpor-arousal cycle in order to facilitate protein synthesis of essential gene products (Figure 4.7). In summary, liver exhibits a tendency to have activated or more abundant translation factors during arousal but not during torpor, suggesting that liver may benefit from resynthesizing lost or damaged protein products during euthermic periods. Since liver is the primary organ that makes proteins for export into the blood, this can include many circulating proteins that could may need readjustment at different phases of the torpor-arousal cycle. In muscle, translation could be selectively 
active during both torpor and arousal, where key inhibitors of translation seem to be peIF $2 \alpha$ during entry and torpor as well as p-eEF2 during torpor. The same roadblocks may inhibit translation during both torpor and arousal phases in kidney, as evidenced by low eIF2 $\alpha$ during torpor as well as increases in phosphorylation of eIF $2 \alpha$ and eEF2 during both torpor and arousal. Importantly, these relative changes in protein and phosphorylation levels provide crucial insight into how energy-expensive translation is regulated over the torpor-arousal cycle in different organs. Thus, this research helps elucidate when and how hibernator organs replenish essential protein products and which are the major translation proteins responsible. This research shows that in all three tissues, it may be important for 4EBP1 to be phosphorylated during key times of translation and that eIF4E may need to be upregulated at the protein level or phosphorylated to more efficiently translate key transcripts. This study on three separate hibernator organs rejects the hypothesis that capdependent translation must be inhibited in order to promote the translation of mRNAs specific to hibernation survival, based on changes in total protein and pro-translation phosphorylation events of key translation regulators. Finally, it is of note that the inhibition of eIF2 $\alpha$ or eEF2 in muscle and kidney during torpor is not consistent with inhibited 4EBP and/or upregulated eIF4E during this time. Since it would be energetically unfavourable to upregulate translation factor total protein levels while preventing translation initiation or elongation, it is possible that active eIF4E (phosphorylated at S209 and not bound by 4EBP) has an alternative role during torpor, such as serving as an RNA-binding protein capable of transporting transcripts to stress granules (Frydryskova et al., 2016). 


\subsection{FigureS}

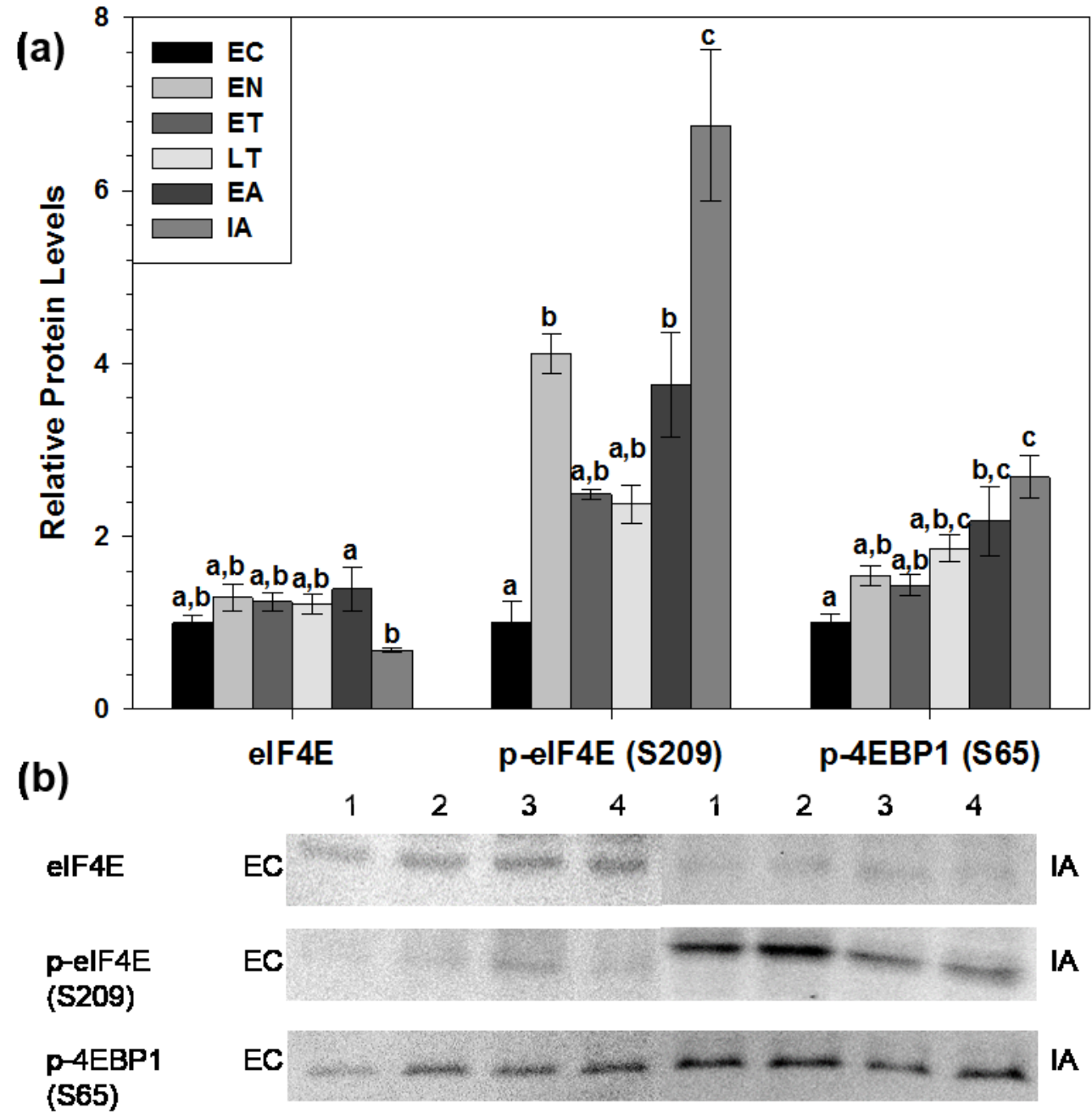

Figure 4.1: Relative protein and phosphorylation levels of eIF4F complex proteins and inhibitors in ground squirrel liver. (a) Histogram showing mean standardized expression levels of eIF4E, $p$ eIF4E (S209), and p-4EBP1 (S65) ( \pm S.E.M., $n=4$ independent protein isolations from different animals. (b) Representative western blots. Data were analyzed using ANOVA with a Tukey posthoc test. Shared letters indicate data that are not significantly different from each other and different letters indicate statistically significant differences between sample points $(p<0.05)$. 


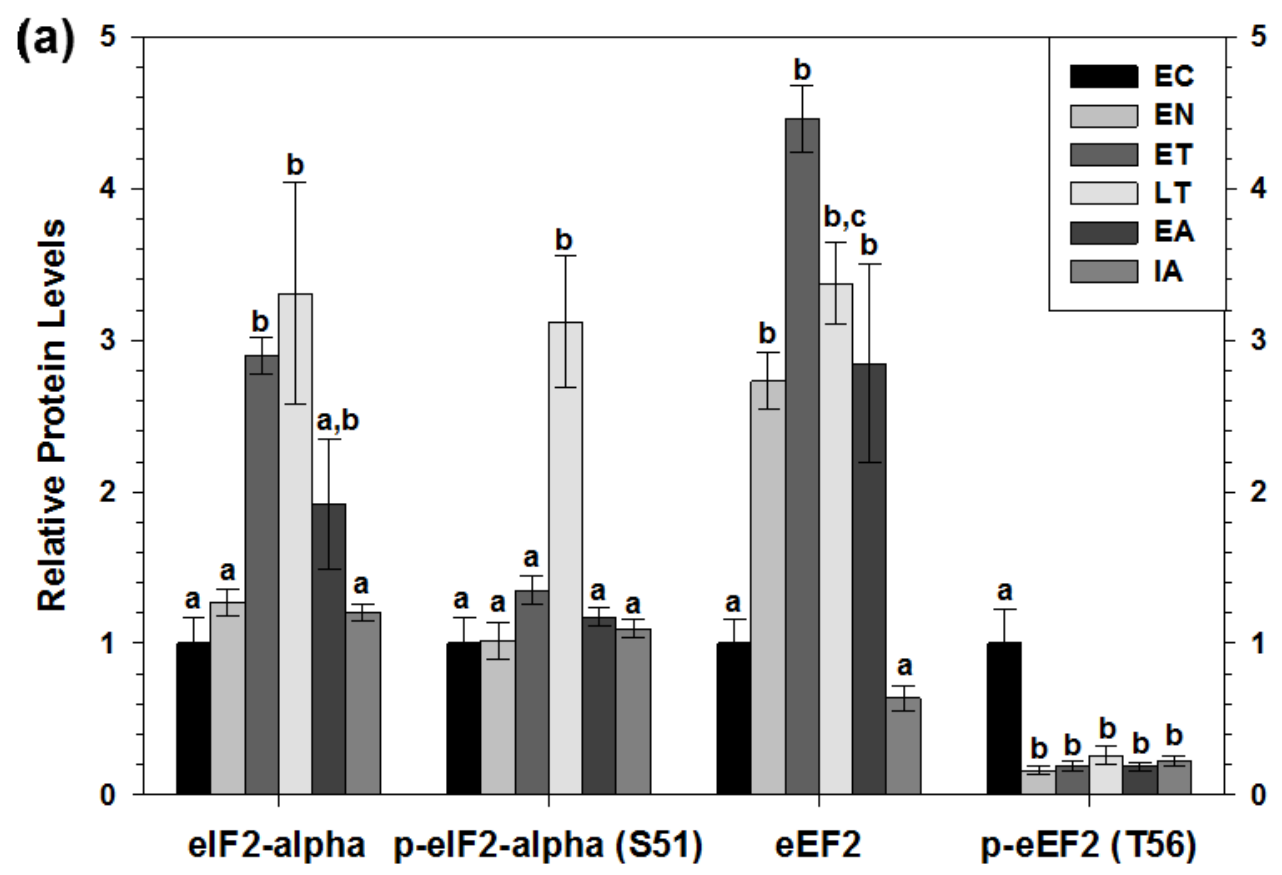

(b)

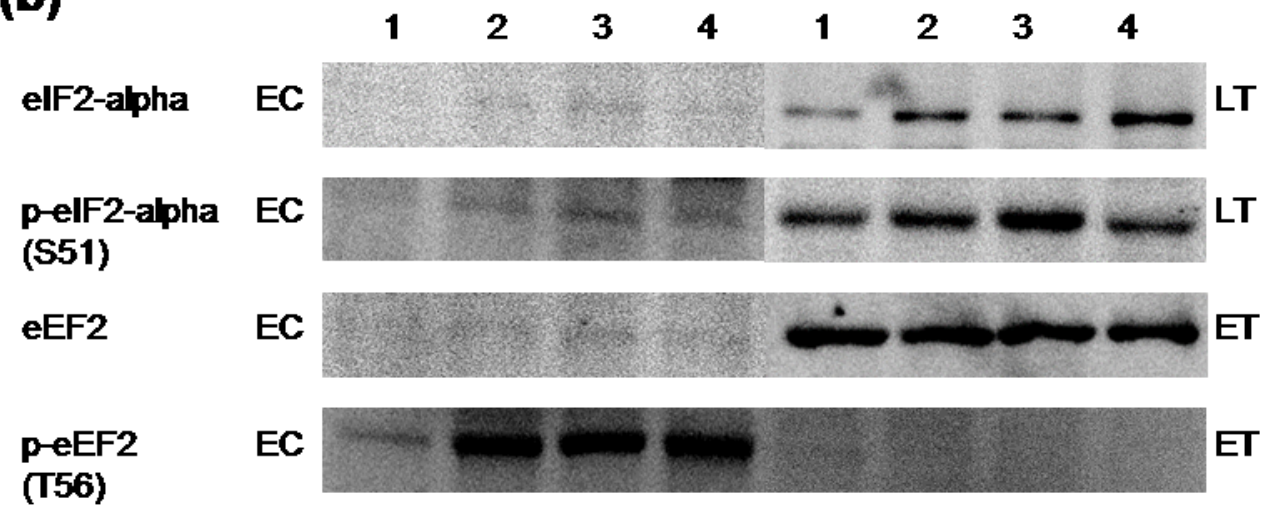

Figure 4.2: Relative eIF2 $\alpha$ and eEF2 protein and phosphorylation levels in ground squirrel liver. (a) Histogram showing mean standardized expression levels of eIF2 $\alpha, p-e I F 2 \alpha$ (S51), eEF2, and p-eEF2 (T56) ( \pm S.E.M., $n=4$ independent protein isolations from different animals. (b) Representative western blots. Other information as in Figure 4.1. 
(a)

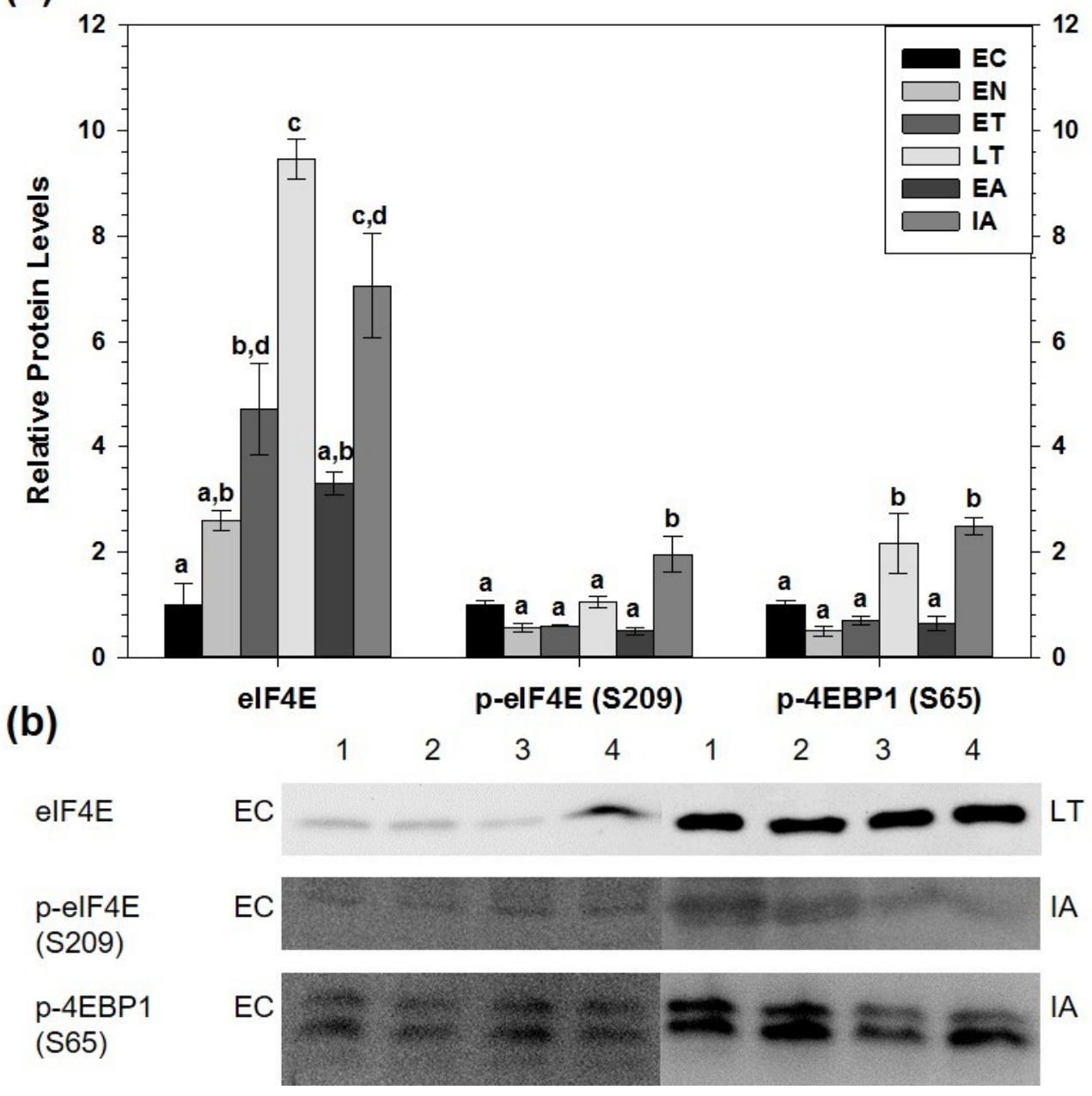

Figure 4.3: Relative protein and phosphorylation levels of eIF4F complex proteins and inhibitors in ground squirrel muscle. (a) Histogram showing mean standardized expression levels of eIF4E, p-eIF4E (S209), and p-4EBPI (S65) ( \pm S.E.M., $n=4$ independent protein isolations from different animals. (b) Representative western blots. Other information as in Figure 4.1. 


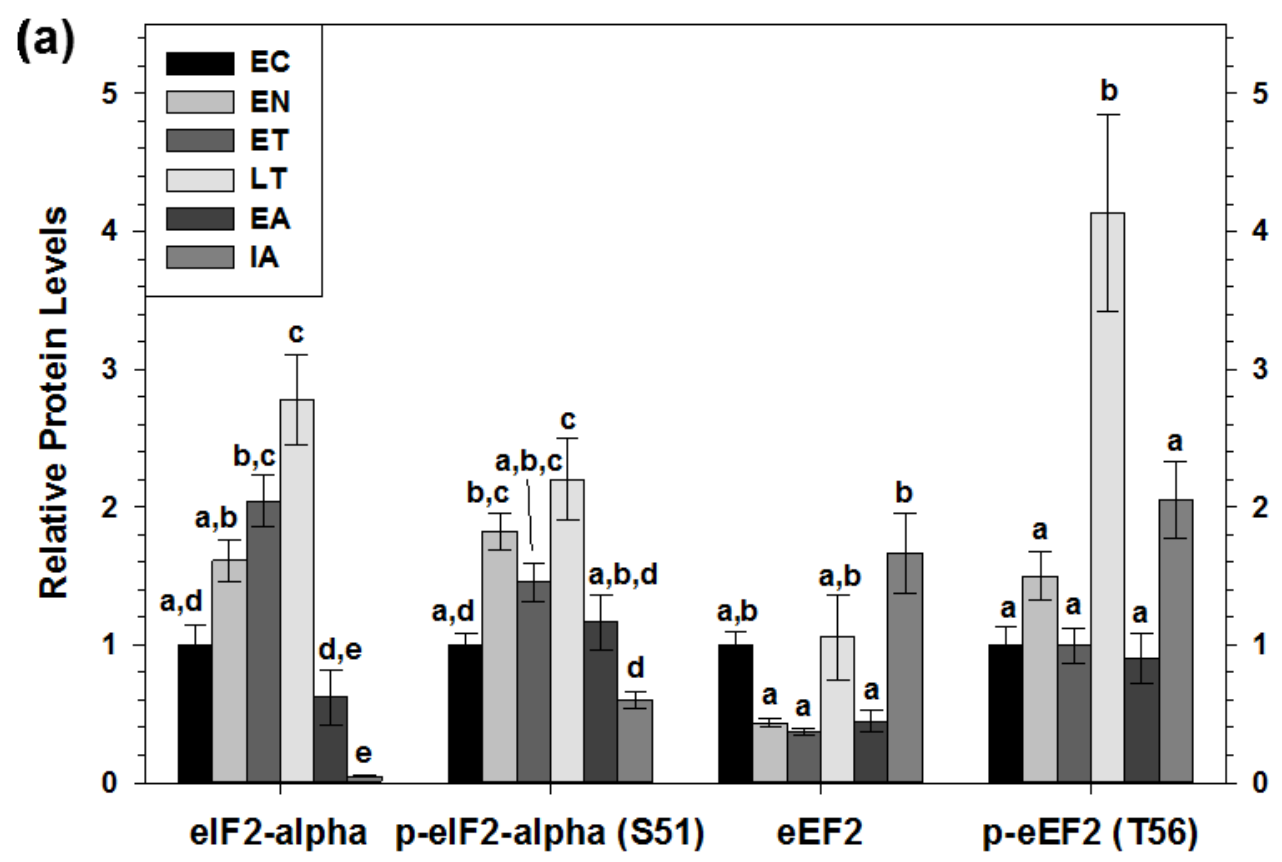

(b)

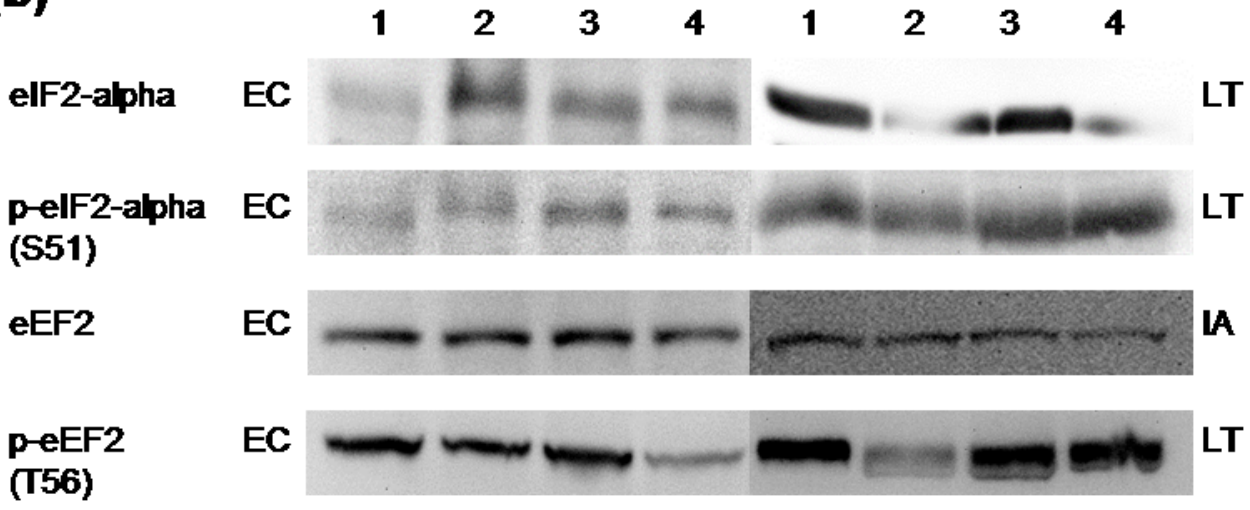

Figure 4.4: Relative eIF2 $\alpha$ and eEF2 protein and phosphorylation levels in ground squirrel muscle. (a) Histogram showing mean standardized expression levels of eIF $2 \alpha$, $p$-eIF2 $\alpha$ (S51), $e E F 2$, and p-eEF2 (T56) ( \pm S.E.M., $n=4$ independent protein isolations from different animals. (b) Representative western blots. Other information as in Figure 4.1. 
(a)

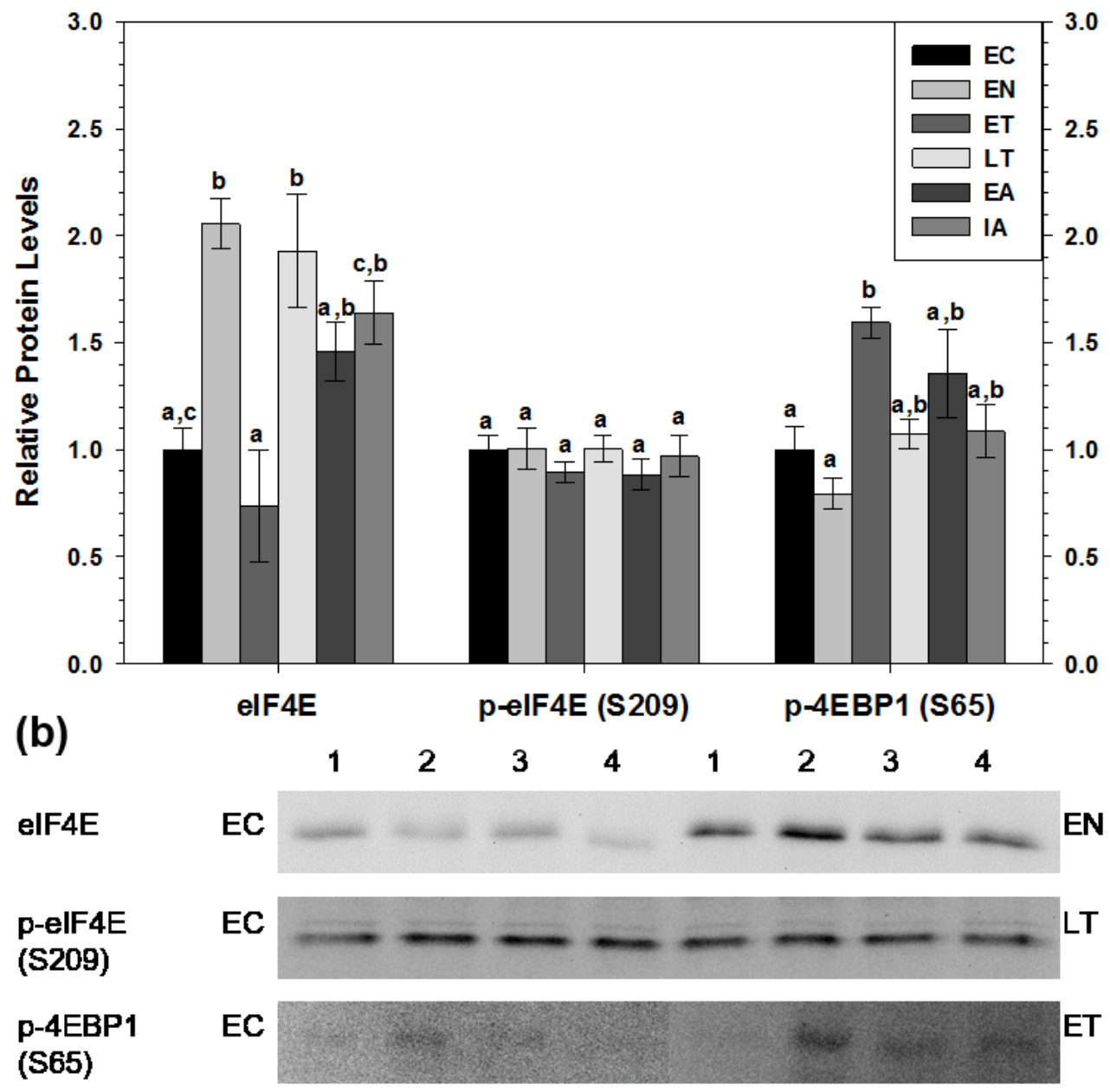

Figure 4.5: Relative protein and phosphorylation levels of eIF4F complex proteins and inhibitors in ground squirrel kidney. (a) Histogram showing mean standardized expression levels of eIF4E, p-eIF4E (S209), and p-4EBPI (S65) ( \pm S.E.M., $n=4$ independent protein isolations from different animals. (b) Representative western blots. Other information as in Figure 4.1. 


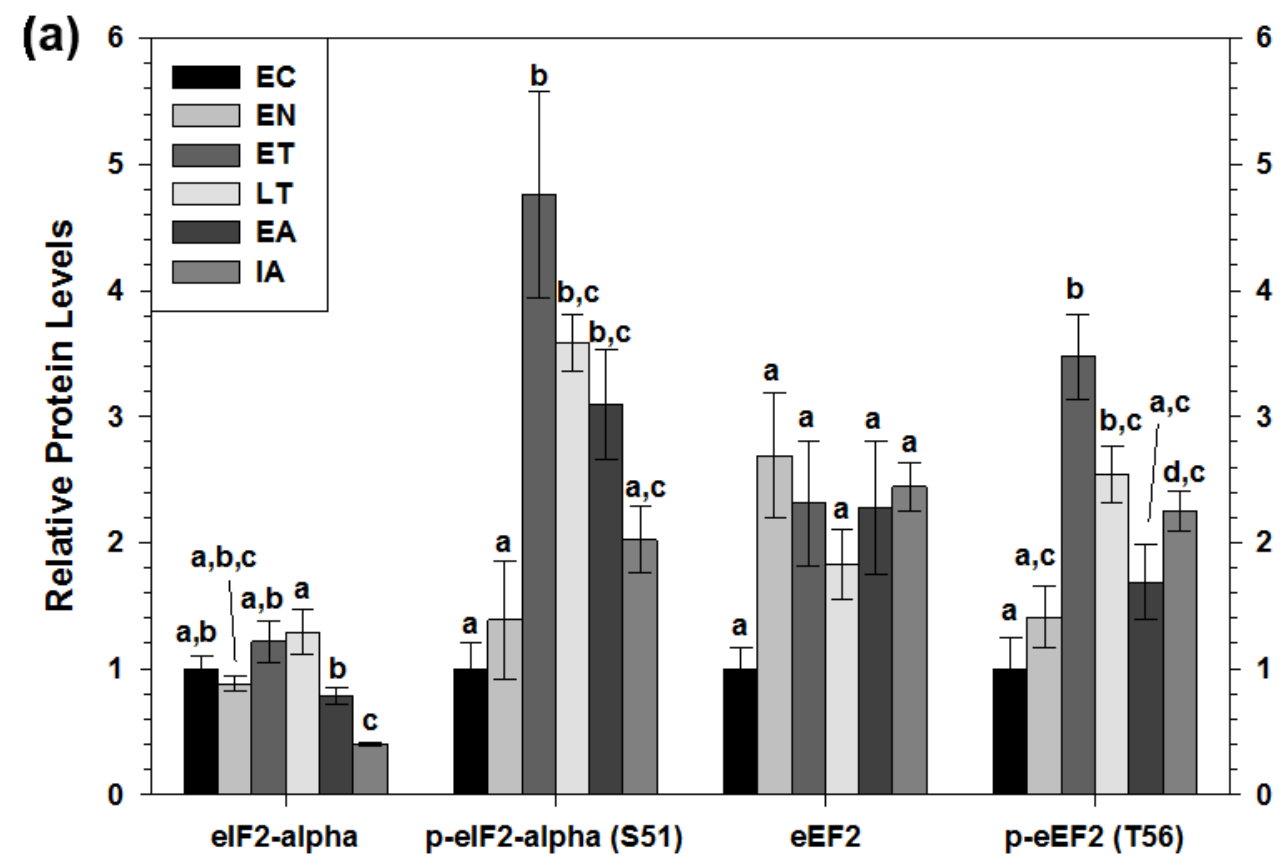

(b)

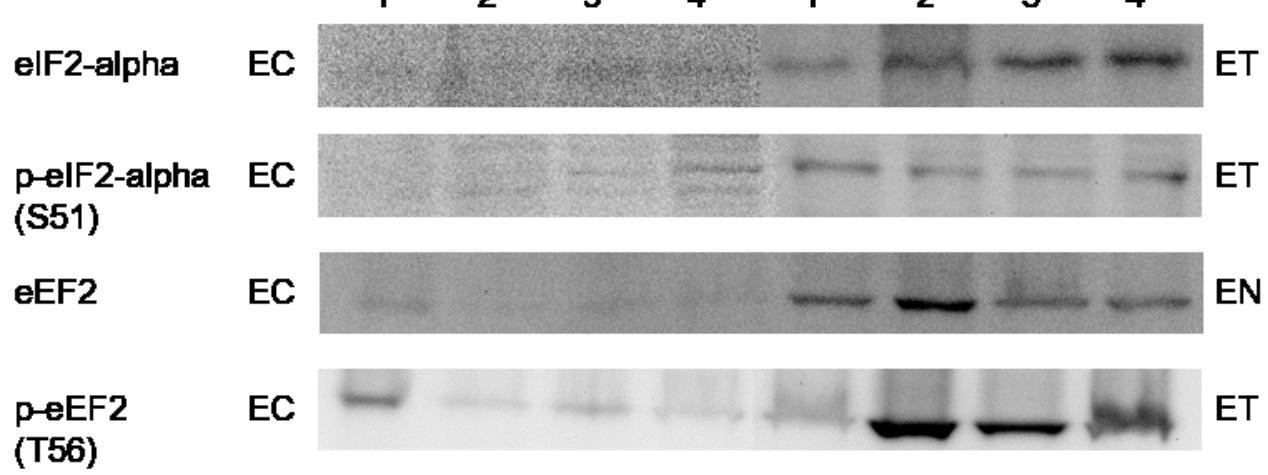

Figure 4.6: Relative eIF2 $\alpha$ and eEF2 protein and phosphorylation levels in ground squirrel kidney. (a) Histogram showing mean standardized expression levels of eIF2 $\alpha$, $p$-eIF2 $\alpha$ (S51), $e E F 2$, and p-eEF2 (T56) ( \pm S.E.M., $n=4$ independent protein isolations from different animals. (b) Representative western blots. Other information as in Figure 4.1. 


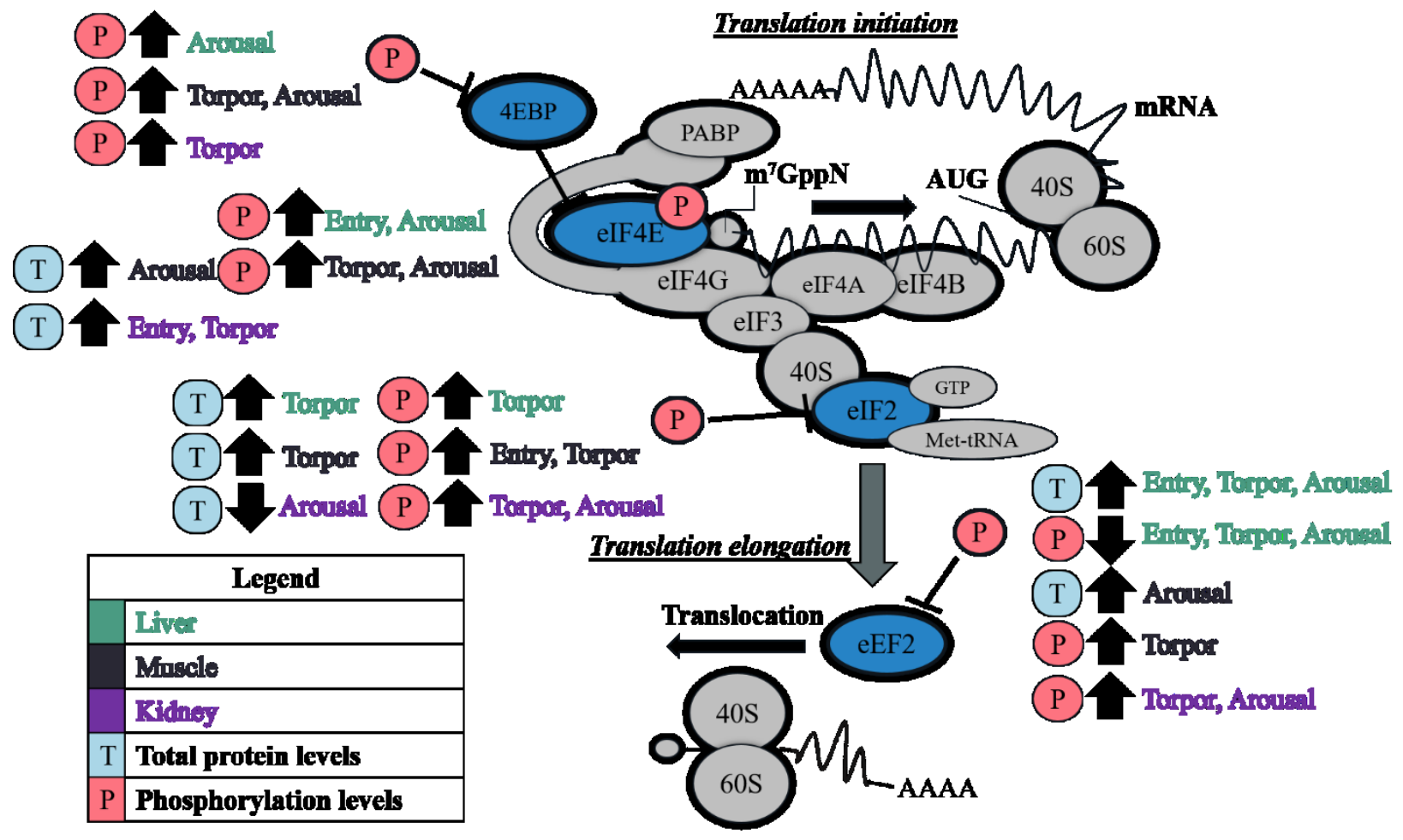

Figure 4.7: Summary of relative changes in translation factor protein levels and phosphorylation states throughout the torpor-arousal cycle of thirteen-lined ground squirrels in liver, muscle, and kidney. Relative changes in each tissue are lined up with the corresponding translation factor seen in blue or phosphorylation event depicted as pink circles containing " $P$ ". Lettering colour indicates the tissue (green-blue for liver, black for muscle, and purple for kidney) associated with each set of arrows, that point upwards if a significant increase was observed or downwards if a significant downregulation was observed. Relative to the euthermic control (EC), total protein changes and phosphorylation level changes are depicted as either a blue circle with a " $T$ " or a pink circle with a " $P$ ", respectively. Inhibitory events are symbolized with blunted lines, and general movement of translation factors is symbolized by black arrows. The grey arrow symbolizes a change in process, i.e. translation initiation vs. translation elongation. 


\section{Chapter 5 - General discussion}


Hypometabolism, whether it be torpor, estivation, hibernation, dauer, or diapause, is exhibited in a vast range of animal species (Storey et al., 2010; Wang and Lee, 1996). The thirteen-lined ground squirrel is just one of these - a well-studied seasonal hibernator, capable of reducing its metabolism to less than $5 \%$ of euthermic levels when in deep torpor which allows it to save nearly $90 \%$ of the energy it would otherwise expend if it remained homeothermic throughout the winter (Ruf and Geiser, 2015; Wang and Wolowyk, 1988). Metabolic suppression is accompanied by other incredible changes in physiology including a significant decrease in heart rate from 200-300 beats/minute to 3-5 beats/minute, a decrease in breathing rate from 100-200 breaths/minute to about 5 breaths/minute, a substantial decrease in organ perfusion to less than $10 \%$ of euthermic levels, and an astounding decrease in core body temperature to values approaching $0{ }^{\circ} \mathrm{C}$ (Wang, 1989). The biochemistry of hibernation is still incompletely understood but several common mechanisms of reducing metabolic rate have been identified. Hypometabolism involves a global suppression of metabolism, where energy expensive processes are turned down or off to suppress cellular energy (ATP) expenditure. This can be mediated by posttranslational modifications of proteins to regulate their activity, by differential gene and protein expression, and/or by temperature-regulated changes in protein structure and function (Storey and Storey, 2004). In this thesis, two mechanisms of regulating selective protein translation were assessed over the course of the torpor-arousal cycle, surveying 4 different organs from thirteen-lined ground squirrels. It is necessary to fully understand how hibernators can coordinate differential protein expression of essential genes while reducing metabolism if similar molecular adaptations are to be replicated in nonhibernating organisms (e.g. to extend the viability of an organ awaiting transplant by 
suppressing its metabolism). In this thesis, Chapter 3 characterized the stress-inducible activity of RNA-binding proteins that are known to bind and transport mRNA transcripts from the nucleus to the cytoplasm, at several points of the torpor-arousal cycle. Additionally, Chapter 4 analyzed the tissue-specific post-translational regulation of the translation initiation and elongation machinery over the course of a torpor bout. Together, each chapter demonstrated that ground squirrels do indeed regulate selective gene and protein expression in a manner that appears to restrict unnecessary energy expenditure. This thesis shows that hibernating ground squirrels do modulate and regulate stressinducible RNA binding proteins as well as translation machinery such that redundant proteins are less expressed and the roles of essential proteins are elucidated via changes in protein abundance, subcellular localization, and post-translational modifications.

The present studies help to illuminate how hibernators may selectively upregulate the translation of specific gene products during periods of hypometabolism. Firstly, Chapter 3 revealed that Cirp and HuR proteins were upregulated and located in the cytoplasm during torpor, suggesting that these proteins may play an adaptive role in the transport of select mRNA transcripts from the nucleus to the cytoplasm. In fact, previous studies with ground squirrels demonstrated that global mRNA levels do not change between EC and LT and that mRNA poly(A) tails do not shorten during the torpor-arousal cycle, suggesting that RNA-stabilizing mechanisms must be utilized during torpor (Frerichs et al., 1998; Knight et al., 2000). Cirp and Rbm3 can bind identical nucleotide sequences on target mRNAs (usually in the 5' and 3' untranslated regions of mRNA). At low $\mathrm{T}_{\mathrm{b}}$, Cirp and Rbm3 can regulate the poly(A) tail length of transcripts that oscillate expression with circadian rhythm, including the transcripts of other RNA-binding proteins (e.g. the polypyrimidine 
tract binding protein 1 gene, PTBP1), protein folding genes (e.g. the heat shock protein gene, HSP90), and circadian clock genes (e.g. the nuclear receptor subfamily 1 group D member 2 gene, NR1D2) (Liu et al., 2013). In developing Xenopus oocytes, Cirp and its binding partner HuR cooperate in the maintenance of mRNA poly(A). Specifically, Xenopus Cirp (xCIRP2) has been demonstrated to shuttle from the nucleus to the cytoplasm and prevent the deadenylation of specific mRNAs. While HuR could not prevent deadenylation on its own, HuR cooperation and stabilization of mRNA was necessary for xCIRP2 to prevent mRNA deadenylation (Aoki et al., 2003). The current study showed increased Cirp and HuR protein levels, increased cytoplasmic localization, and unchanging transcript levels of Cirp binding partners $n r l d 2$ and $p t b p 1$ over the torpor-arousal cycle in several key thirteen-lined ground squirrel organs. These results suggest that Cirp and its protein binding partner HuR may indeed have important roles in regulating transcript stability during hibernation.

Over $90 \%$ of transcripts are translated via cap-dependent translation (Lleonart, 2010) so the inhibition of cap-mediated translation could facilitate global protein synthesis shutdown during torpor. Indeed, this suggestion has been made in several studies published in the broader field of hibernation biochemistry, partially based on an observed relative increase in the abundance of transcripts that are translated with the aid of IRES motifs over torpor-arousal cycles, implicating a lower use of cap-mediated translation (Pan and van Breukelen, 2011; Tessier and Storey, 2014). However, the most interesting findings of Chapter 4 show that cap-dependent translation is likely not inhibited by hypophosphorylation of 4EBP. Indeed, eIF4E levels and/or p-eIF4E (S209) levels increased in liver, muscle, and kidney during torpor and/or arousal, depending on the tissue, further 
implying this hypothesis to be incorrect. The increases in p-4EBP and p-eIF4E are consistent with increases in Cirp protein levels. Not only can Cirp increase the translation of select transcripts by stabilizing their poly(A) tails and transporting them to cytoplasmic translation machinery, Cirp can also increase protein synthesis by influencing phosphorylated extracellular signal-regulated kinase $1 / 2$ (phospho-ERK1/2) to phosphorylate 4EBP (Lleonart, 2010). Since Chapter 3 shows an increase in Cirp and Chapter 4 shows an increase in 4EBP phosphorylation in several hibernator organs, Cirp may be important for regulating the activation of translation machinery. Increases in Rbm3 are associated with increased translation and decreased eIF $2 \alpha$ phosphorylation (Zhu et al., 2016). To recap, phosphorylation of eIF2 $\alpha$ at Ser51 inhibits translation by strengthening the interaction between eIF2 $\alpha$-GDP and eIF2B, such that eIF2B cannot catalyze the GDPGTP exchange on eIF2 $\alpha$ (Gebauer and Hentze, 2004). This prevents eIF2 $\alpha$-GTP from catalyzing the GTP-mediated reaction between tRNA (particularly the initiating methionine tRNA) and the large ribosomal P subunit. Liver Rbm3 levels were lowest during LT, when liver p-eIF $2 \alpha$ levels were highest and skeletal muscle Rbm3 levels were lowest during entry when muscle p-eIF $2 \alpha$ levels were also relatively high. Thus, it is possible that $\mathrm{Rbm} 3$ levels are coordinately downregulated to minimize all translation initiation, cap-mediated and IRES-mediated alike, (i.e. by increasing eIF2 $\alpha$ phosphorylation) during metabolic suppression in hibernators. The combined results of Chapter 3 and 4 suggest that RNA binding proteins are not only able to regulate transcript stability, but they may also have a key role in regulating global translation over the torporarousal cycle. 
The thirteen-lined ground squirrel, a seasonal hibernator, is an amazing model to study the biochemical changes that accompany hypometabolism. In this thesis, two pathways were explored in the context of hibernation for their promise in regulating the translation of essential gene products. More specifically, cold-shock RNA-binding proteins had never been characterized in the context of mammalian hibernation when $T_{b}$ decreases to near 0 ${ }^{\circ} \mathrm{C}$ levels, and translation had never been thoroughly investigated using multiple sampling points from the torpor-arousal cycle with a euthermic in the cold room control. Thus, this thesis provides new insights on how hibernating thirteen-lined ground squirrels may regulate which transcripts are stabilized and how translation is regulated to promote selective protein synthesis and subsequent changes in cell phenotype to support torpor. In summary, Cirp and HuR are known to stabilize a diverse range of transcripts and transport them to the cytoplasm for translation so their increase in expression during torpor could be a novel mechanism of selective protein translation. Since protein and transcript levels provide a relatively narrow window into Cirp and HuR regulation during torpor, two experiments should be done to follow up this research. First, it is of great interest to know which transcripts Cirp and HuR preferentially bind to at different points of the torporarousal cycle to understand which pathways are being upregulated, and second, it is of great interest to know if Cirp and HuR binding capacity may change at different time points over the torpor-arousal cycle due to changes in body temperature. Furthermore, Cirp may regulate 4EBP phosphorylation since it would enable cap-mediated translation during torpor. To confirm this, it will be necessary to investigate phospho-ERK1/2 activity over the torpor-arousal cycle. Regardless, the results shown in this thesis suggest that translation would only be inhibited at the eIF2 $\alpha$ and eEF2 levels in several organs, further suggesting 
that global translation is inhibited downstream of 5' cap-binding at the point when initiation or elongation are catalyzed. Decreased eIF2 $\alpha$ and eEF2 levels could also promote the translation of specific open reading frames due to a decreased abundance of translation machinery proteins. Overall, these studies provide evidence for tissue- and time- specific changes in selective protein expression via RNA-binding proteins and modulation of translation machinery proteins in the hibernating thirteen-lined ground squirrel. 


\section{REFERENCES}

Al-Fageeh, M. B. and Smales, C. M. (2006). Control and regulation of the cellular responses to cold shock: the responses in yeast and mammalian systems. Biochem. J. 397, 247-259.

Anantharaman, V., Koonin, E. V and Aravind, L. (2002). Comparative genomics and evolution of proteins involved in RNA metabolism. Nucleic Acids Res. 30, 1427-1464.

Andres-Mateos, E., Brinkmeier, H., Burks, T. N., Mejias, R., Files, D. C., Steinberger, M., Soleimani, A., Marx, R., Simmers, J. L., Lin, B., et al. (2013). Activation of serum/glucocorticoid-induced kinase 1 (SGK1) is important to maintain skeletal muscle homeostasis and prevent atrophy. EMBO Mol. Med. 5, 80-91.

Aoki, K., Matsumoto, K. and Tsujimoto, M. (2003). Xenopus cold-inducible RNA-binding protein 2 interacts with ElrA, the Xenopus homolog of HuR, and inhibits deadenylation of specific mRNAs. J. Biol. Chem. 278, 48491-48497.

Atasoy, U., Watson, J., Patel, D. and Keene, J. D. (1998). ELAV protein HuA (HuR) can redistribute between nucleus and cytoplasm and is upregulated during serum stimulation and T cell activation. J. Cell Sci. 111, 3145-3156.

Biggar, Y. and Storey, K. B. (2014). Global DNA modifications suppress transcription in brown adipose tissue during hibernation. Cryobiology 69, 333-338.

Biggar, K. K. and Storey, K. B. (2015). Insight into post-transcriptional gene regulation: stressresponsive microRNAs and their role in the environmental stress survival of tolerant animals. J. Exp. Biol. 218, 1281-1289.

Boyer, B. B. and Barnes, B. M. (1999). Molecular and metabolic aspects of mammalian hibernation. Bioscience 49, 713-724.

Buck, M. J., Squire, T. L., Andrews, M. T., Michael, J., Squire, T. L. and Matthew, T. (2002). Coordinate expression of the PDK4 gene : a means of regulating fuel selection in a hibernating mammal. Physiol. Genomics 8, 5-13.

Chan, C. P., Kok, K. H., Tang, H. M. V., Wong, C. M. and Jin, D. Y. (2013). Internal ribosome entry site-mediated translational regulation of ATF4 splice variant in mammalian unfolded protein response. Biochim. Biophys. Acta-Mol. Cell Res. 1833, 2165-2175.

Danno, S., Nishiyama, H., Higashitsuji, H., Yokoi, H., Xue, J.-H., Itoh, K., Matsuda, T. and Fujita, J. (1997). Increased transcript level of RBM3, a member of the glycine-rich RNAbinding protein family, in Human cells in response to cold stress. Biochem. Biophys. Res. Commun. 236, 804-807.

De Leeuw, F., Zhang, T., Wauquier, C., Huez, G., Kruys, V. and Gueydan, C. (2007). The cold-inducible RNA-binding protein migrates from the nucleus to cytoplasmic stress granules by a methylation-dependent mechanism and acts as a translational repressor. Exp. Cell Res. 313, 4130-4144.

Derry, J. M. J., Kerns, J. A. and Francke, U. (1995). RBM3, a novel human gene in Xp11.23 with a putative RNA-binding domain. Hum. Mol. Genet. 4, 2307-11.

Drew, K. L., Buck, C. L., Barnes, B. M., Christian, S. L., Rasley, B. T. and Harris, M. B. (2007). Central nervous system regulation of mammalian hibernation: Implications for metabolic suppression and ischemia tolerance. J. Neurochem. 102, 1713-1726. 
Eaton, S. L., Roche, S. L., Llavero Hurtado, M., Oldknow, K. J., Farquharson, C., Gillingwater, T. H. and Wishart, T. M. (2013). Total Protein Analysis as a Reliable Loading Control for Quantitative Fluorescent Western Blotting. PLoS One 8, 1-9.

Epperson, L. E., Rose, J. C., Carey, H. V and Martin, S. L. (2010). Seasonal proteomic changes reveal molecular adaptations to preserve and replenish liver proteins during ground squirrel hibernation. Am. J. Physiol. Regul. Integr. Comp. Physiol. 298, R329-R340.

Fedorov, V. B., Goropashnaya, A. V, Tøien, O., Stewart, N. C., Gracey, A. Y., Chang, C., Qin, S., Pertea, G., Quackenbush, J., Showe, L. C., et al. (2009). Elevated expression of protein biosynthesis genes in liver and muscle of hibernating black bears (Ursus americanus). Physiol. Genomics 37, 108-18.

Fedorov, V. B., Goropashnaya, A. V, Tøien, O., Stewart, N. C., Chang, C., Wang, H., Yan, J., Showe, L. C., Showe, M. K. and Barnes, B. M. (2011). Modulation of gene expression in heart and liver of hibernating black bears (Ursus americanus). BMC Genomics 12, 171.

Flynn, a. and Proud, C. G. (1995). Serine 209, not serine 53, is the major site of phosphorylation in initiation factor eIF-4E in serum-treated Chinese hamster ovary cells. $J$. Biol. Chem. 270, 21684-21688.

Frerichs, K. U., Smith, C. B., Brenner, M., DeGracia, D. J., Krause, G. S., Marrone, L., Dever, T. E. and Hallenbeck, J. M. (1998). Suppression of protein synthesis in brain during hibernation involves inhibition of protein initiation and elongation. Proc Natl Acad Sci USA 95, 14511-14516.

Frydryskova, K., Masek, T., Borcin, K., Mrvova, S., Venturi, V. and Pospisek, M. (2016). Distinct recruitment of human eIF4E isoforms to processing bodies and stress granules. BMC Mol. Biol. 17, 21.

Gebauer, F. and Hentze, M. W. (2004). Molecular mechanisms of translational control. Nat Rev Mol Cell Biol 5, 827-35.

Gerstberger, S., Hafner, M. and Tuschl, T. (2014). A census of human RNA-binding proteins. Nat. Rev. Genet. 15, 829-845.

Gingras, A. C., Raught, B., Gygi, S. P., Niedzwiecka, A., Miron, M., Burley, S. K., Polakiewicz, R. D., Wyslouch-Cieszynska, A., Aebersold, R. and Sonenberg, N. (2001). Hierarchical phosphorylation of the translation inhibitor 4E-BP1. Genes Dev. 15, 2852-64.

Grabek, K. R. and Martin, S. L. (2012). Theme and variation: proteomic changes across three organs in hibernation cycles of the 13-lined ground squirrel. In Living in a Seasonal World, pp. $423-432$.

Grabek, K. R., Behn, C. D., Barsh, G. S., Hesselberth, J. R. and Martin, S. L. (2015a). Enhanced stability and polyadenylation of select mRNAs support rapid thermogenesis in the brown fat of a hibernator. Elife 2015, 1-19.

Grabek, K. R., Martin, S. L. and Hindle, A. G. (2015b). Proteomics approaches shed new light on hibernation physiology. J. Comp. Physiol. B Biochem. Syst. Environ. Physiol. 185, 607627.

Guo, X., Wu, Y. and Hartley, R. S. (2010). Cold-inducible RNA-binding protein contributes to human antigen R and cyclin E1 deregulation in breast cancer. Mol. Carcinog. 49, 130-140.

Hampton, M., Nelson, B. T. and Andrews, M. T. (2010). Circulation and metabolic rates in a 
natural hibernator: an integrative physiological model. Am. J. Physiol. Regul. Integr. Comp. Physiol. 299, R1478-R1488.

Hindle, A. G., Grabek, K. R., Epperson, L. E., Karimpour-Fard, A. and Martin, S. L. (2014). Metabolic changes associated with the long winter fast dominate the liver proteome in 13-lined ground squirrels. Physiol. Genomics 46, 348-61.

Hittel, D. and Storey, K. B. (2002). The translation state of differentially expressed mRNAs in the hibernating 13-lined ground squirrel (Spermophilus tridecemlineatus). Arch. Biochem. Biophys. 401, 244-254.

Ivakine, E. A. and Cohn, R. D. (2014). Maintaining skeletal muscle mass: lessons learned from hibernation. Exp. Physiol. 99, 632-637.

Jani, A., Martin, S. L., Jain, S., Keys, D. and Edelstein, C. L. (2013). Renal adaptation during hibernation. Am J Physiol Ren. Physiol 305, F1521-F1532.

Joshi, B., Cai, A.-L., Keiper, B. D., Minich, W. B., Mendez, R., Beach, C. M., Stepinski, J., Stolarski, R., Darzynkiewicz, E. and Rhoads, R. E. (1995). Phosphorylation of eukaryotic protein synthesis initiation factor 4E at Ser-209. J. Biochem. Chem. 270, 14597-603.

Knight, J. E., Narus, E. N., Martin, S. L., Jacobson, A., Barnes, B. M. and Boyer, B. B. (2000). mRNA stability and polysome loss in hibernating Arctic ground squirrels (Spermophilus parryii). Mol. Cell. Biol. 20, 6374-6379.

Larade, K. and Storey, K. B. (2007). Arrest of transcription following anoxic exposure in a marine mollusc. Mol. Cell. Biochem. 303, 243-249.

Li, H., Park, S., Kilburn, B., Jelinek, M. A., Henschen-Edman, A., Aswad, D. W., Stallcup, M. R. and Laird-Offringa, I. A. (2002). Lipopolysaccharide-induced methylation of HuR, an mRNA-stabilizing protein, by CARM1. J. Biol. Chem. 277, 44623-44630.

Liu, Y., Hu, W., Murakawa, Y., Yin, J., Wang, G., Landthaler, M. and Yan, J. (2013). Coldinduced RNA-binding proteins regulate circadian gene expression by controlling alternative polyadenylation. Sci. Rep. 3, 2054.

Lleonart, M. E. (2010). A new generation of proto-oncogenes: Cold-inducible RNA binding proteins. Biochim. Biophys. Acta - Rev. Cancer 1805, 43-52.

Luu, B. E., Tessier, S. N., Duford, D. L. and Storey, K. B. (2015). The regulation of troponins I, C and ANP by GATA4 and Nkx2-5 in heart of hibernating thirteen-lined ground squirrels, Ictidomys tridecemlineatus. PLoS One 10, 0117747.

Ma, W., Cheng, S., Campbell, C., Wright, A. and Furneaux, H. (1996). Cloning and characterization of HuR, a ubiquitously expressed elav-like protein. J. Biol. Chem. 271, 8144-8151.

McMullen, D. C. and Hallenbeck, J. M. (2010). Regulation of Akt during torpor in the hibernating ground squirrel, Ictidomys tridecemlineatus. J. Comp. Physiol. B Biochem. Syst. Environ. Physiol. 180, 927-934.

Miyake, S.-I., Wakita, H., Bernstock, J. D., Castri, P., Ruetzler, C., Miyake, J., Lee, Y. and Hallenbeck, J. M. (2015). Hypophosphorylation of ribosomal protein S6 is a molecular mechanism underlying ischemic tolerance induced by either hibernation or preconditioning. J. Neurochem. 135, 943-957. 
Morin, P. and Storey, K. B. (2006). Evidence for a reduced transcriptional state during hibernation in ground squirrels. Cryobiology 53, 310-318.

Nishiyama, H., Itoh, K., Kaneko, Y., Kishishita, M., Yoshida, O. and Fujita, J. (1997a). A glycine-rich RNA-binding protein mediating cold-inducible suppression of mammalian cell growth. J. Cell Biol. 137, 899-908.

Nishiyama, H., Higashitsuji, H., Yokoi, H., Itoh, K., Danno, S., Matsuda, T. and Fujita, J. (1997b). Cloning and characterization of human CIRP (cold-inducible RNA-binding protein) cDNA and chromosomal assignment of the gene. Gene 204, 115-120.

Pan, P. and van Breukelen, F. (2011). Preference of IRES-mediated initiation of translation during hibernation in golden-mantled ground squirrels, Spermophilus lateralis. Am. J. Physiol. Regul. Integr. Comp. Physiol. 301, R370-R377.

Pang, L., Tian, H., Chang, N., Yi, J., Xue, L., Jiang, B., Gorospe, M., Zhang, X. and Wang, W. (2013). Loss of CARM1 is linked to reduced HuR function in replicative senescence. BMC Mol. Biol. 14, 15.

Proud, C. G., Wang, X., Patel, J. V, Campbell, L. E., Kleijn, M., Li, W. and Browne, G. J. (2001). Interplay between insulin and nutrients in the regulation of translation factors. Biochem. Soc. Trans. 29, 541-547.

Ramnanan, C. J., Allan, M. E., Groom, A. G. and Storey, K. B. (2009). Regulation of global protein translation and protein degradation in aerobic dormancy. Mol. Cell. Biochem. 323, 9-20.

Rigano, K., Gehring, J., Evans Hutzenbiler, B., Chen, A., Nelson, O., Vella, C., Robbins, C. and Jansen, H. (2016). Life in the fat lane: seasonal regulation of insulin sensitivity, food intake, and adipose biology in brown bears. J. Comp. Physiol. B 1-28.

Rouble, A. N., Hefler, J., Mamady, H., Storey, K. B. and Tessier, S. N. (2013). Anti-apoptotic signaling as a cytoprotective mechanism in mammalian hibernation. PeerJ 1, e29.

Ruf, T. and Geiser, F. (2015). Daily torpor and hibernation in birds and mammals. Biol Rev Camb Philos Soc. 90, 891-926.

Rui, L. (2014). Energy metabolism in the liver. Compr. Physiol. 4, 177-197.

Sano, Y., Shiina, T., Naitou, K., Nakamori, H. and Shimizu, Y. (2015). Hibernation-specific alternative splicing of the mRNA encoding cold-inducible RNA-binding protein in the hearts of hamsters. Biochem. Biophys. Res. Commun. 462, 322-325.

Schwartz, C., Hampton, M. and Andrews, M. T. (2013). Seasonal and regional differences in gene expression in the brain of a hibernating mammal. PLoS One $\mathbf{8}$,

Seibel, B. a., Häfker, N. S., Trübenbach, K., Zhang, J., Tessier, S. N., Pörtner, H.-O., Rosa, R. and Storey, K. B. (2014). Metabolic suppression during protracted exposure to hypoxia in the jumbo squid, Dosidicus gigas, living in an oxygen minimum zone. J. Exp. Biol. 217, $2555-2568$.

Shao, C., Liu, Y., Ruan, H., Li, Y., Wang, H., Kohl, F., Goropashnaya, A. V, Fedorov, V. B., Zeng, R., Barnes, B. M., et al. (2010). Shotgun proteomics analysis of hibernating arctic ground squirrels. Mol. Cell. Proteomics 9, 313-326.

Si, J., Cui, J., Cheng, J. and Wu, R. (2015). Computational prediction of RNA-binding proteins 
and binding sites. Int. J. Mol. Sci. 16, 26303-26317.

Sonenberg, N. and Hinnebusch, A. G. (2009). Regulation of translation initiation in eukaryotes: Mechanisms and biological targets. Cell 136, 731-745.

Spriggs, K. A., Bushell, M. and Willis, A. E. (2010). Translational regulation of gene expression during conditions of cell stress. Mol. Cell 40, 228-237.

Storey, K. B. (2010). Out cold: Biochemical regulation of mammalian hibernation - A minireview. Gerontology 56, 220-230.

Storey, K. B. (2015). The gray mouse lemur: a model for studies of primate metabolic rate depression. Genomics. Proteomics Bioinformatics 13, 77-80.

Storey, K. B. and Storey, J. M. (2000). Gene expression and protein adaptations in mammalian hibernation. In Life in the Cold (ed. Heldmaier, G.) and Klingenspor, M.), pp. 303-313. Springer-Verlag.

Storey, K. B. and Storey, J. M. (2004). Mammalian hibernation: biochemical adaptation and gene expression. In Functional Metabolism: Regulation and Adaptation (ed. Storey, K. B.), pp. 443-472. John Wiley \& Sons, Inc.

Storey, K. B. and Storey, J. M. (2013). Molecular biology of freezing tolerance. Compr. Physiol. 3, 1283-1308.

Storey, K. B., Heldmaier, G. and Rider, M. H. (2010). Mammalian hibernation: Physiology, cell signaling, and gene control on metabolic rate depression. In Dormancy and resistance in harsh environments (ed. Lubzens, E.), pp. 227-252. Springer-Verlag Berlin Heidelberg.

Tessier, S. N. and Storey, K. B. (2014). To be or not to be: the regulation of mRNA fate as a survival strategy during mammalian hibernation. Cell Stress Chaperones 763-776.

Tessier, S. N., Audas, T. E., Wu, C. W., Lee, S. and Storey, K. B. (2014). The involvement of mRNA processing factors TIA-1, TIAR, and PABP-1 during mammalian hibernation. Cell Stress Chaperones 1-13.

Tong, G., Endersfelder, S., Rosenthal, L. M., Wollersheim, S., Sauer, I. M., Bührer, C., Berger, F. and Schmitt, K. R. L. (2013). Effects of moderate and deep hypothermia on RNA-binding proteins RBM3 and CIRP expressions in murine hippocampal brain slices. Brain Res. 1504, 74-84.

van Breukelen, F. and Martin, S. L. (2001). Translational initiation is uncoupled from elongation at 18 degrees $\mathrm{C}$ during mammalian hibernation. Am. J. Physiol. Regul. Integr. Comp. Physiol. 281, R1374-R1379.

van Breukelen, F., Sonenberg, N. and Martin, S. L. (2004). Seasonal and state-dependent changes of eIF4E and 4E-BP1 during mammalian hibernation: implications for the control of translation during torpor. Am. J. Physiol. Regul. Integr. Comp. Physiol. 287, R349-R353.

van Breukelen, F., Krumschnabel, G. and Podrabsky, J. E. (2010). Vertebrate cell death in energy-limited conditions and how to avoid it: What we might learn from mammalian hibernators and other stress-tolerant vertebrates. Apoptosis 15, 386-399.

Vaughan, D. K., Gruber, A. R., Michalski, M. L., Seidling, J. and Schlink, S. (2006). Capture, care, and captive breeding of 13-lined ground squirrels, Spermophilus tridecemlineatus. Lab Anim. (NY). 35, 33-40. 
Wang, L. C. H. (1979). Time patterns and metabolic rates of natural torpor in the Richardson's ground squirrel. Can. J. Zool. 57, 149-155.

Wang, L. C. H. (1989). Ecological, Physiological, and Biochemical Aspects of Torpor in Mammals and Birds. (ed. Wang, L. C. H.) Berlin Heidelberg: Springer-Verlag.

Wang, L. C. H. and Lee, T. F. (1996). Torpor and hibernation in mammals: metabolic, physiological, and biochemical adaptations. In Handbook of Physiology - Environmental Physiology, pp. 507-532.

Wang, L. C. H. and Wolowyk, M. W. (1988). Torpor in mammals and birds. Can. J. Zool. 66, $133-137$.

Wang, X., Che, H., Zhang, W., Wang, J., Ke, T., Cao, R., Meng, S., Li, D., Weiming, O., Chen, J., et al. (2015). Effects of mild chronic intermittent cold exposure on rat organs. Int. J. Biol. Sci. 11, 1171-1180.

Williams, D. R., Epperson, L. E., Li, W., Hughes, M. a, Taylor, R., Rogers, J., Martin, S. L., Cossins, A. R. and Gracey, A. Y. (2005). Seasonally hibernating phenotype assessed through transcript screening. Physiol. Genomics 24, 13-22.

Wu, C.-W. and Storey, K. B. (2012). Regulation of the mTOR signaling network in hibernating thirteen-lined ground squirrels. J. Exp. Biol. 215, 1720-1727.

Wu, C.-W., Biggar, K. K. and Storey, K. B. (2013). Biochemical adaptations of mammalian hibernation: exploring squirrels as a perspective model for naturally induced reversible insulin resistance. Brazilian J. Med. Biol. Res. 46, 1-13.

Yaman, I., Fernandez, J., Sarkar, B., Schneider, R. J., Snider, M. D., Nagy, L. E. and Hatzoglou, M. (2002). Nutritional control of mRNA stability is mediated by a conserved AU-rich element that binds the cytoplasmic shuttling protein HuR. J. Biol. Chem. 277, 41539-41546.

Yan, J., Burman, A., Nichols, C., Alila, L., Showe, L. C., Showe, M. K., Boyer, B. B., Barnes, B. M. and Marr, T. G. (2006). Detection of differential gene expression in brown adipose tissue of hibernating arctic ground squirrels with mouse microarrays. Physiol. Genomics 25, $346-353$.

Yan, J., Barnes, B. M., Kohl, F. and Marr, T. G. (2007). Modulation of gene expression in hibernating arctic ground squirrels. Physiol. Genomics 32, 170-181.

Yang, W.-H. and Bloch, D. B. (2007). Probing the mRNA processing body using protein macroarrays and "autoantigenomics". RNA 13, 704-12.

Zhang, J., Tessier, S. N., Biggar, K. K., Wu, C.-W., Pifferi, F., Perret, M. and Storey, K. B. (2015). Regulation of torpor in the gray mouse lemur: transcriptional and translational controls and role of AMPK signaling. Genomics. Proteomics Bioinformatics 13, 103-110.

Zhu, X., Bührer, C. and Wellmann, S. (2016). Cold-inducible proteins CIRP and RBM3, a unique couple with activities far beyond the cold. Cell. Mol. Life Sci. 3839-3859. 


\section{APPENDICES}

\section{APPENDiX A: ANTIBOdies USED FOR WeSTERn BLOTTING}

Table A.1: Antibody companies and product codes for the antibodies used in the experiments described in this thesis

\begin{tabular}{l|l|l} 
Protein Target & Manufacturer & Product code \\
\hline CIRP (Z-25) & Santa Cruz Biotechnology, Inc. & sc-133460 \\
\hline Rbm3 & Santa Cruz Biotechnology, Inc. & sc-367851 \\
\hline HuR & Cell Signaling & 12582 \\
\hline eIF4E & Genetex & GTX82525 \\
\hline p-eIF4E Ser209 & Genetex & GTX50268 \\
\hline eIF2-alpha & Genscript & A00518 \\
\hline eIF2-alpha S51 & Genscript & A00559 \\
\hline eEF2 & Cell Signaling & 2332 \\
\hline p-eEF2 Thr56 & Cell Signaling & 2331 \\
\hline p-4EBP S65 & Cell Signaling & 9451 \\
\hline
\end{tabular}




\section{APPENDiX B: Western BLOTTING CONDITIONS}

Table B.1: Western blotting conditions used to quantify the relative levels of proteins in Chapter 3, including Cirp, HuR, and Rbm3

\begin{tabular}{|c|c|c|c|c|c|c|c|}
\hline $\begin{array}{r}1^{\circ} \text { Antibody } \\
\text { Protein } \\
\text { Target }\end{array}$ & $\begin{array}{l}\text { Tissue and } \\
\text { protein load* }\end{array}$ & $\begin{array}{l}\text { Gel \% } \\
\text { Acryla } \\
\text { mide }\end{array}$ & $\begin{array}{l}\text { Run time at } \\
180 V \text { (min) }\end{array}$ & $\begin{array}{l}\text { Transfer } \\
\text { conditions** } \\
(\mathrm{min})\end{array}$ & $\begin{array}{l}\text { Membrane } \\
\text { blocking }\end{array}$ & $\begin{array}{l}1^{\circ} \text { Antibody } \\
\text { dilution and } \\
\text { incubation }\end{array}$ & $\begin{array}{l}2^{\circ} \text { Antibody } \\
\text { dilution and } \\
\text { incubation }\end{array}$ \\
\hline \multirow[t]{4}{*}{ Cirp } & Liver $-18 \mathrm{kDa}$ & 15 & 70 & 55 & 30 min $5 \%$ milk & 1:1000 overnight & $1: 8000$ for $30 \mathrm{~min}$ \\
\hline & $\begin{array}{l}\text { Liver - } 28 \mathrm{kDa} \\
(15 \mu \mathrm{g})\end{array}$ & 15 & 100 & 55 & $\begin{array}{l}30 \min 2.5 \% \\
\text { milk }\end{array}$ & 1:1000 overnight & 1:8000 for $30 \mathrm{~min}$ \\
\hline & $\begin{array}{l}\text { Muscle }-28 \mathrm{kDa} \\
(10 \mu \mathrm{g})\end{array}$ & 15 & 100 & 55 & 30 min $5 \%$ milk & 1:1000 overnight & 1:8000 for $30 \mathrm{~min}$ \\
\hline & $\mathrm{BAT}-28 \mathrm{kDa}$ & 15 & 80 & $60 \mathrm{~min} 30 \mathrm{~V}$ & $15 \min 2.5 \%$ milk & 1:1000 overnight & $1: 4000$ for $30 \mathrm{~min}$ \\
\hline \multirow[t]{3}{*}{$\operatorname{Rbm} 3$} & Liver & 15 & 80 & $\begin{array}{l}60 \text { min at constant } \\
\text { voltage }(30 \mathrm{~V})\end{array}$ & 30 min $5 \%$ milk & $1: 1000$ overnight & $1: 4000$ for $30 \mathrm{~min}$ \\
\hline & Muscle & 15 & 80 & $\begin{array}{l}60 \text { min at constant } \\
\text { voltage }(30 \mathrm{~V})\end{array}$ & 30 min $5 \%$ milk & 1:1000 overnight & $1: 8000$ for $30 \mathrm{~min}$ \\
\hline & BAT & 15 & 80 & $\begin{array}{l}60 \text { min at constant } \\
\text { voltage }(30 \mathrm{~V})\end{array}$ & $\begin{array}{l}15 \min 2.5 \% \\
\text { milk }\end{array}$ & 1:1000 overnight & $1: 4000$ for $30 \mathrm{~min}$ \\
\hline \multirow[t]{3}{*}{ HuR } & Liver $(30 \mu g)$ & 15 & 80 & 55 & 30 min $5 \%$ milk & 1:1000 overnight & 1:8000 for $30 \mathrm{~min}$ \\
\hline & Kidney & 15 & 100 & 55 & 30 min $5 \%$ milk & 1:1000 overnight & 1:4000 for $30 \mathrm{~min}$ \\
\hline & BAT & 15 & 80 & $\begin{array}{l}60 \text { min at constant } \\
\text { voltage }(30 \mathrm{~V})\end{array}$ & 15 min $5 \%$ milk & 1:1000 overnight & 1:8000 for $30 \mathrm{~min}$ \\
\hline
\end{tabular}

*25 $\mu \mathrm{g}$ per well unless otherwise stated; **Transfer at $160 \mathrm{~mA}$ unless otherwise stated 
Table B.2: Western blotting conditions used to quantify the relative levels of proteins in Chapter 4, including total and phosphoeIF4E, eIF2 $\alpha$, and eEF2, as well as phospho-4EBP S65

\begin{tabular}{|c|c|c|c|c|c|c|c|}
\hline $\begin{array}{r}1^{\circ} \text { Antibody } \\
\text { Protein } \\
\text { Target }\end{array}$ & $\begin{array}{l}\text { Tissue and } \\
\text { protein load* }\end{array}$ & $\begin{array}{l}\text { Gel \% } \\
\text { Acrylamide }\end{array}$ & $\begin{array}{l}\text { Run time at } \\
180 V \text { (min) }\end{array}$ & $\begin{array}{l}\text { Transfer } \\
\text { conditions** (min) }\end{array}$ & $\begin{array}{l}\text { Membrane } \\
\text { blocking }\end{array}$ & $\begin{array}{l}1^{\circ} \text { Antibody } \\
\text { dilution and } \\
\text { incubation }\end{array}$ & $\begin{array}{l}2^{\circ} \text { Antibody } \\
\text { dilution and } \\
\text { incubation }\end{array}$ \\
\hline \multirow[t]{3}{*}{ eIF4E } & Liver & 15 & 100 & 70 & $30 \min 2 \%$ milk & $1: 1000$ overnight & $1: 4000$ for $30 \mathrm{~min}$ \\
\hline & Muscle & 15 & 100 & 60 & $30 \min 2 \%$ milk & $1: 1000$ overnight & 1:4000 for $30 \mathrm{~min}$ \\
\hline & Kidney & 15 & 90 & 55 & $30 \min 2 \%$ milk & 1:1000 overnight & $1: 4000$ for $30 \mathrm{~min}$ \\
\hline \multirow{3}{*}{$\begin{array}{r}p-e I F 4 E \\
\text { S209 }\end{array}$} & Liver & 15 & 100 & 70 & $30 \min 5 \%$ milk & 1:2000 overnight & $1: 4000$ for $30 \mathrm{~min}$ \\
\hline & Muscle & 15 & 100 & 60 & 30 min $2 \%$ milk & 1:2000 overnight & $1: 4000$ for $30 \mathrm{~min}$ \\
\hline & Kidney & 15 & 90 & 55 & $30 \min 2 \%$ milk & 1:2000 overnight & 1:4000 for $30 \mathrm{~min}$ \\
\hline \multirow[t]{3}{*}{ p-4EBP S65 } & Liver $(30 \mu g)$ & 15 & 80 & $\begin{array}{l}60 \text { min at constant } \\
\text { voltage }(30 \mathrm{~V})\end{array}$ & 30 min $2 \%$ milk & 1:1000 overnight & $1: 8000$ for $30 \mathrm{~min}$ \\
\hline & Muscle $(30 \mu g)$ & 15 & 80 & $\begin{array}{l}60 \text { min at constant } \\
\text { voltage }(30 \mathrm{~V})\end{array}$ & 30 min $2 \%$ milk & 1:1000 overnight & $1: 8000$ for $30 \mathrm{~min}$ \\
\hline & Kidney $(30 \mu g)$ & 15 & 80 & $\begin{array}{l}60 \text { min at constant } \\
\text { voltage }(30 \mathrm{~V})\end{array}$ & $30 \min 2 \%$ milk & $1: 1000$ overnight & $1: 8000$ for $30 \mathrm{~min}$ \\
\hline \multirow[t]{3}{*}{ eIF2-alpha } & Liver & 15 & 80 & 70 & $20 \min 5 \%$ milk & $1: 1000$ overnight & $1: 8000$ for $30 \mathrm{~min}$ \\
\hline & Muscle & 15 & 80 & 55 & 30 min $5 \%$ milk & 1:1000 overnight & $1: 4000$ for $30 \mathrm{~min}$ \\
\hline & Kidney & 15 & 90 & 55 & $30 \mathrm{~min} 5 \%$ milk & $1: 1000$ overnight & $1: 4000$ for $30 \mathrm{~min}$ \\
\hline \multirow{3}{*}{$\begin{array}{r}\text { p-eIF2- } \\
\text { alpha } S 51\end{array}$} & Liver & 15 & 100 & 70 & 30 min $5 \%$ milk & $1: 1000$ overnight & 1:8000 for $30 \mathrm{~min}$ \\
\hline & Muscle & 15 & 80 & 55 & $30 \min 5 \%$ milk & 1:1000 overnight & $1: 4000$ for $30 \mathrm{~min}$ \\
\hline & Kidney & 15 & 90 & 60 & $\begin{array}{l}30 \text { min } 2.5 \% \\
\text { milk }\end{array}$ & 1:1000 overnight & $1: 8000$ for $15 \mathrm{~min}$ \\
\hline \multirow[t]{3}{*}{$e E F 2$} & Liver & 10 & 80 & 90 & $30 \min 5 \%$ milk & 1:1000 overnight & 1:8000 for $30 \mathrm{~min}$ \\
\hline & Muscle & 10 & 80 & 90 & 30 min $5 \%$ milk & $1: 1000$ overnight & 1:8000 for $30 \mathrm{~min}$ \\
\hline & Kidney & 10 & 80 & 90 & $30 \min 2 \%$ milk & $1: 1000$ overnight & $1: 8000$ for $30 \mathrm{~min}$ \\
\hline \multirow[t]{3}{*}{$p-e E F 2 T 56$} & Liver & 10 & 80 & 90 & 30 min $5 \%$ milk & $1: 1000$ overnight & 1:8000 for $30 \mathrm{~min}$ \\
\hline & Muscle & 10 & 80 & 90 & $30 \min 5 \%$ milk & 1:1000 overnight & 1:4000 for $30 \mathrm{~min}$ \\
\hline & Kidney & 10 & 80 & 90 & $30 \min 2 \%$ milk & $1: 1000$ overnight & 1:8000 for $30 \mathrm{~min}$ \\
\hline
\end{tabular}

*25 $\mu \mathrm{g}$ per well unless otherwise stated; **Transfer at $160 \mathrm{~mA}$ unless otherwise stated 


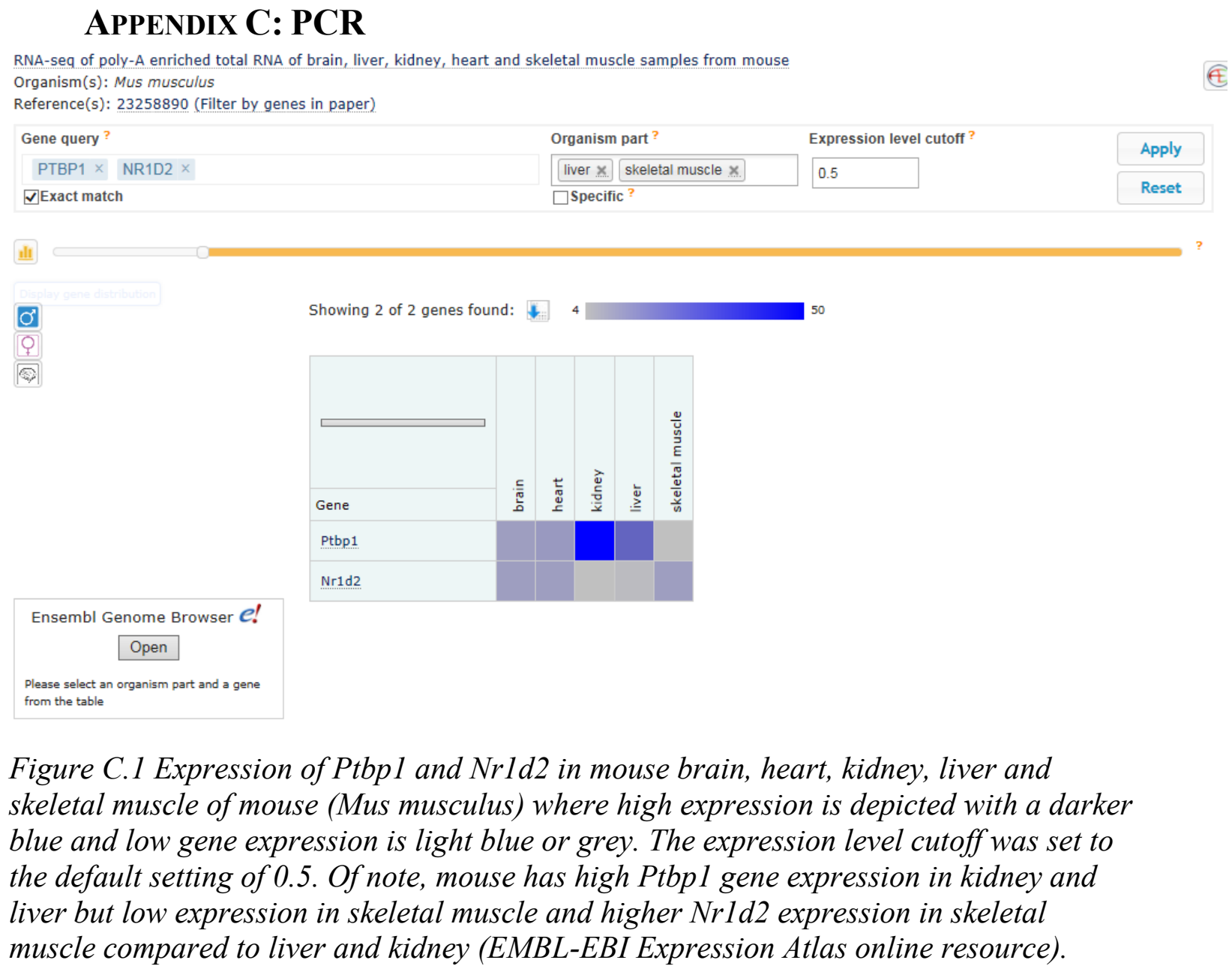

